\title{
Regiocontrol of the Palladium-catalyzed Tin Hydride Addition to Z- Enynols: Remarkable Z-Directing Effects
}

\footnotetext{
Abdallah Hamze ${ }^{1,2}$, Olivier Provot ${ }^{1,2}$, Mouâd Alami ${ }^{2,1 *}$ and Jean-Daniel Brion ${ }^{1,2}$

${ }^{1}$ Univ Paris-Sud, BioCIS UMR 8076, Laboratoire de Chimie Thérapeutique, Faculté de Pharmacie, 5 rue J.-B. Clément, Châtenay-Malabry, F-92296, France.

${ }^{2}$ CNRS, BioCIS UMR-8076, Laboratoire de Chimie Thérapeutique, Faculté de Pharmacie, 5 rue J.-B. Clément, Châtenay-Malabry, F-92296, France.
}

\section{Supporting information}

\section{Table of contents}

1H and 13C NMR spectra for $\mathbf{1 a}$. S3-S4

1H and 13C NMR spectra for $\mathbf{1 b}$. S5-S6

1H and 13C NMR spectra for 1c. S7-S8

1H and 13C NMR spectra for $\mathbf{4 a}$. S9-S11

1H and 13C NMR spectra for $\mathbf{5 a}$ S12-S14

1H and 13C NMR spectra for $\mathbf{6 a}$ S15-S16

1H and 13C NMR spectra for $\mathbf{7 a}$. S17-S18

1H and 13C NMR spectra for $\mathbf{8 a}$ S19-S21

1H and 13C NMR spectra for 9a. S22-S23

1H and 13C NMR spectra for $\mathbf{4 b}$ S24-S26

$1 \mathrm{H}$ and 13C NMR spectra for $\mathbf{7 b}$. S27-S29

$1 \mathrm{H}$ and 13C NMR spectra for $\mathbf{5 b}$ S30-S32

1H and 13C NMR spectra for $\mathbf{8 b}$ S33-S35

1H and 13C NMR spectra for $\mathbf{6 b}$ S36-S38

$1 \mathrm{H}$ and 13C NMR spectra for $\mathbf{9 b}$ S39-S41

1H and 13C NMR spectra for 4c. S42-S44

1H and 13C NMR spectra for 7c. S45-S46

$1 \mathrm{H}$ and 13C NMR spectra for $\mathbf{5 c}$. S47-S49

$1 \mathrm{H}$ and 13C NMR spectra for $\mathbf{8 c}$. S50-S52

$1 \mathrm{H}$ and $13 \mathrm{C}$ NMR spectra for $\mathbf{6 c}$ S53-S55 
1H and 13C NMR spectra for 9c. S56-S58

1H and 13C NMR spectra for $\mathbf{4 d}$. S59-S61

$1 \mathrm{H}$ and 13C NMR spectra for $\mathbf{7 d}$. S62-S63

1H and 13C NMR spectra for $\mathbf{4 e}$ S64-S66

$1 \mathrm{H}$ and 13C NMR spectra for $7 \mathbf{e}$ S67-S68

$1 \mathrm{H}$ and 13C NMR spectra for $\mathbf{4 f}$. S69-S70

$1 \mathrm{H}$ and 13C NMR spectra for $\mathbf{9 d}$. S71-S73

$1 \mathrm{H}$ and 13C NMR spectra for $\mathbf{9 e}$ S74-S76

1H and 13C NMR spectra for $\mathbf{7 g}$. S77-S78

1H and 13C NMR spectra for 22. S79-S80

1H and 13C NMR spectra for 23. S81-S82

1H and 13C NMR spectra for 24. S83-S84

1H and 13C NMR spectra for 25. S85-S86

1H and 13C NMR spectra for 26. S87-S89

1H and 13C NMR spectra for 27. S90-S91

1H and 13C NMR spectra for $\mathbf{2 8}$. S92-S93 


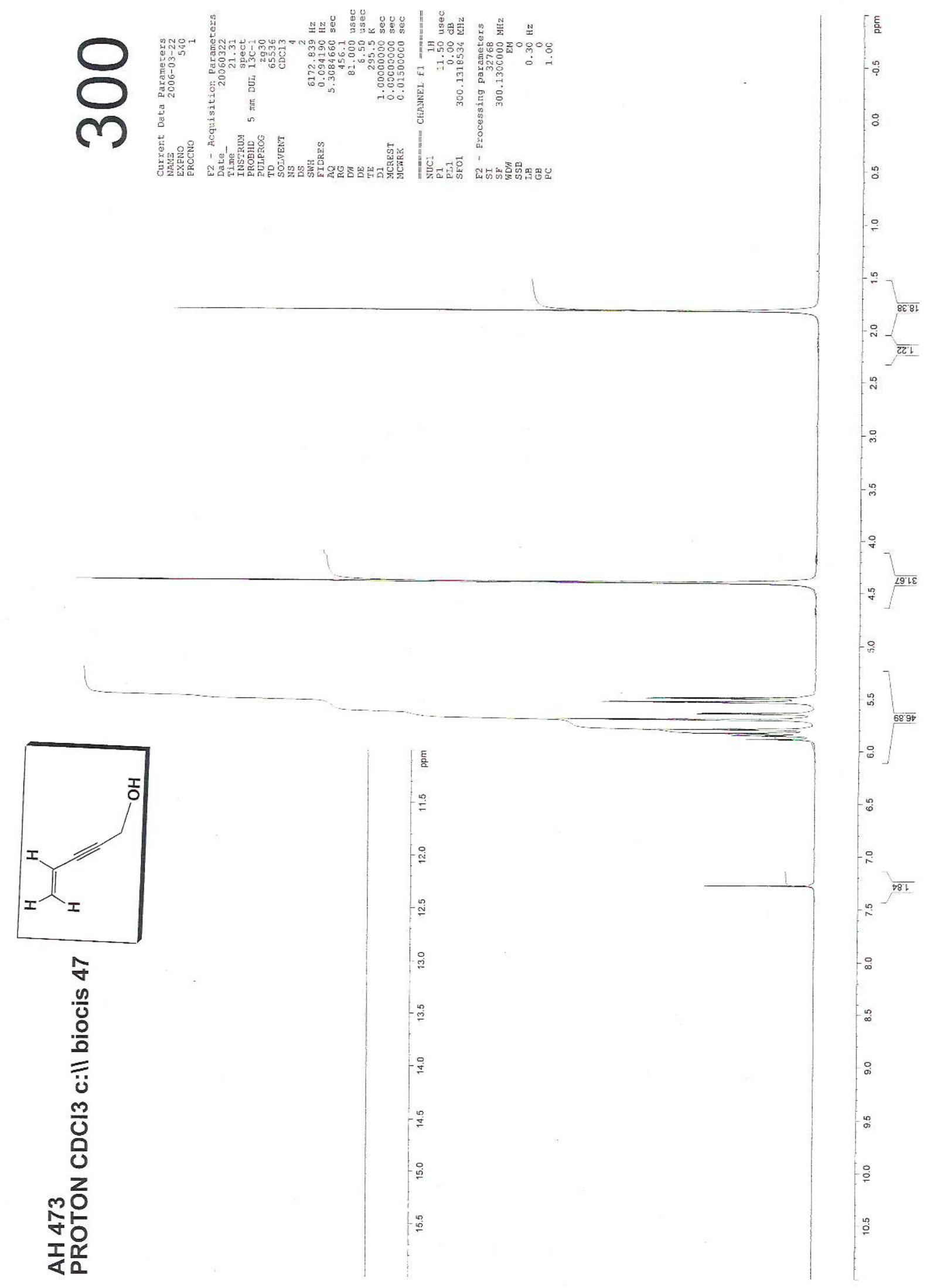




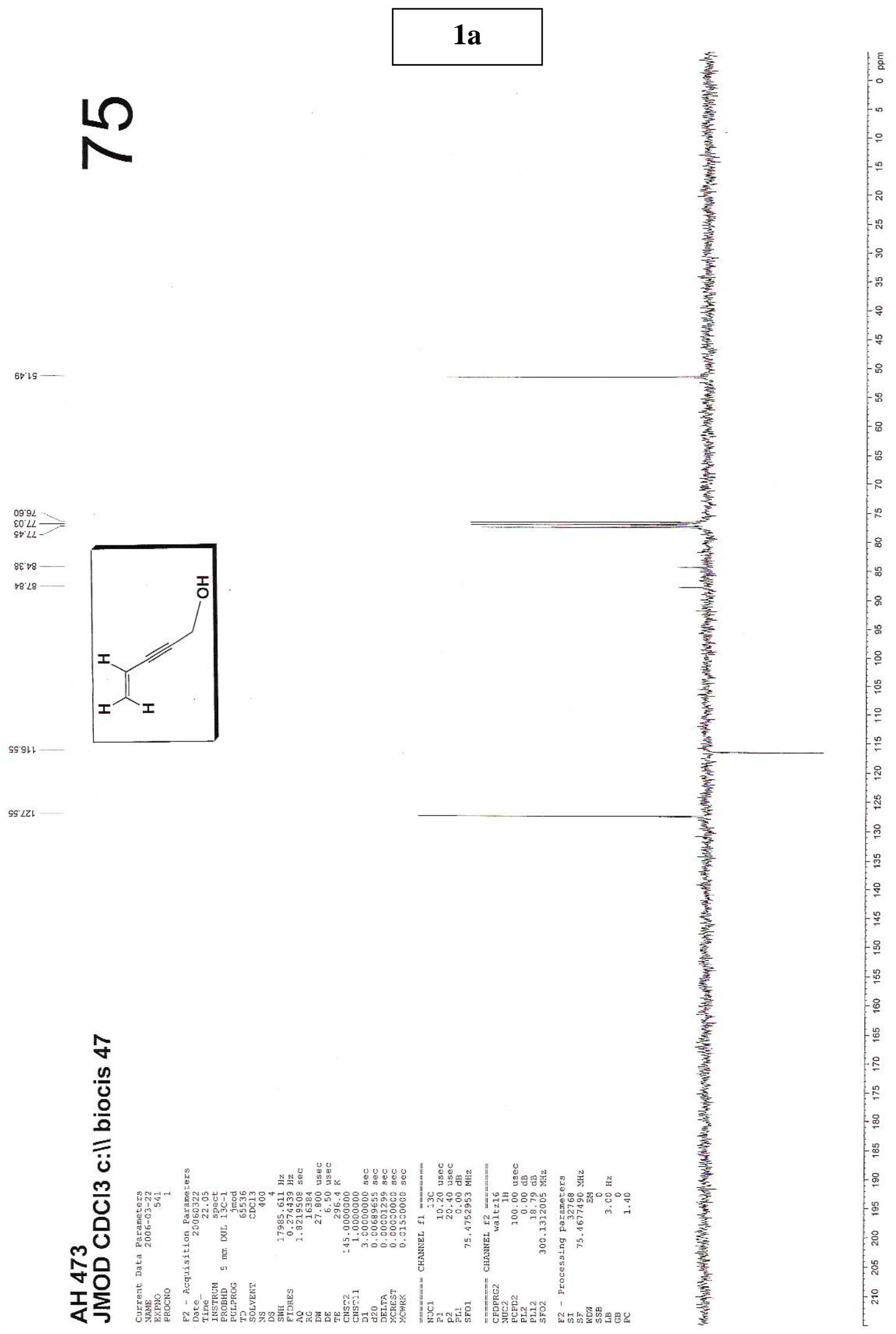



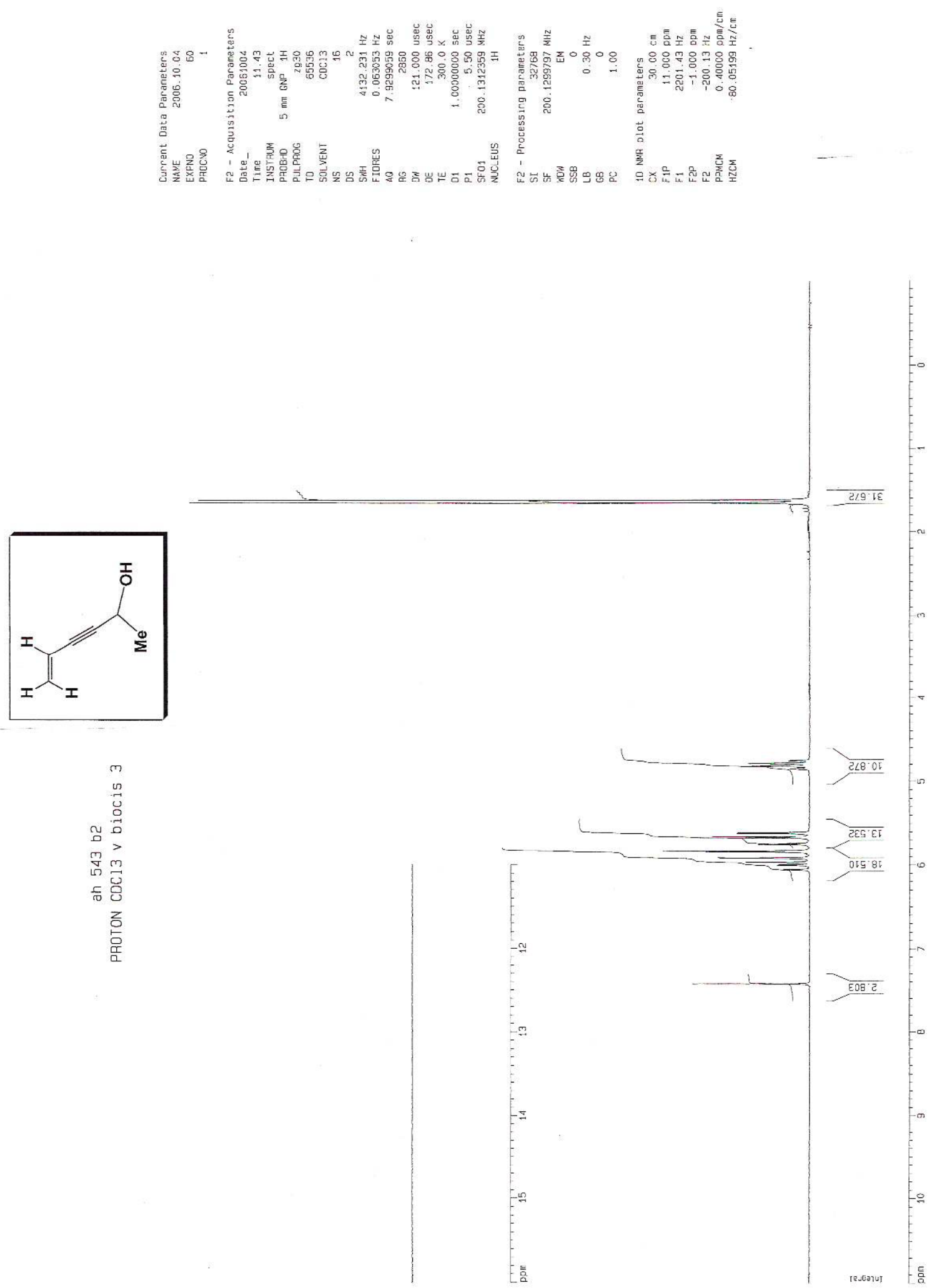


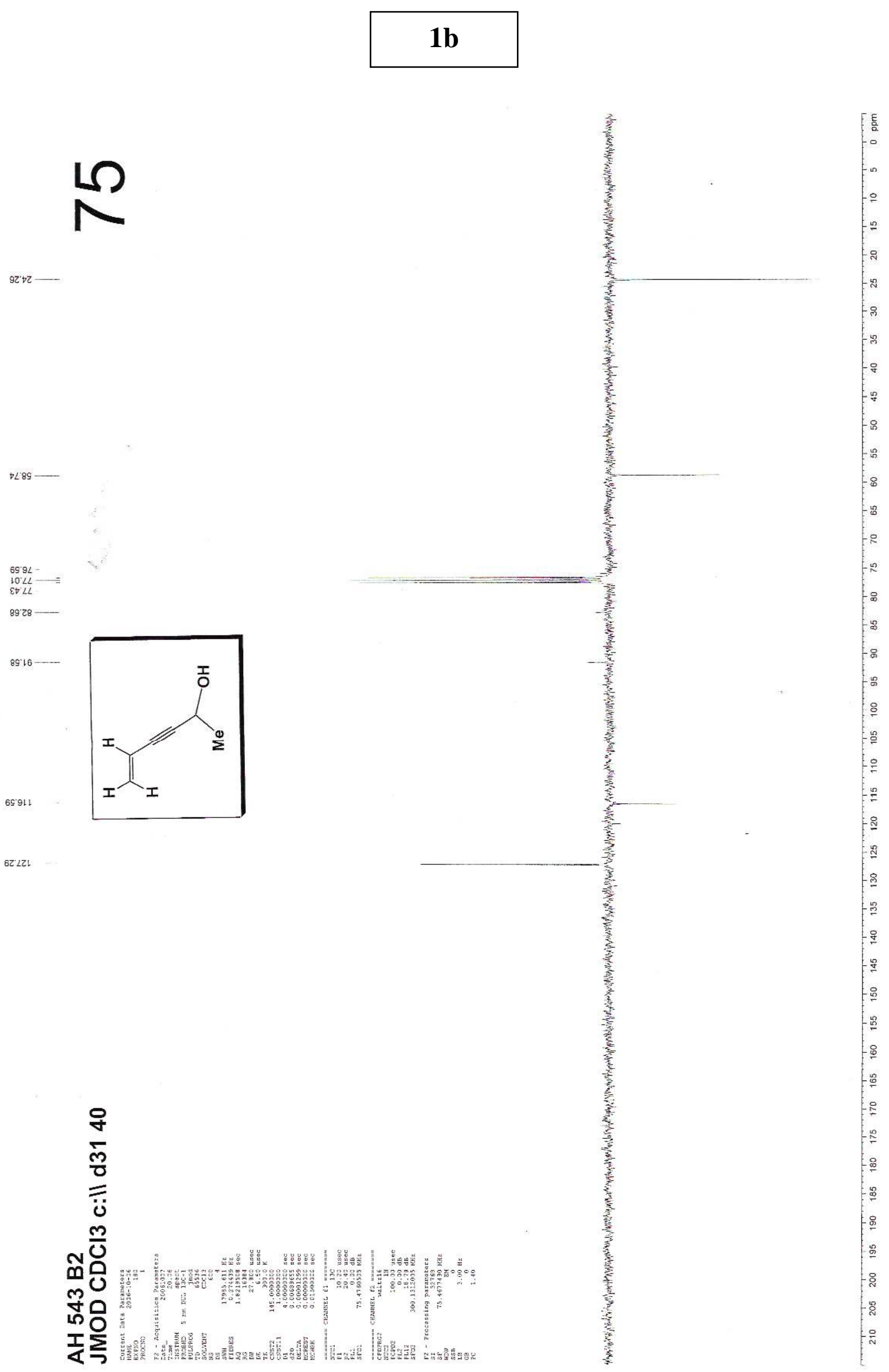




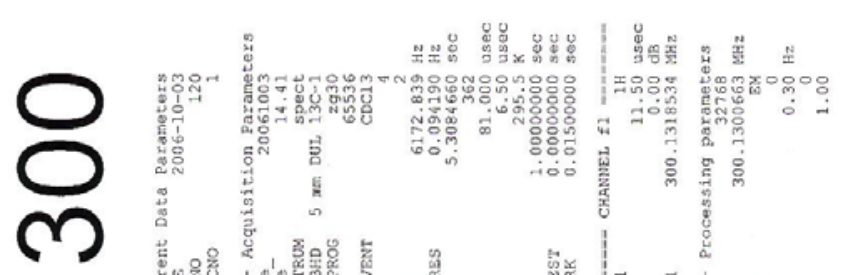

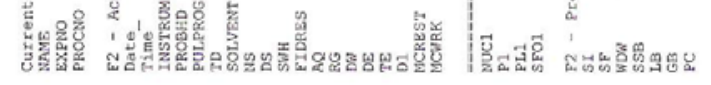

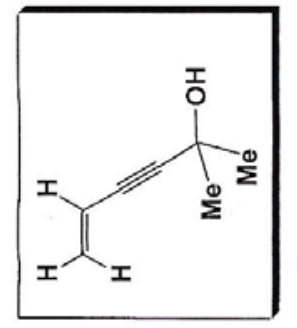

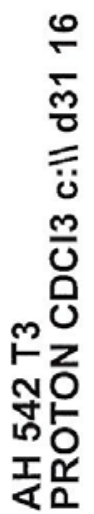


$\stackrel{2}{N}$

ตะเ เ

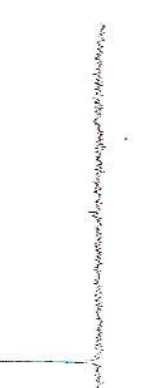

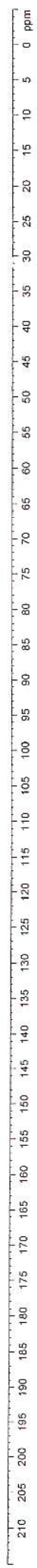

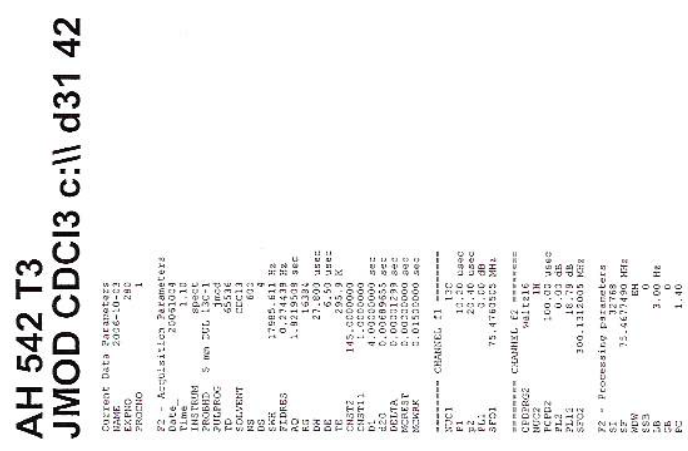




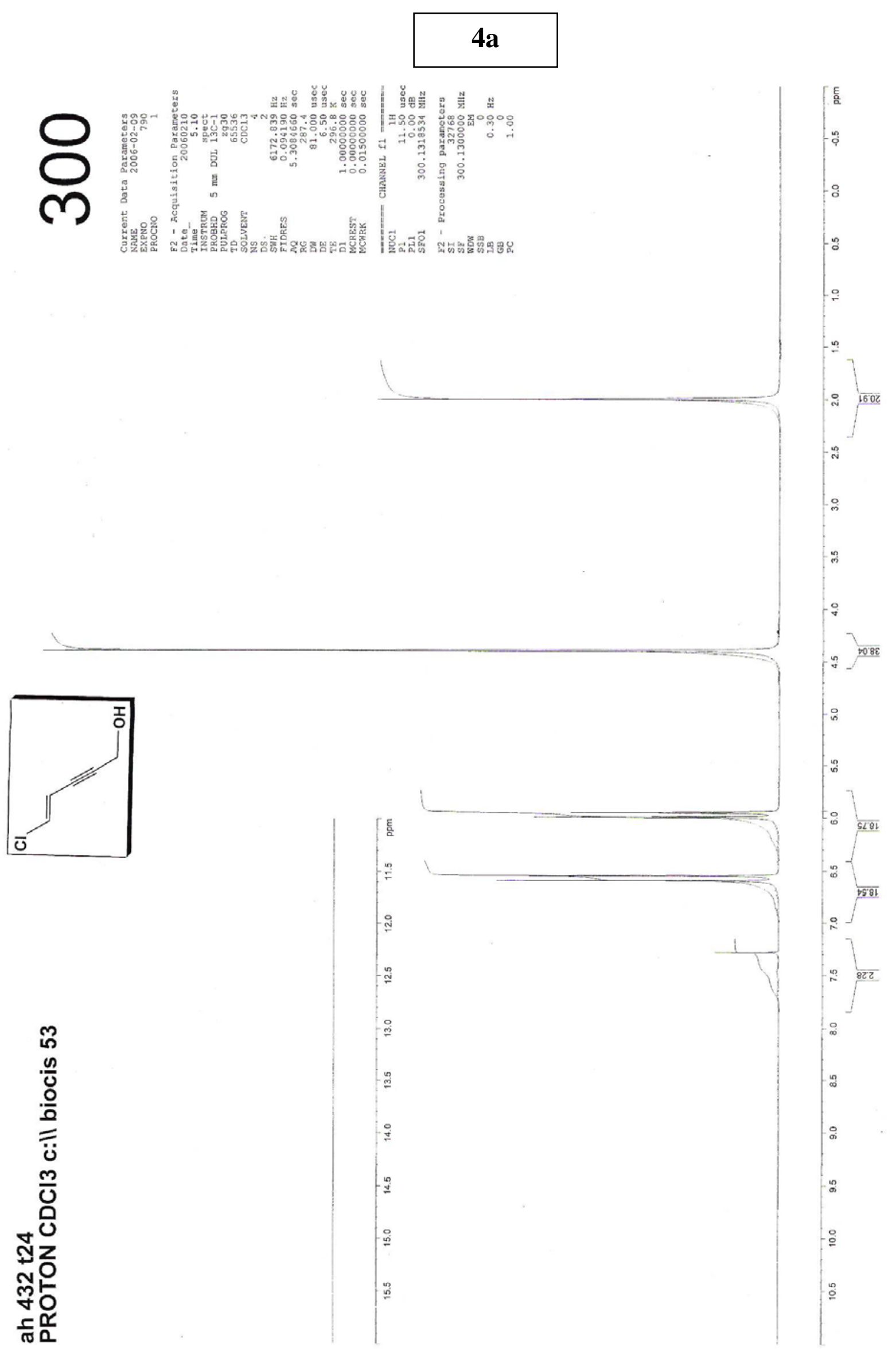




\section{4a}

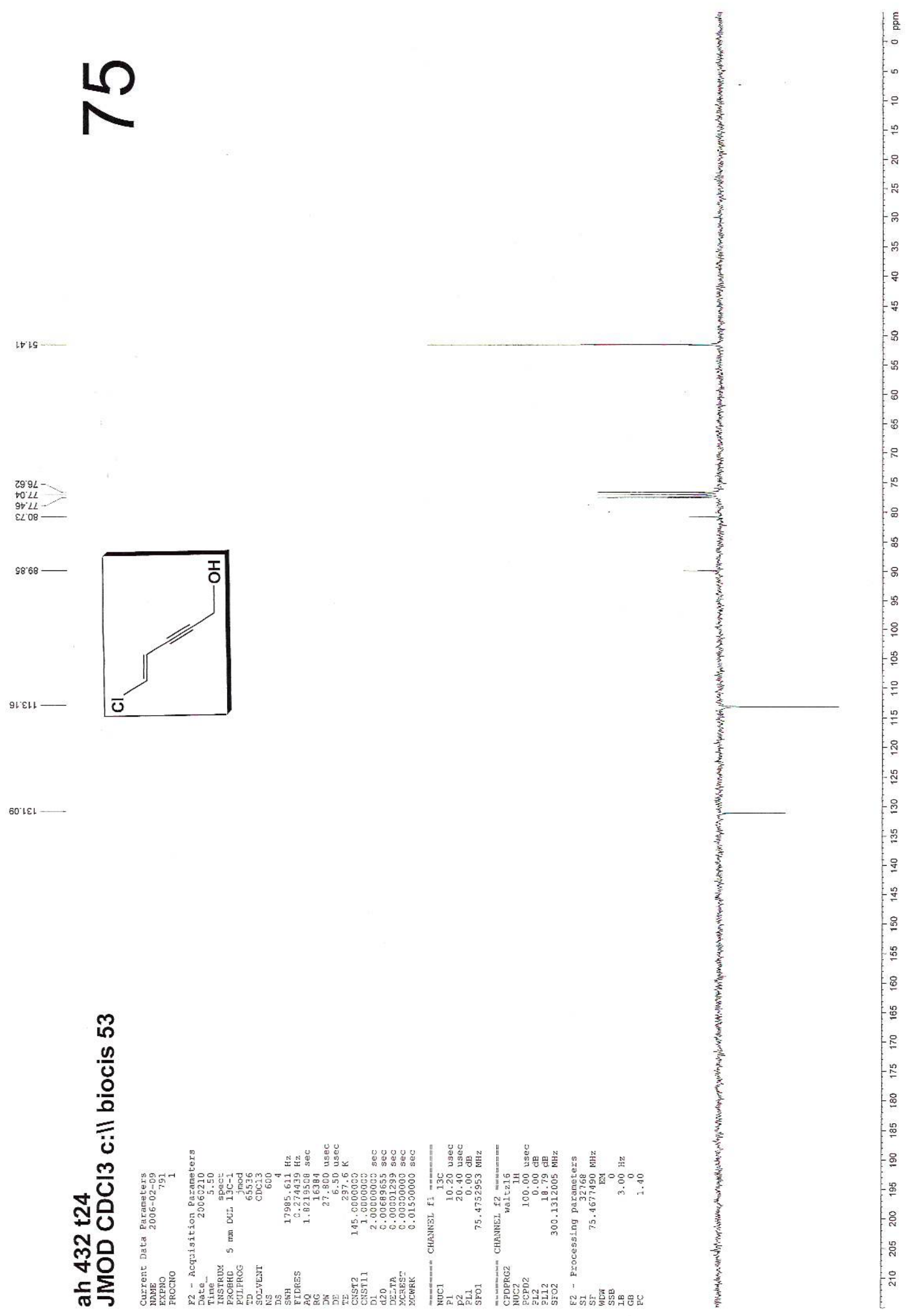


Current Data Parameters

NAME ah432t24.hmbc

EXPNO

PROCNO
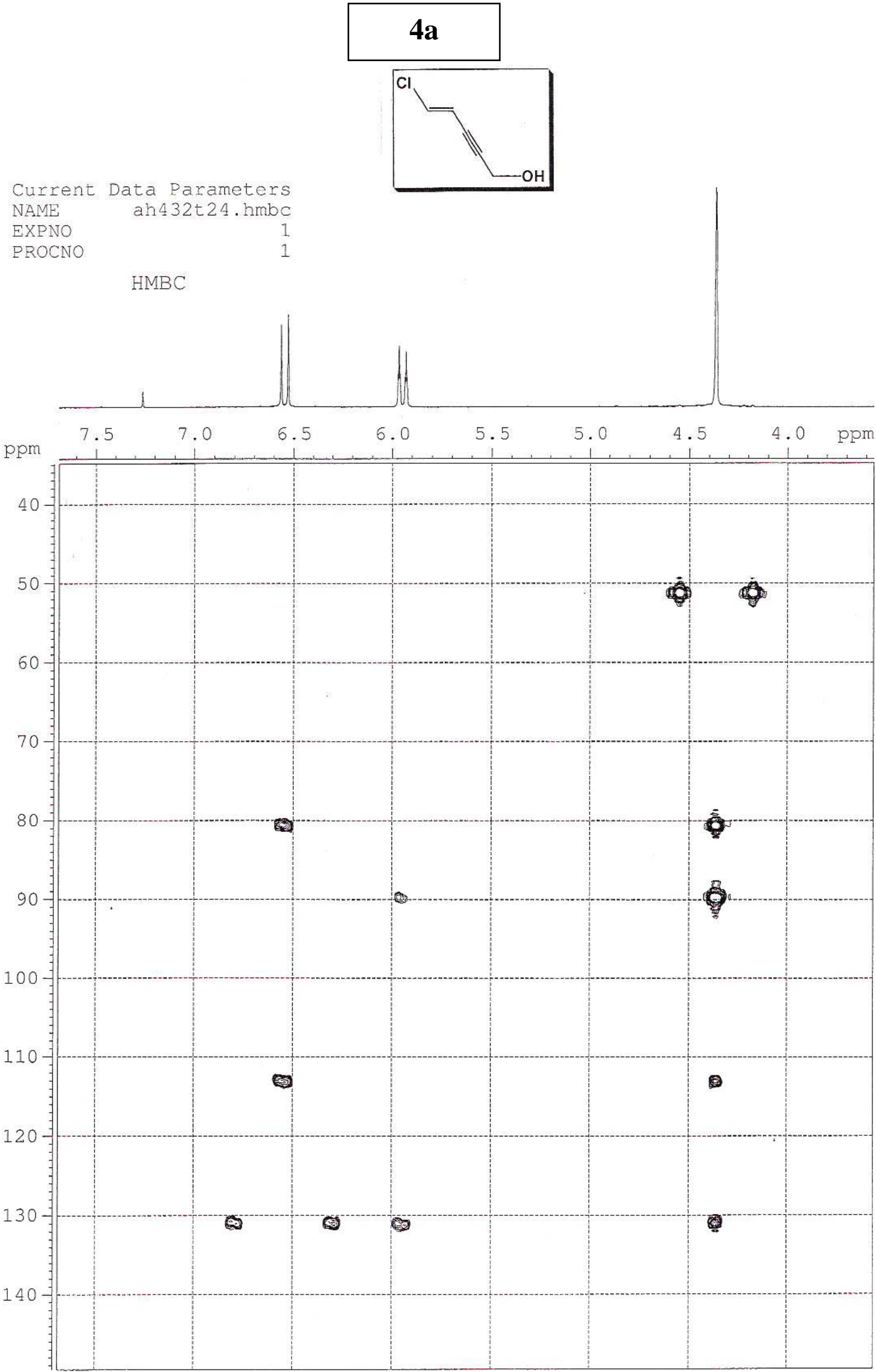


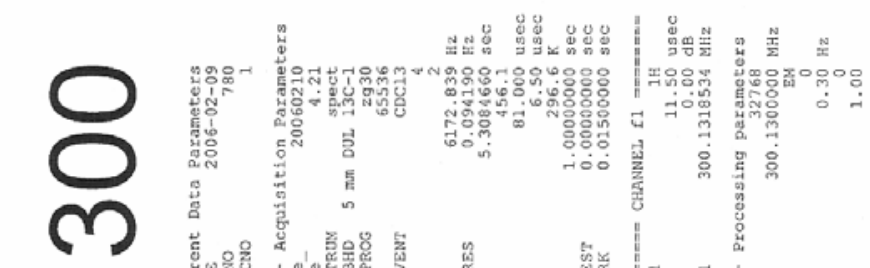

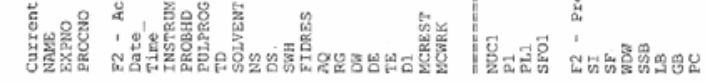

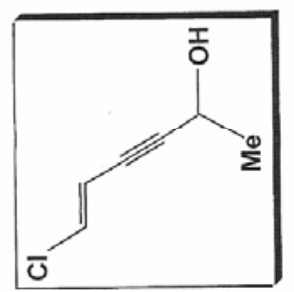

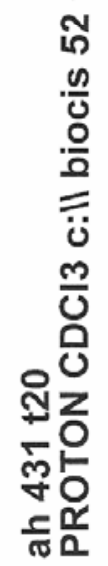
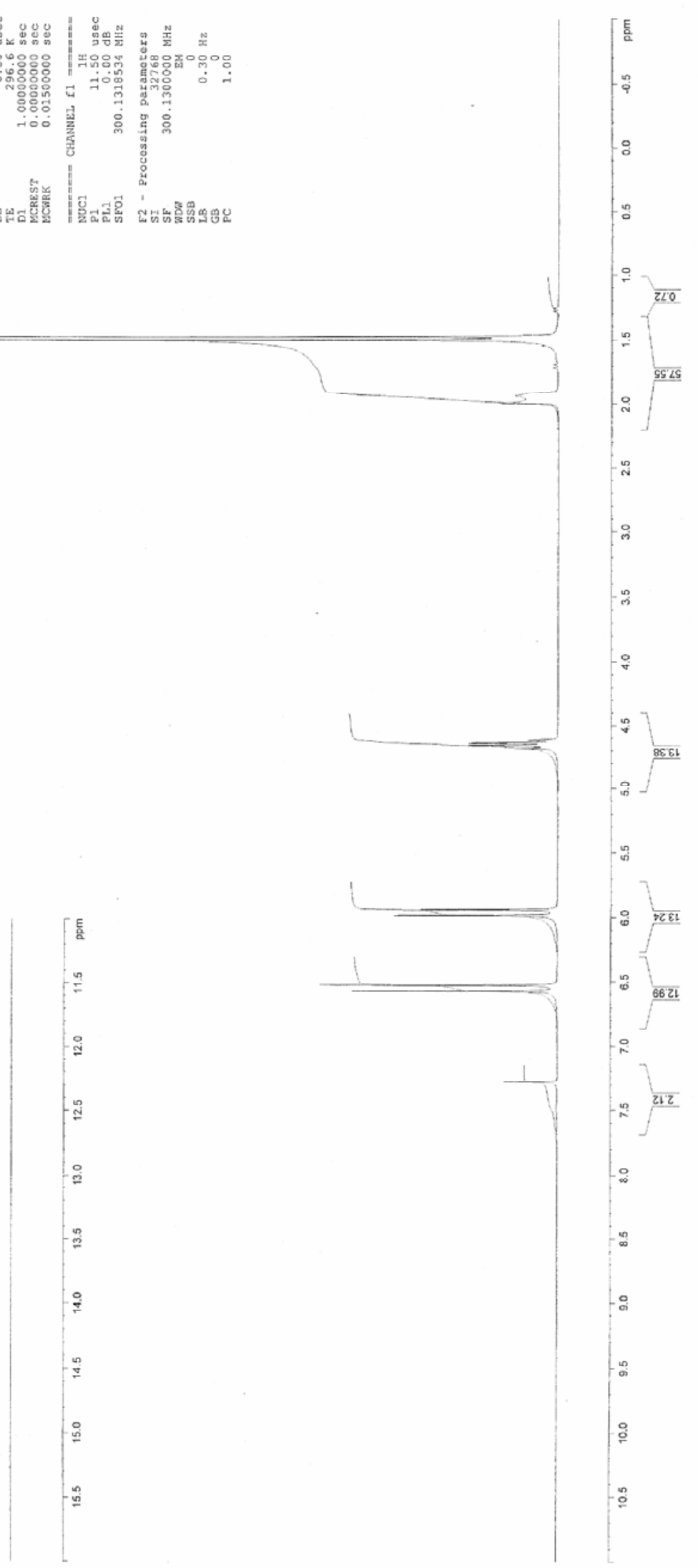


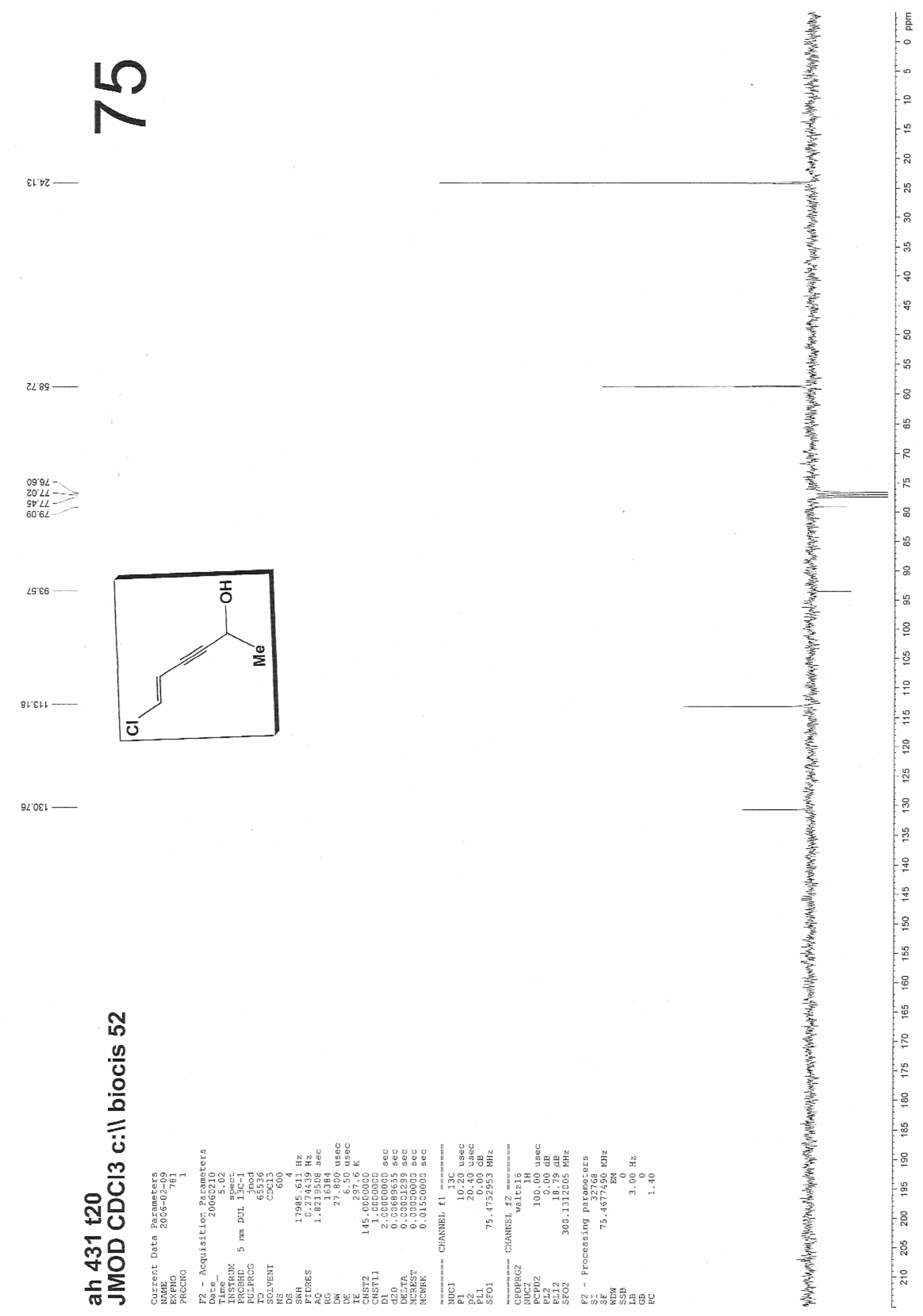


Current Data Parameters

NAME ah431t20.hmbc

EXPNO

ah431t20.hmbc

PROCNO

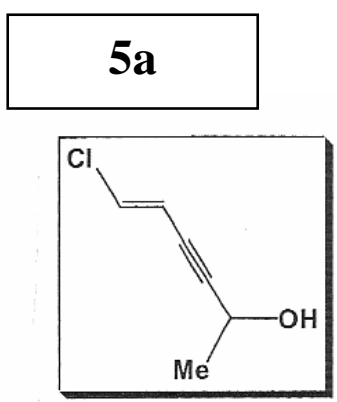

$\mathrm{HMBC}$

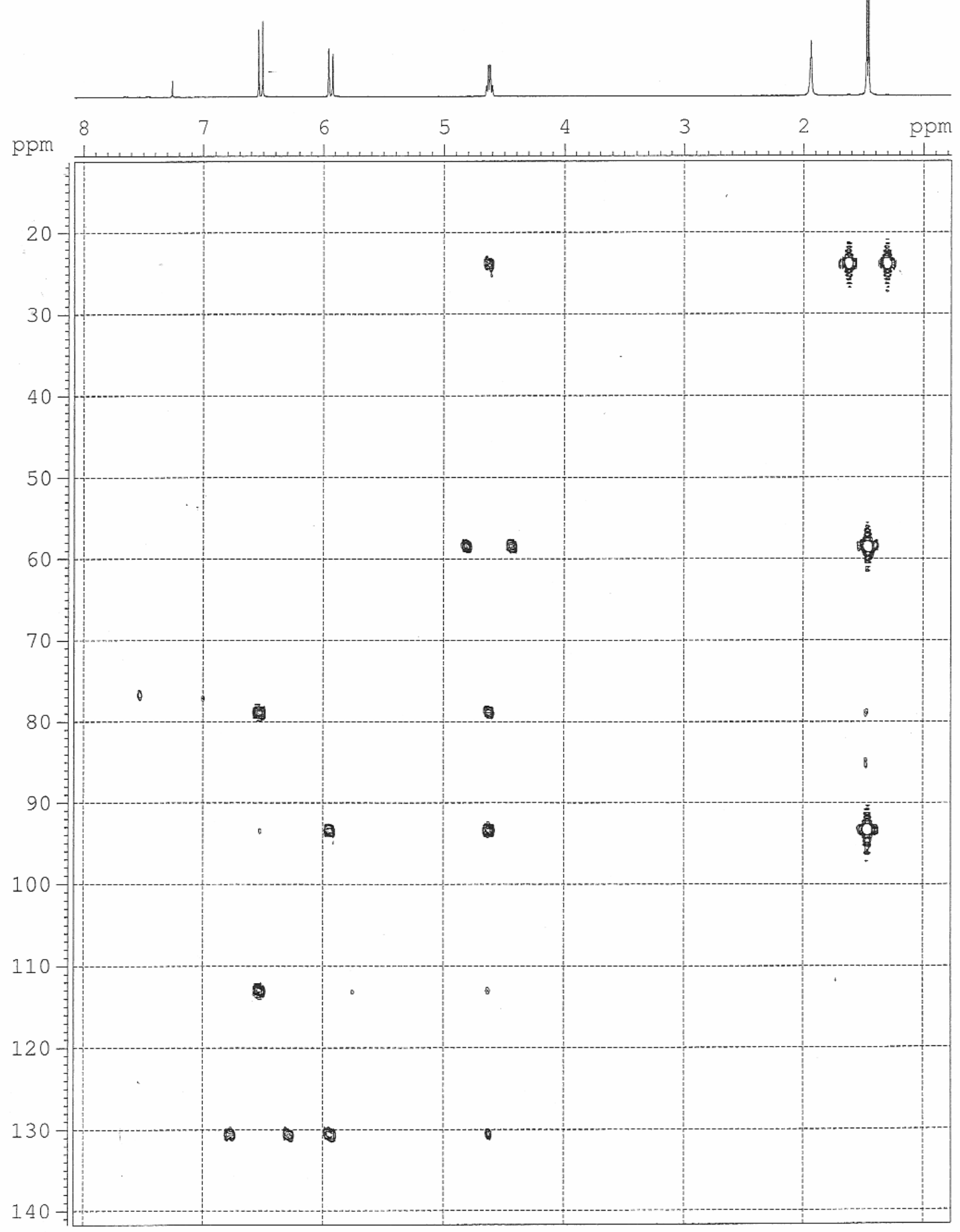




\section{6a}

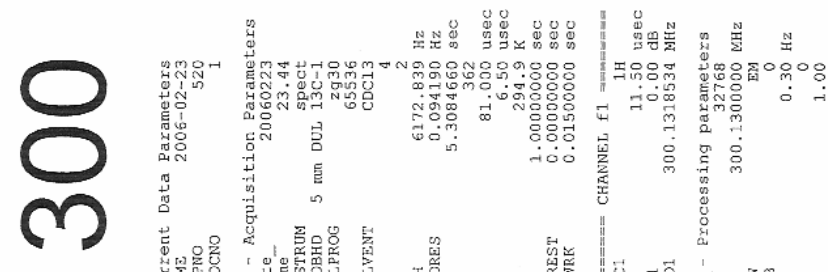

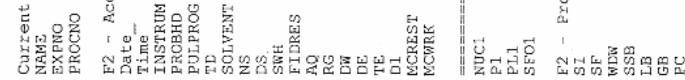
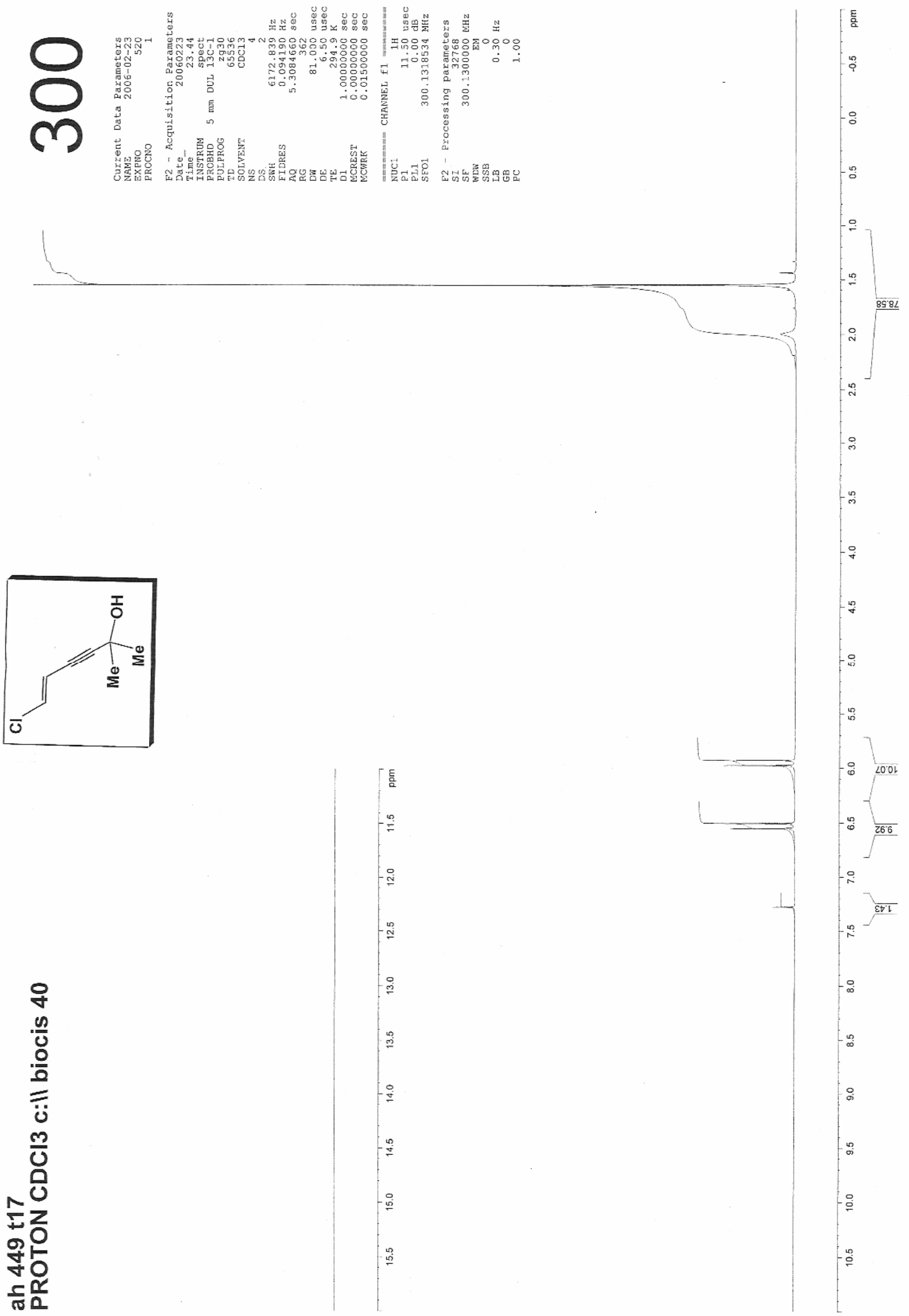


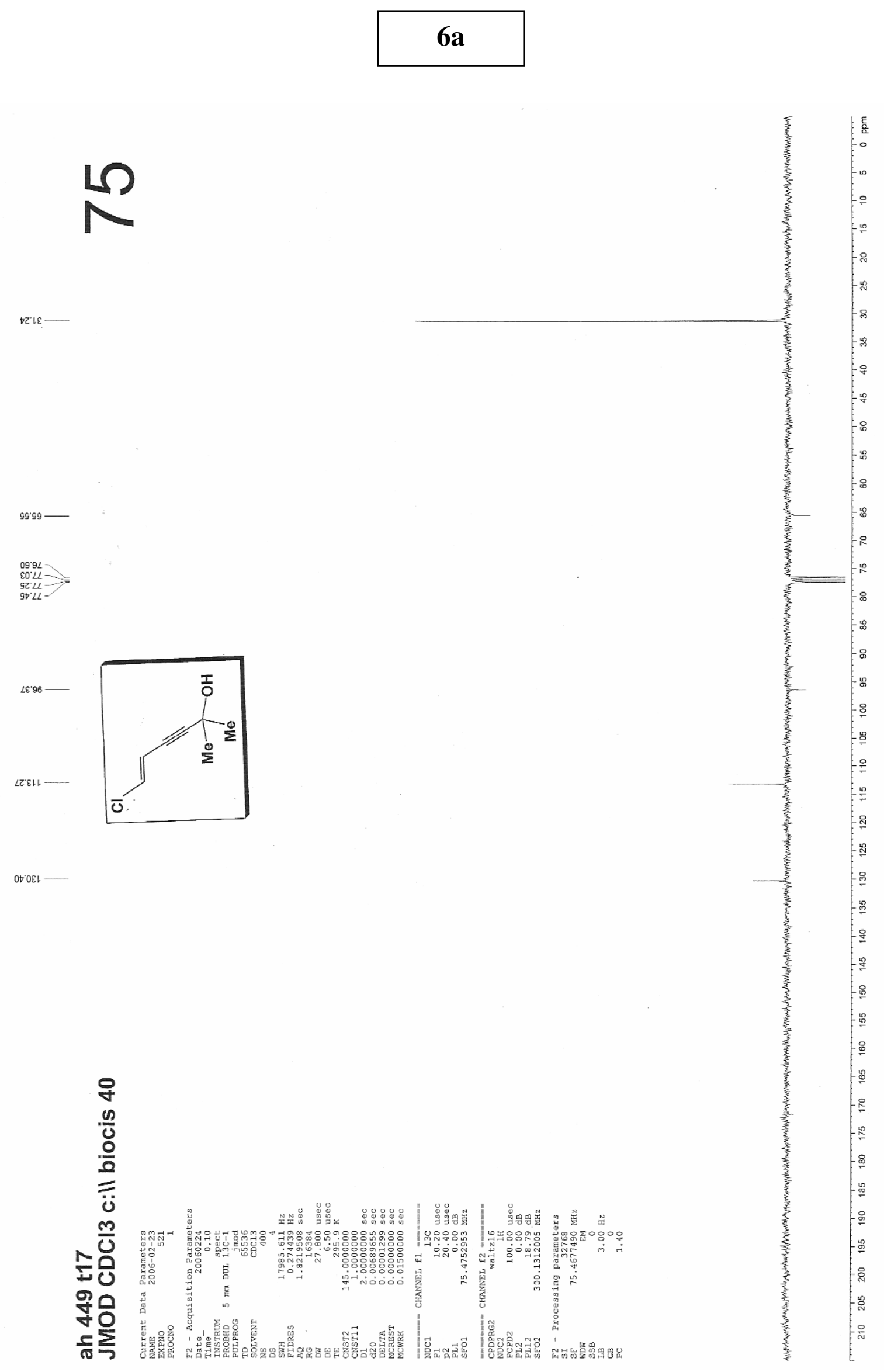




\section{$7 a$}

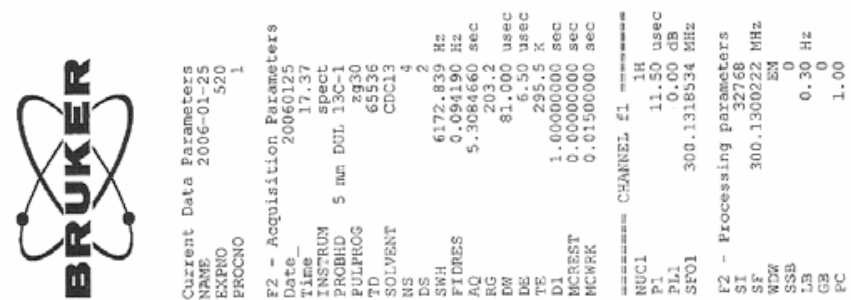

$\underbrace{1}_{\bar{u}}$

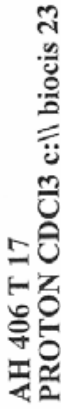

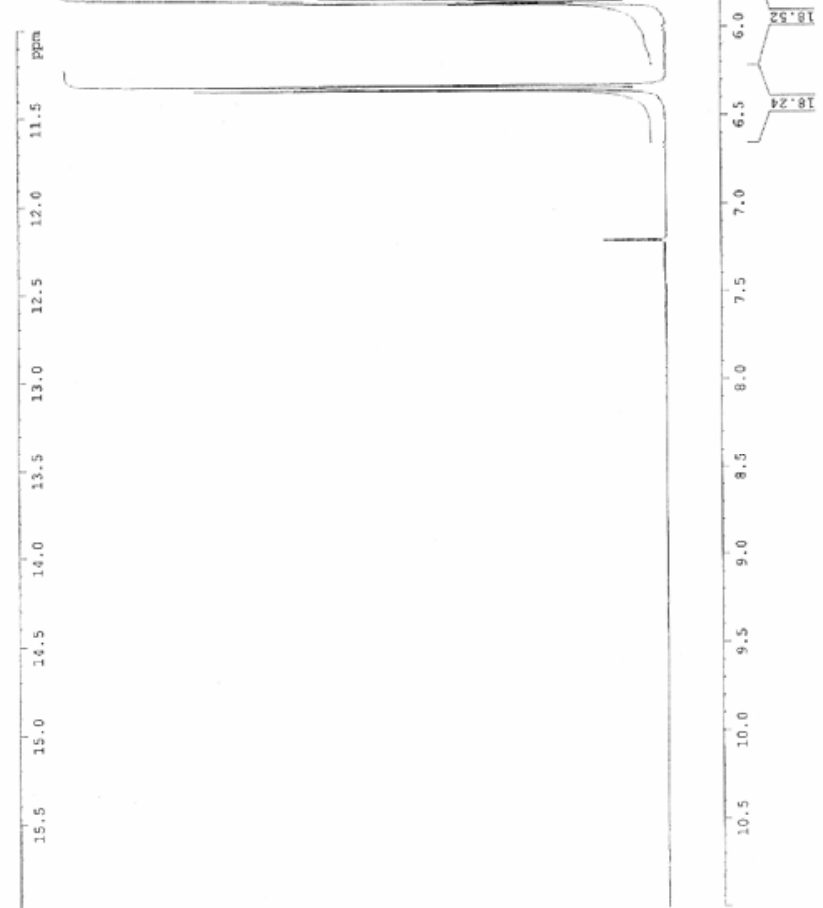




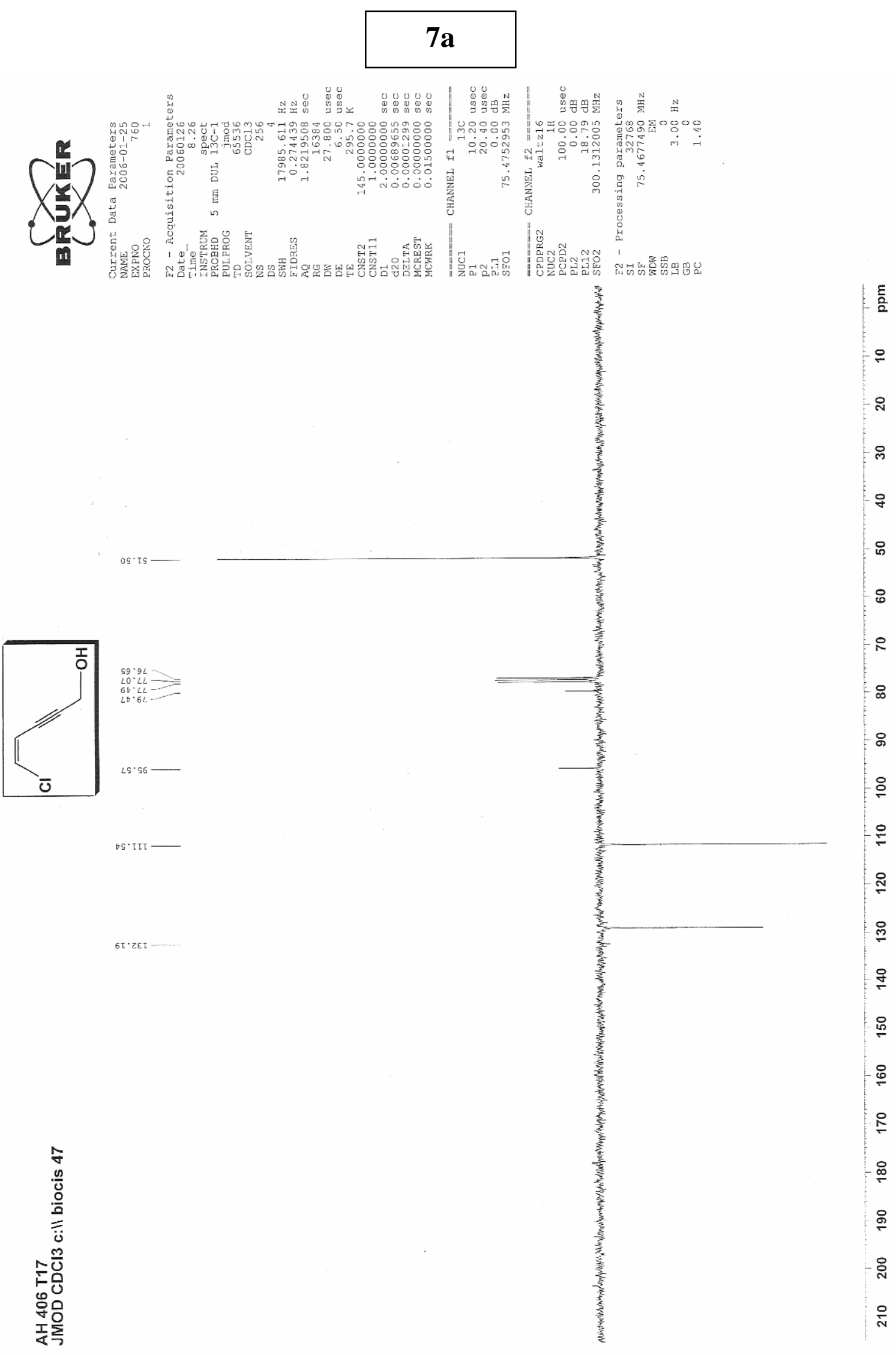




\section{8a}

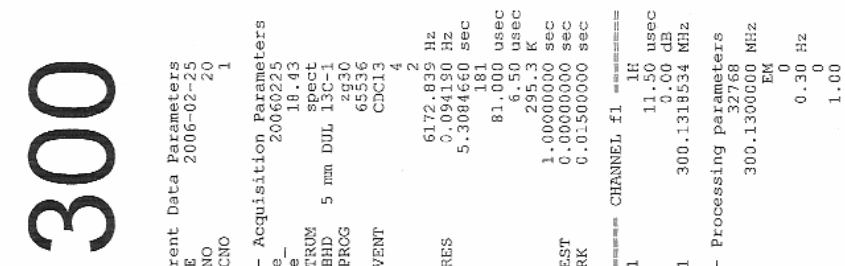

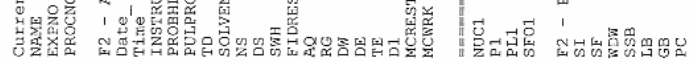

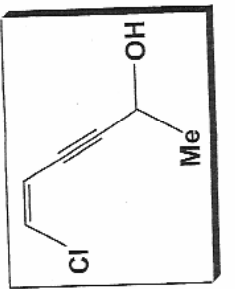

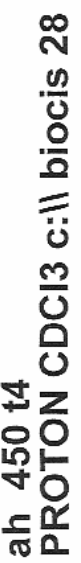




\section{$8 a$}
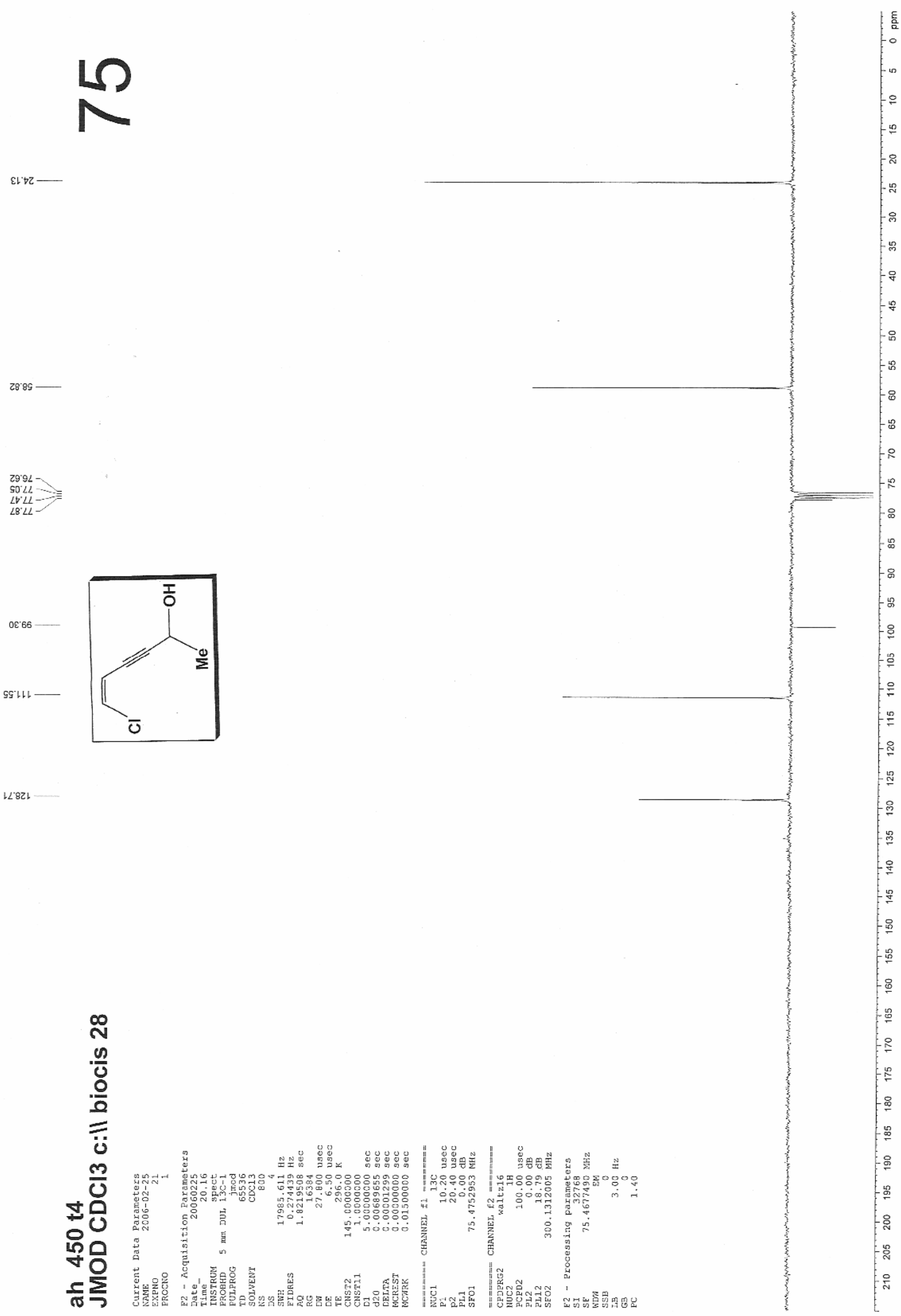


\section{$8 a$}

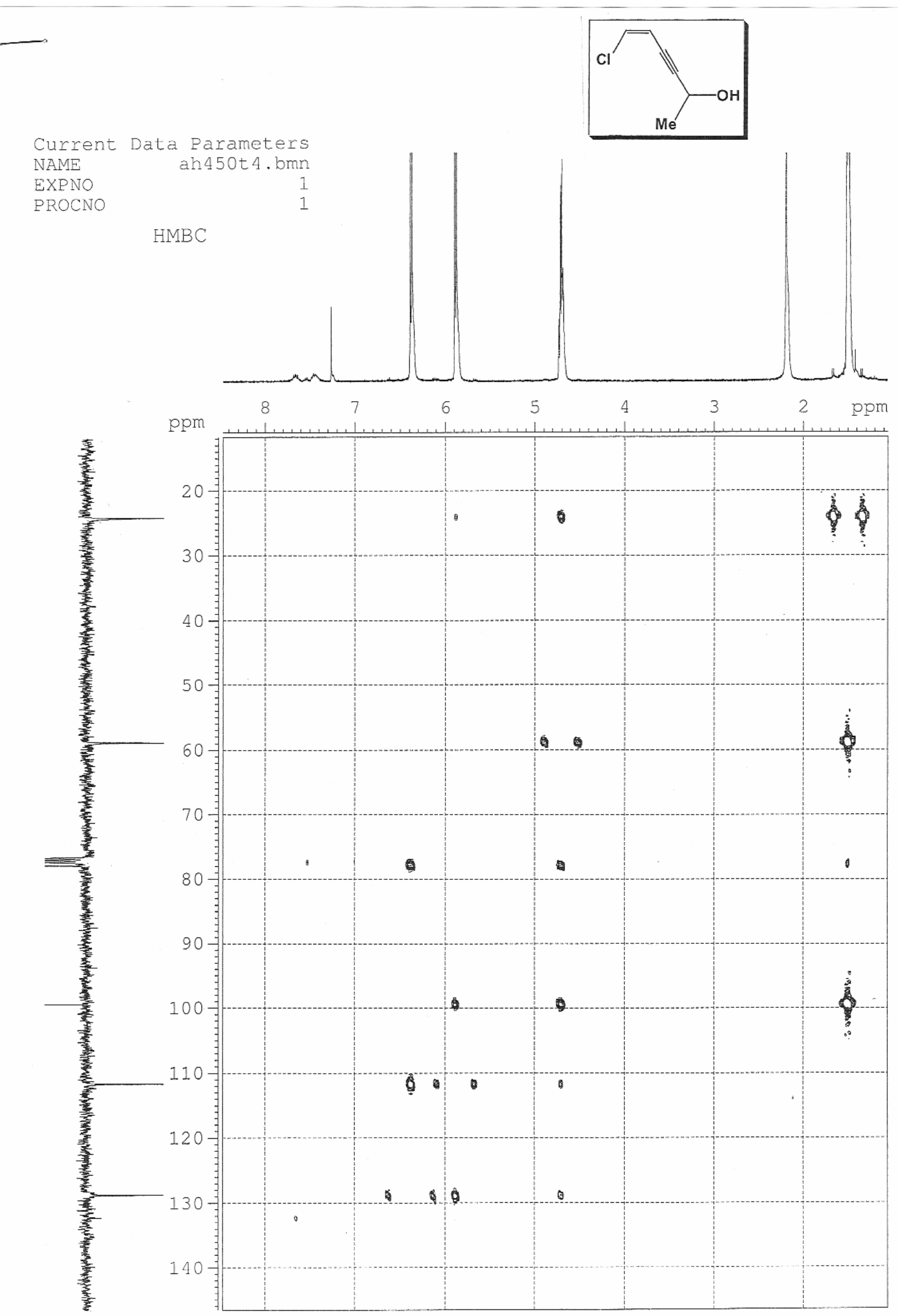




\section{9a}

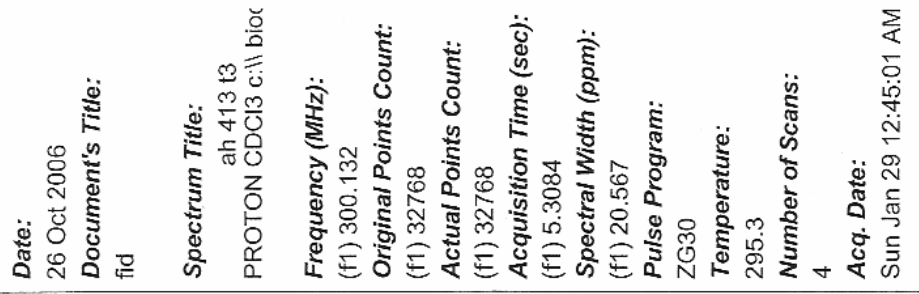

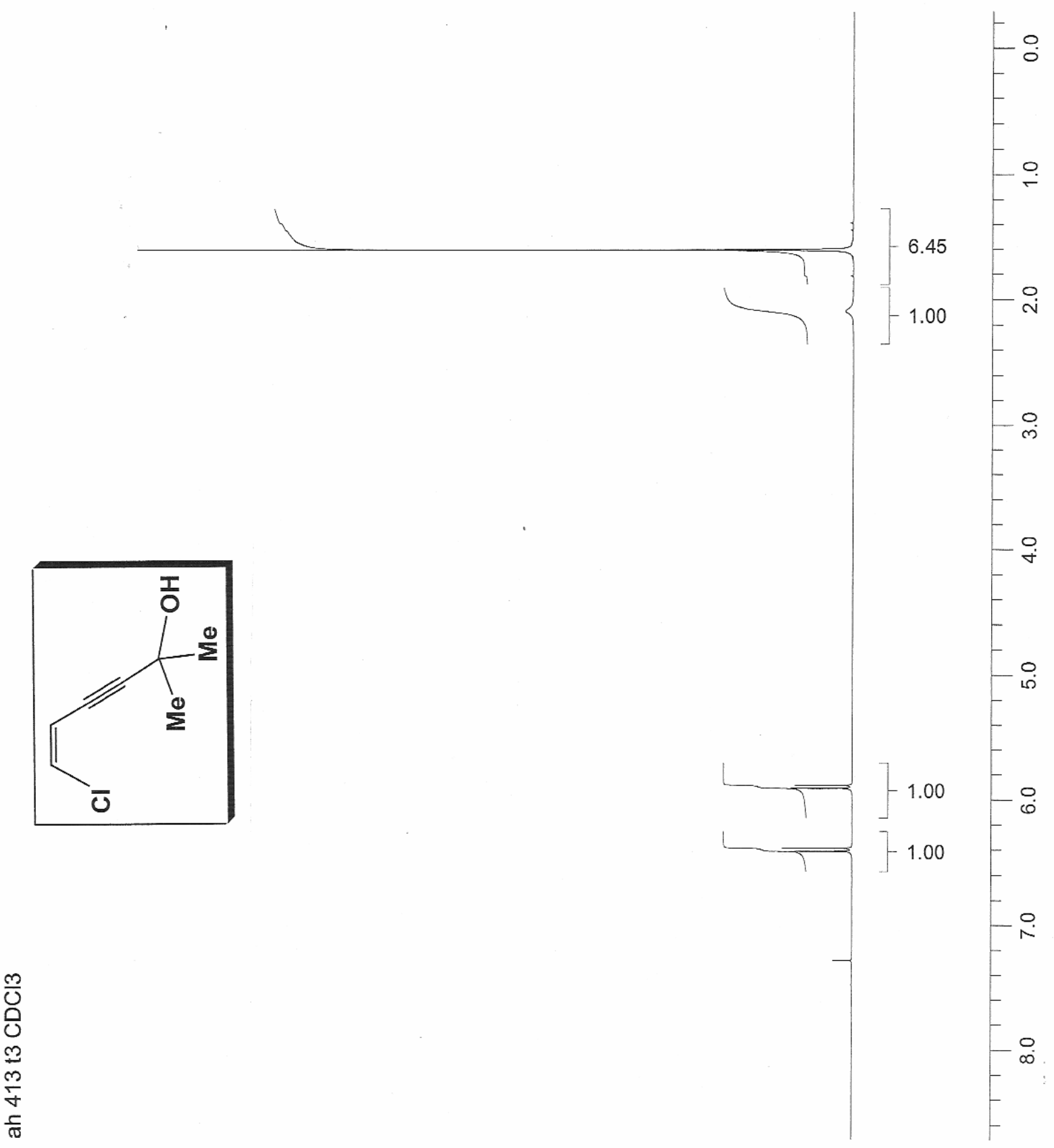




\section{9a}

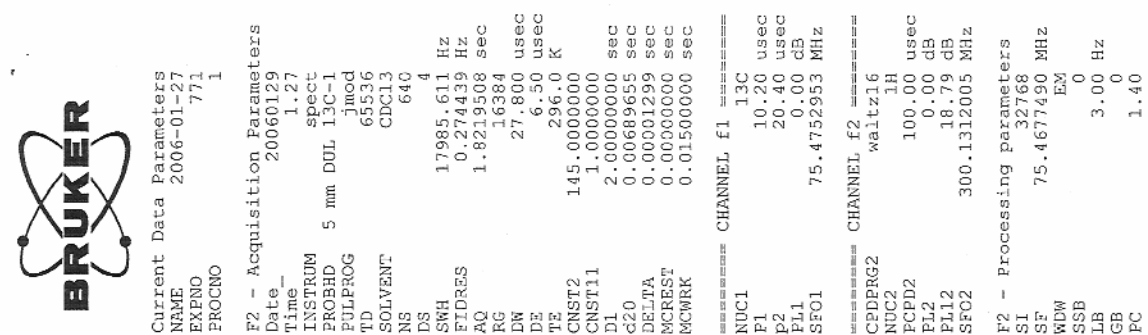

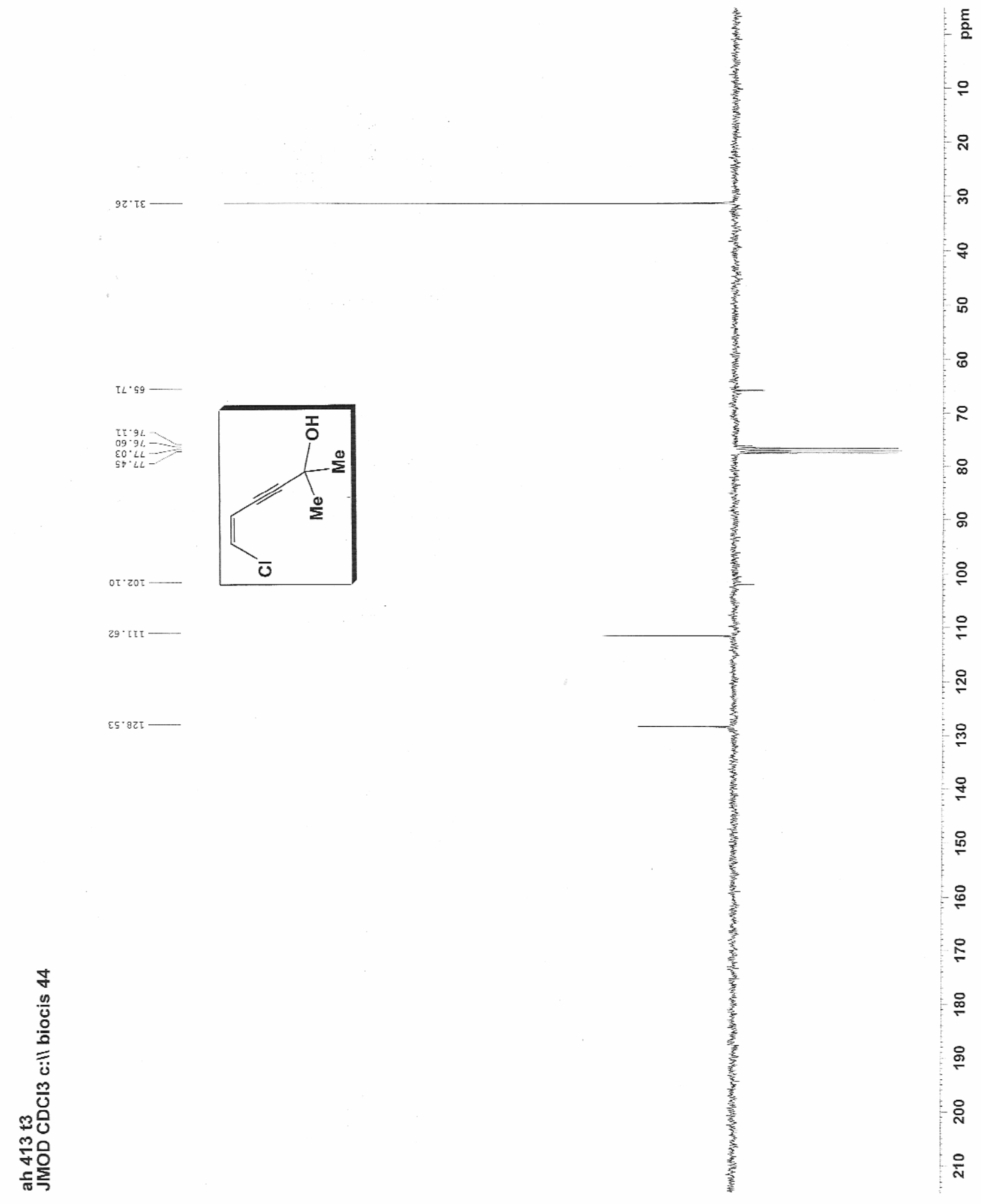

$29 \cdot \operatorname{tit}-$

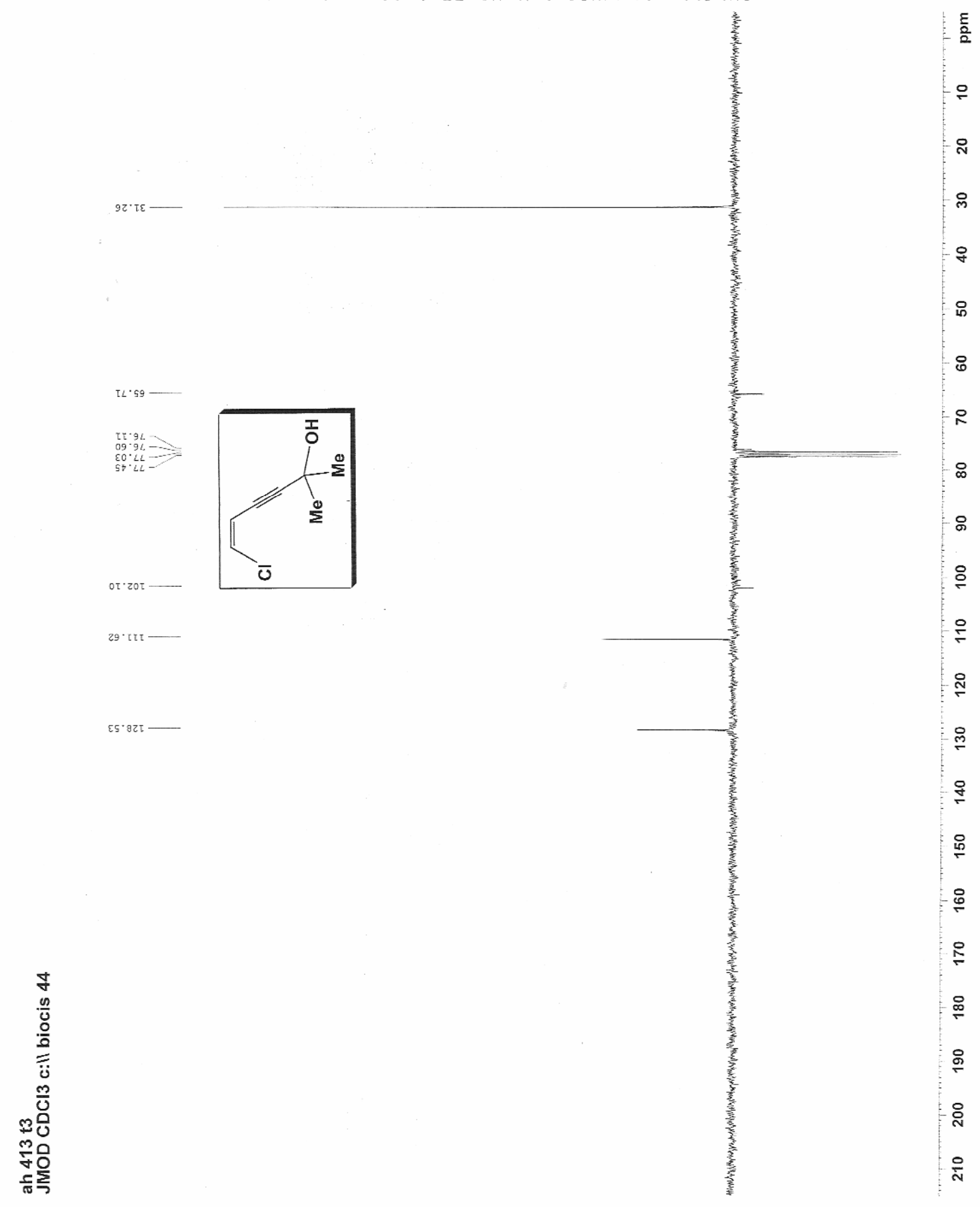




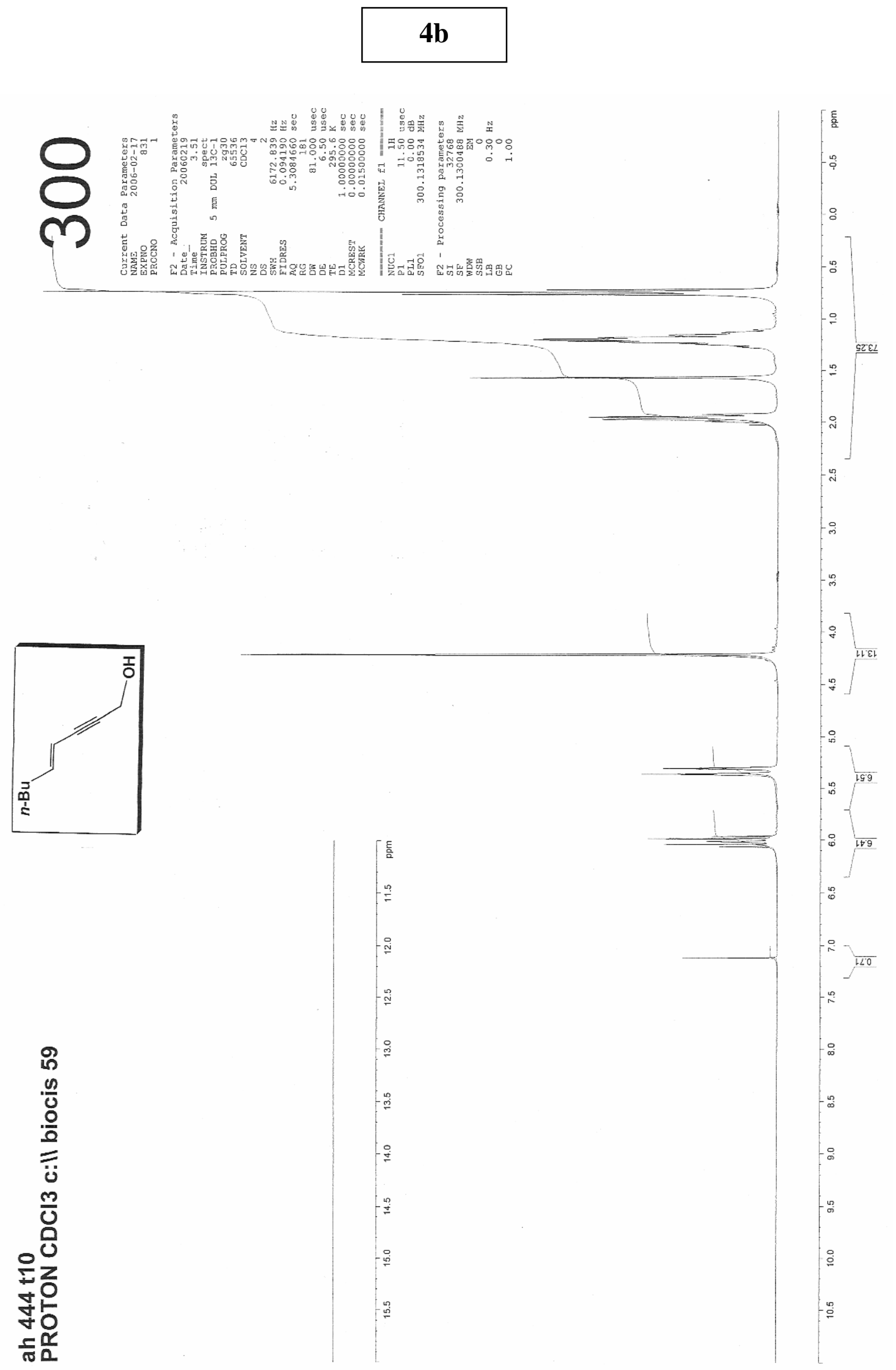




\section{4b}

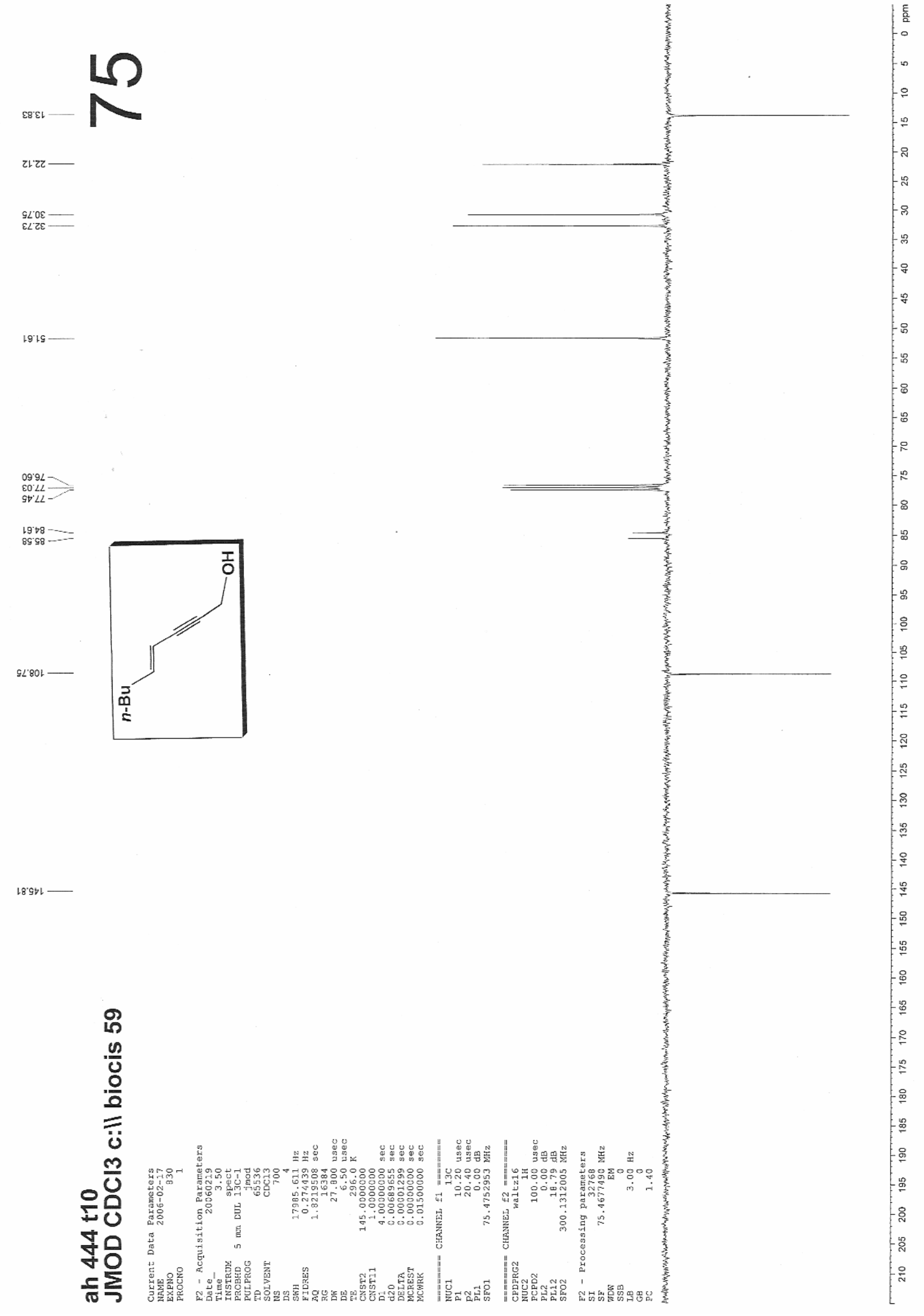



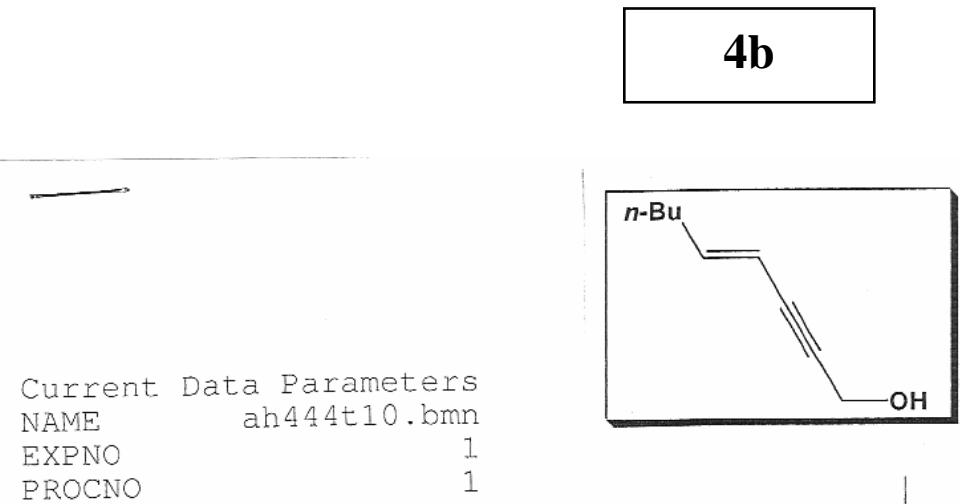

HMBC

\section{.}
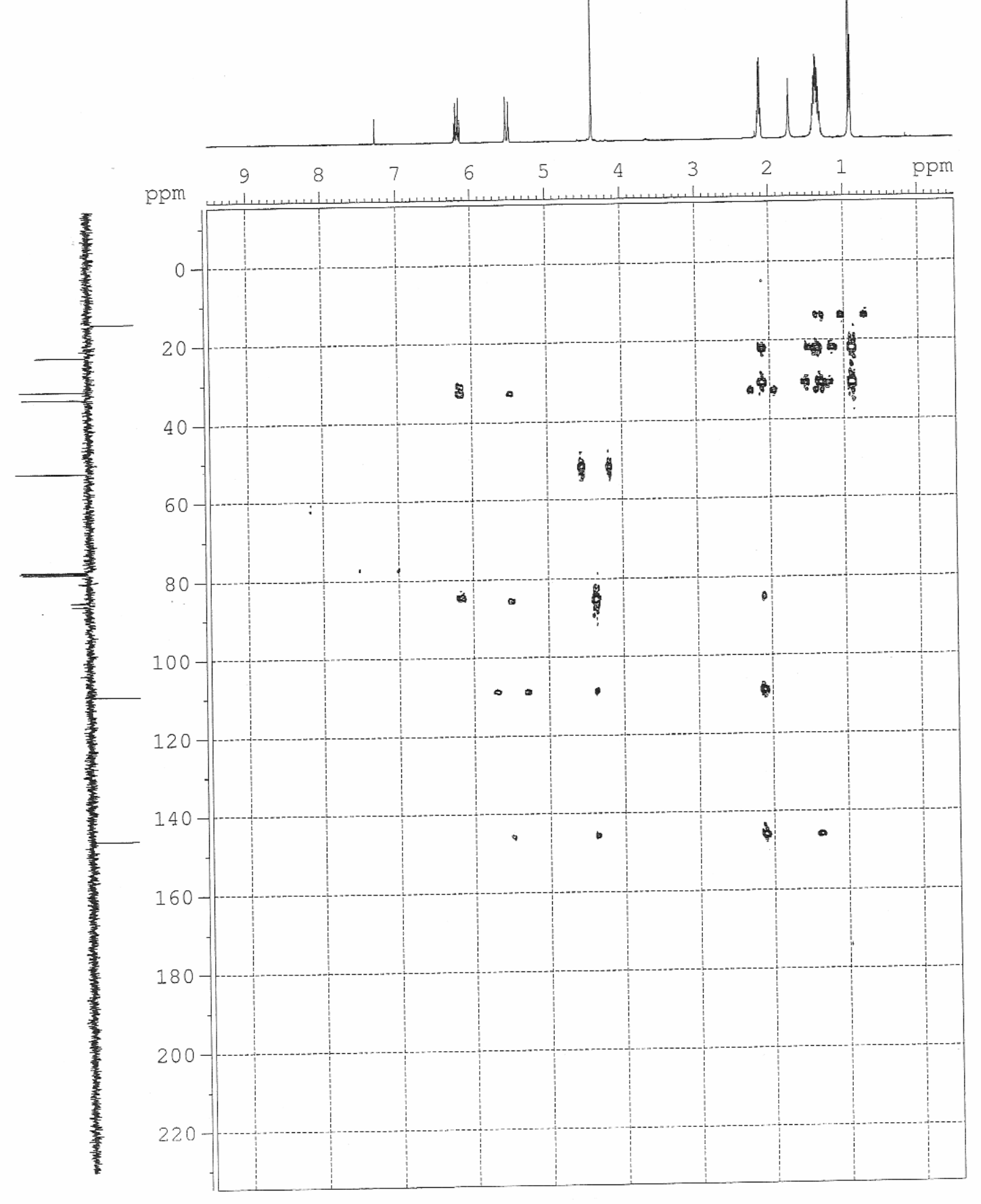


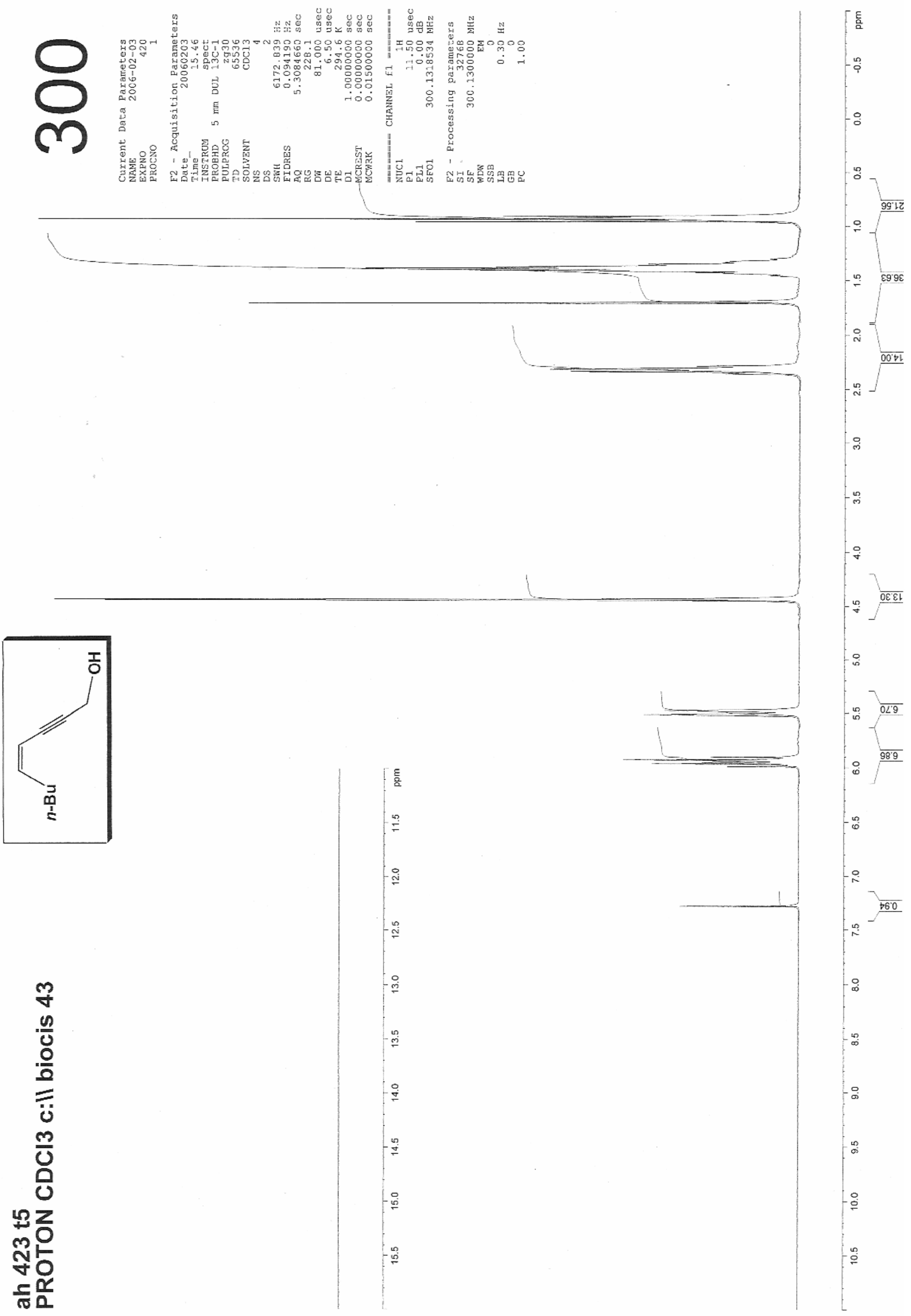




\section{7b}
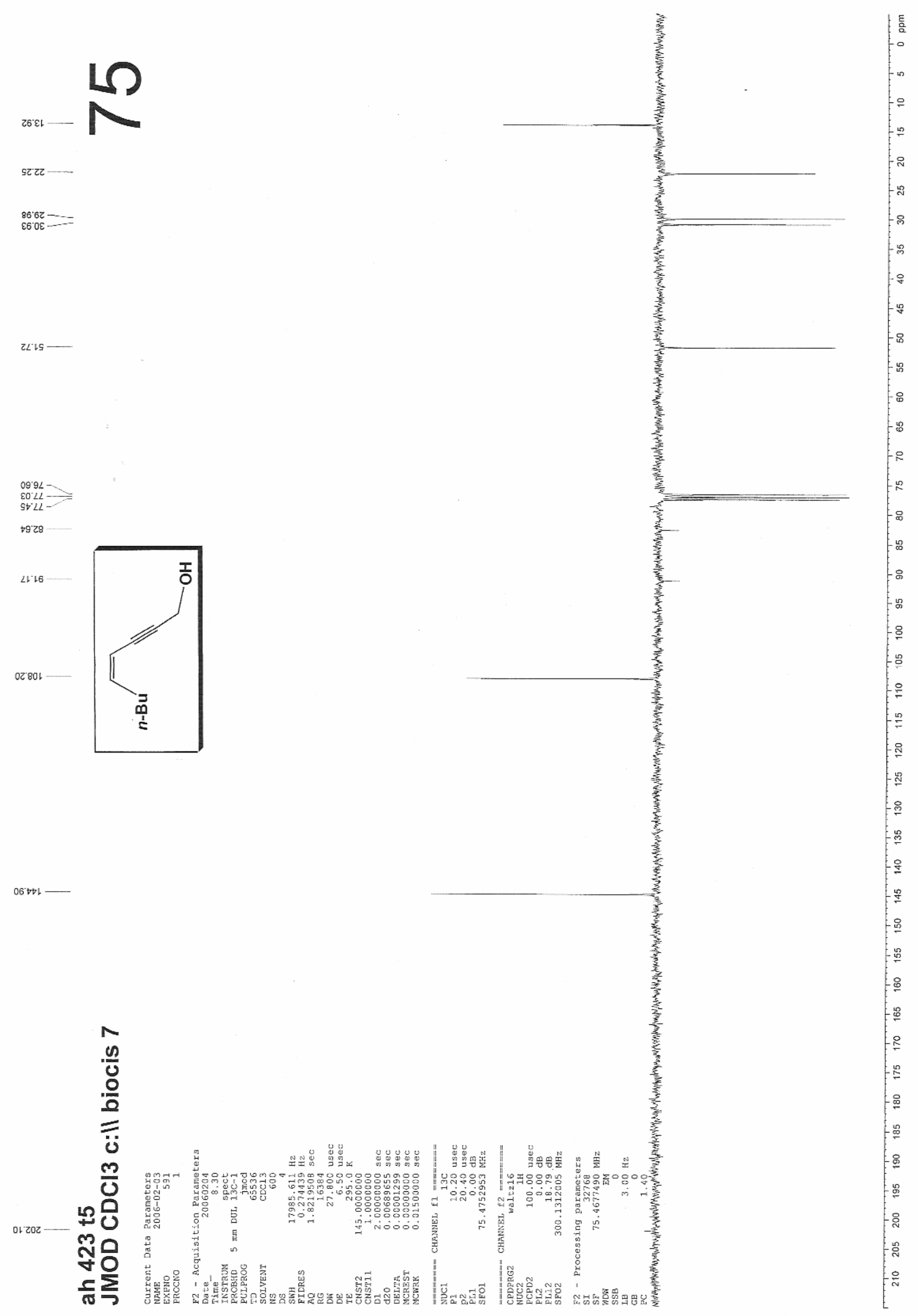


\section{$7 b$}

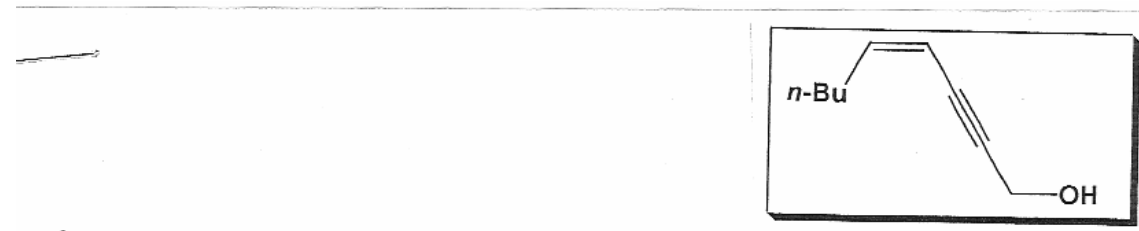

Current Data Parameters

NAME

EXPNO

ah $423 t 5$.bmn

PROCNO

HMBC

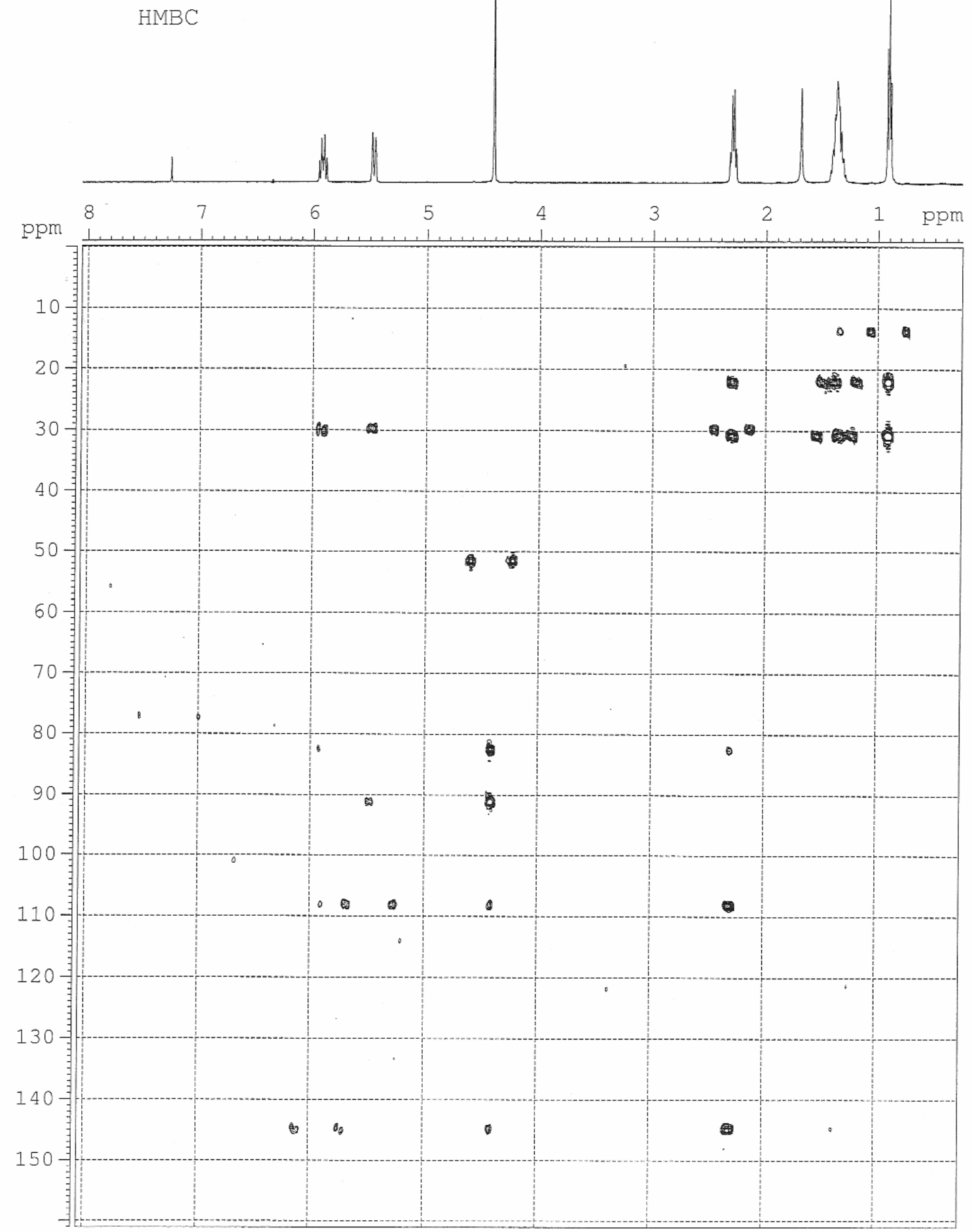




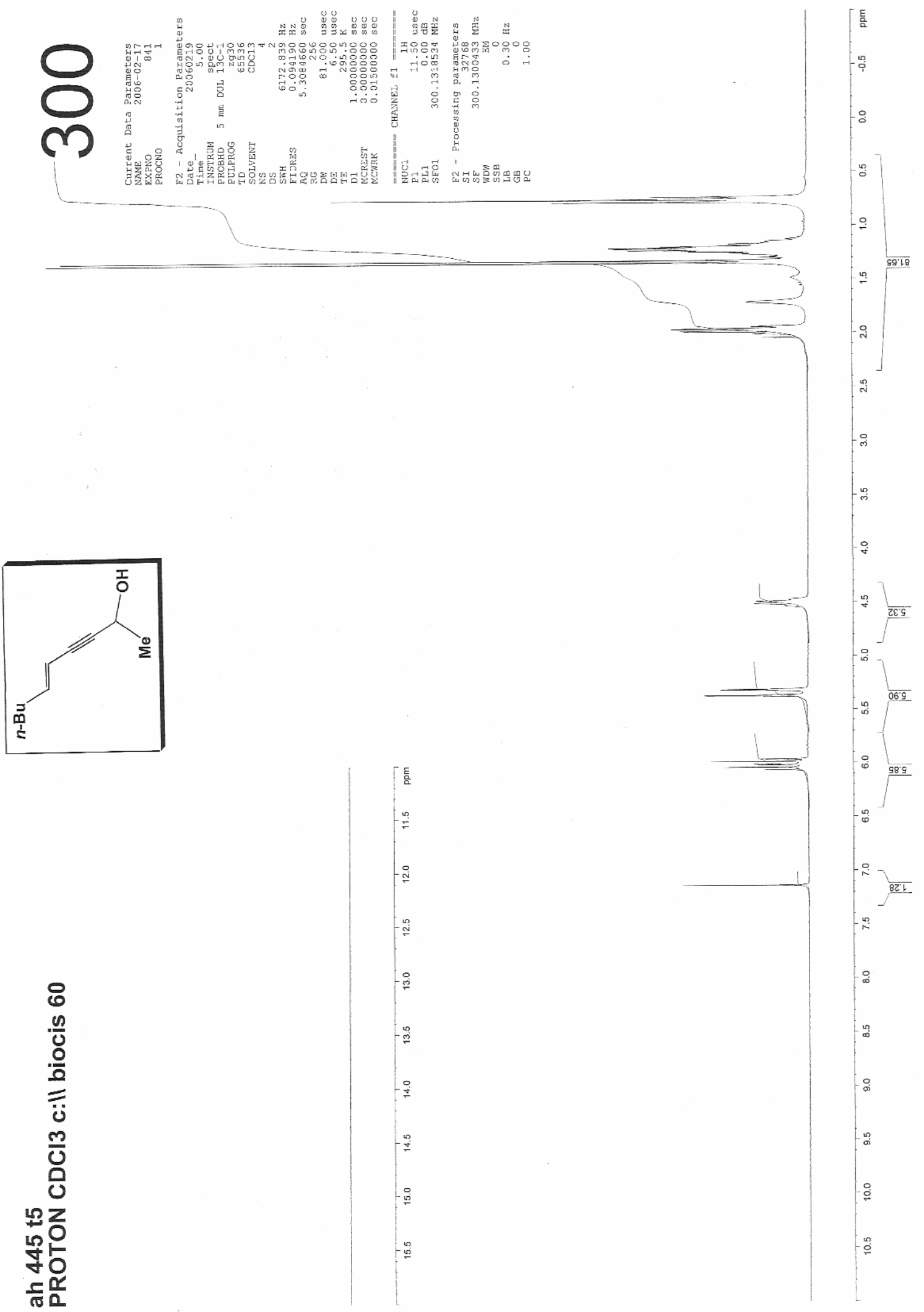




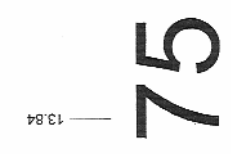

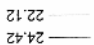

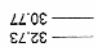

7889

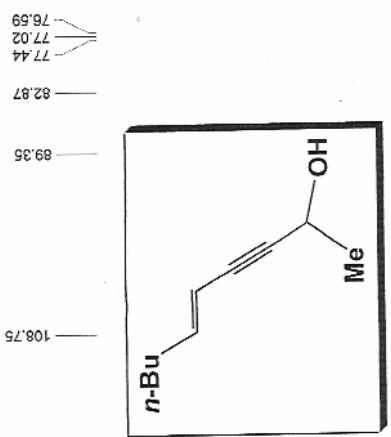

zsฐฺ

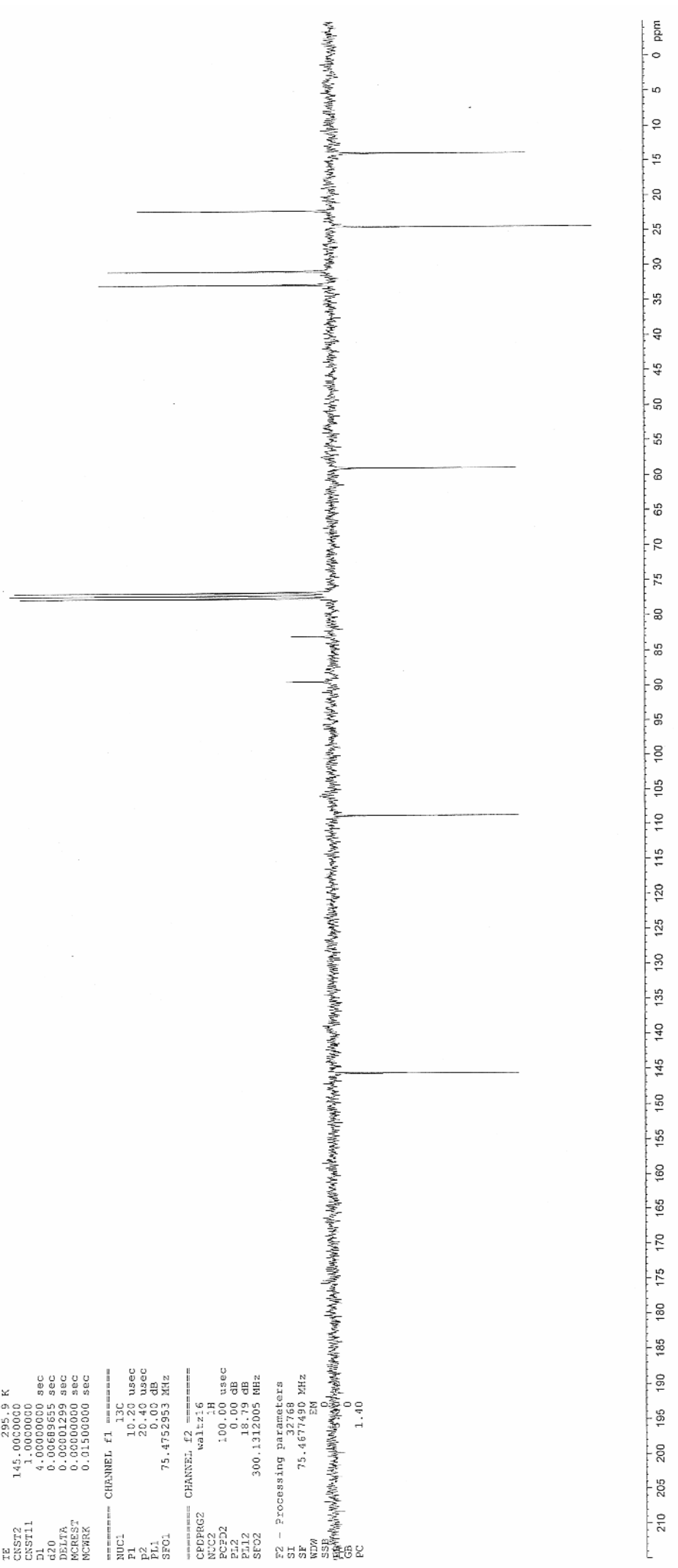




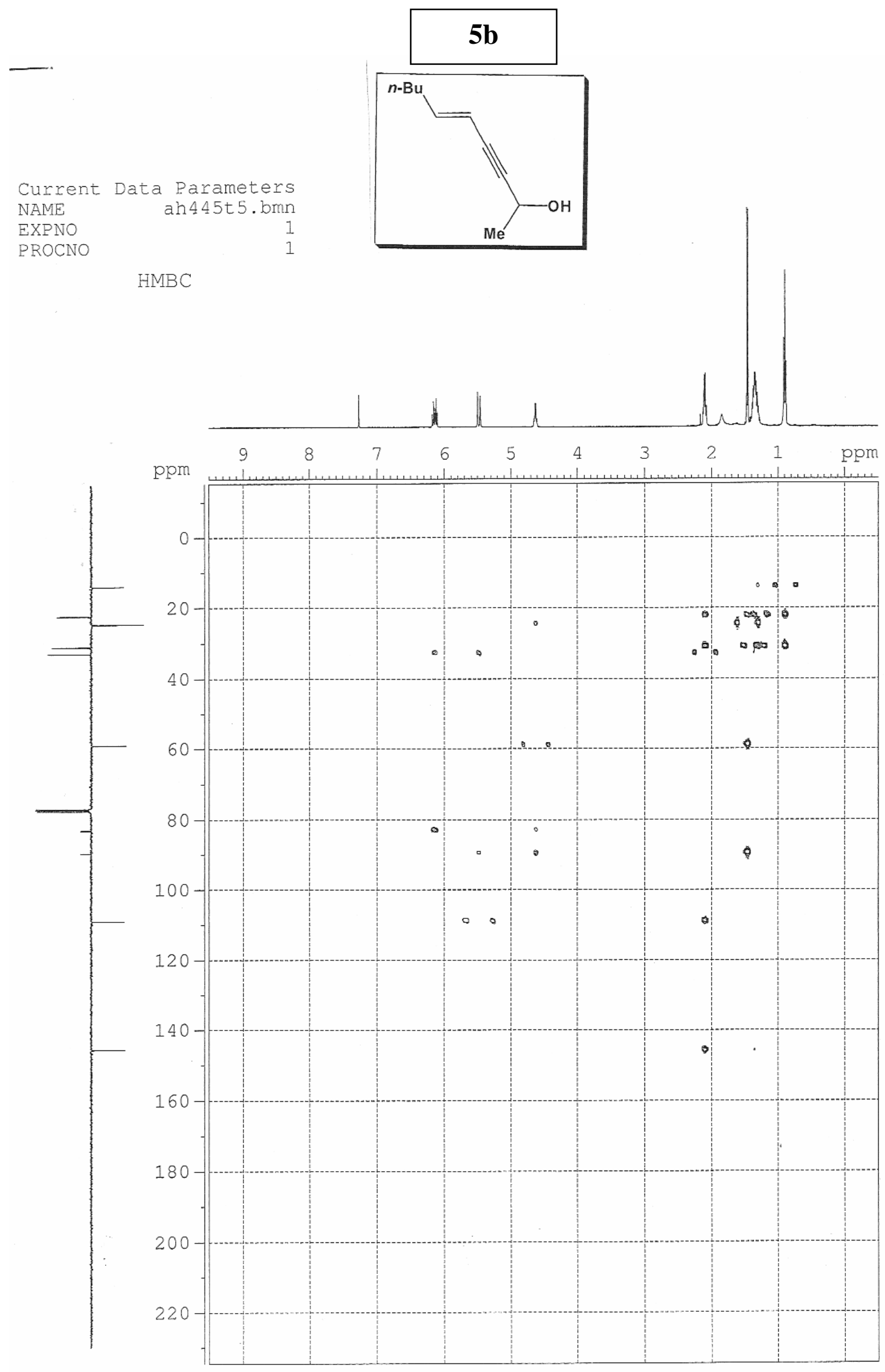




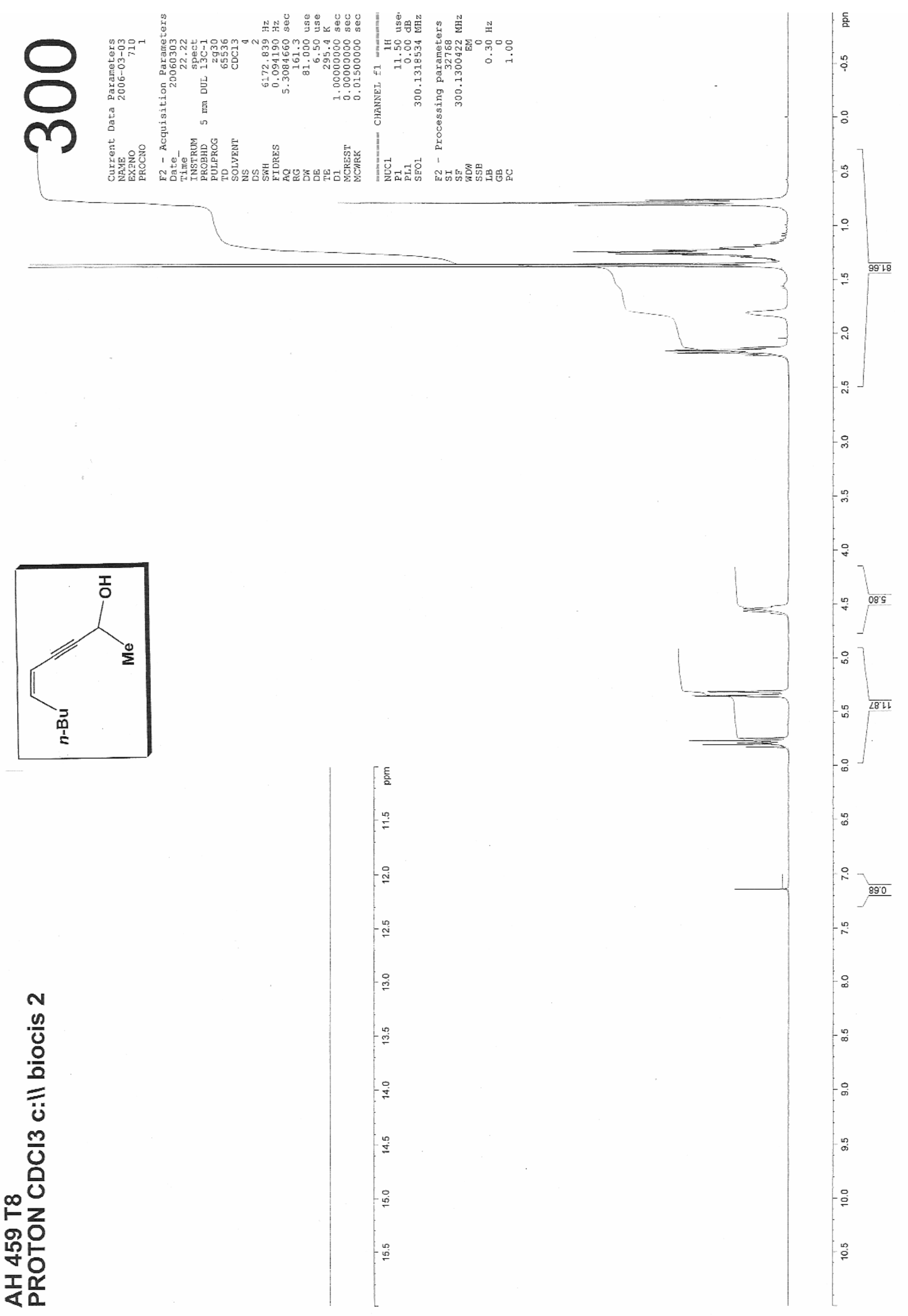




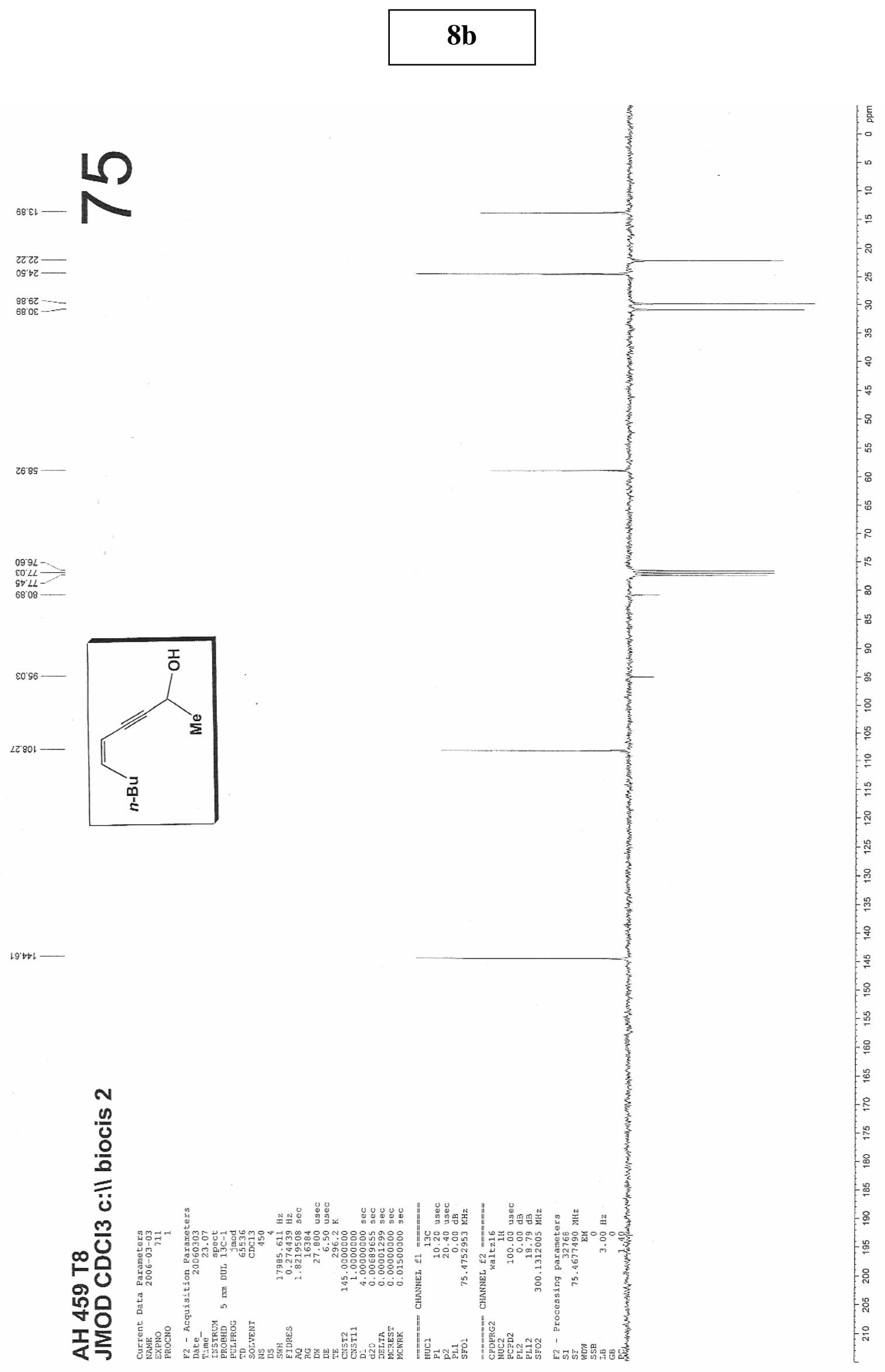




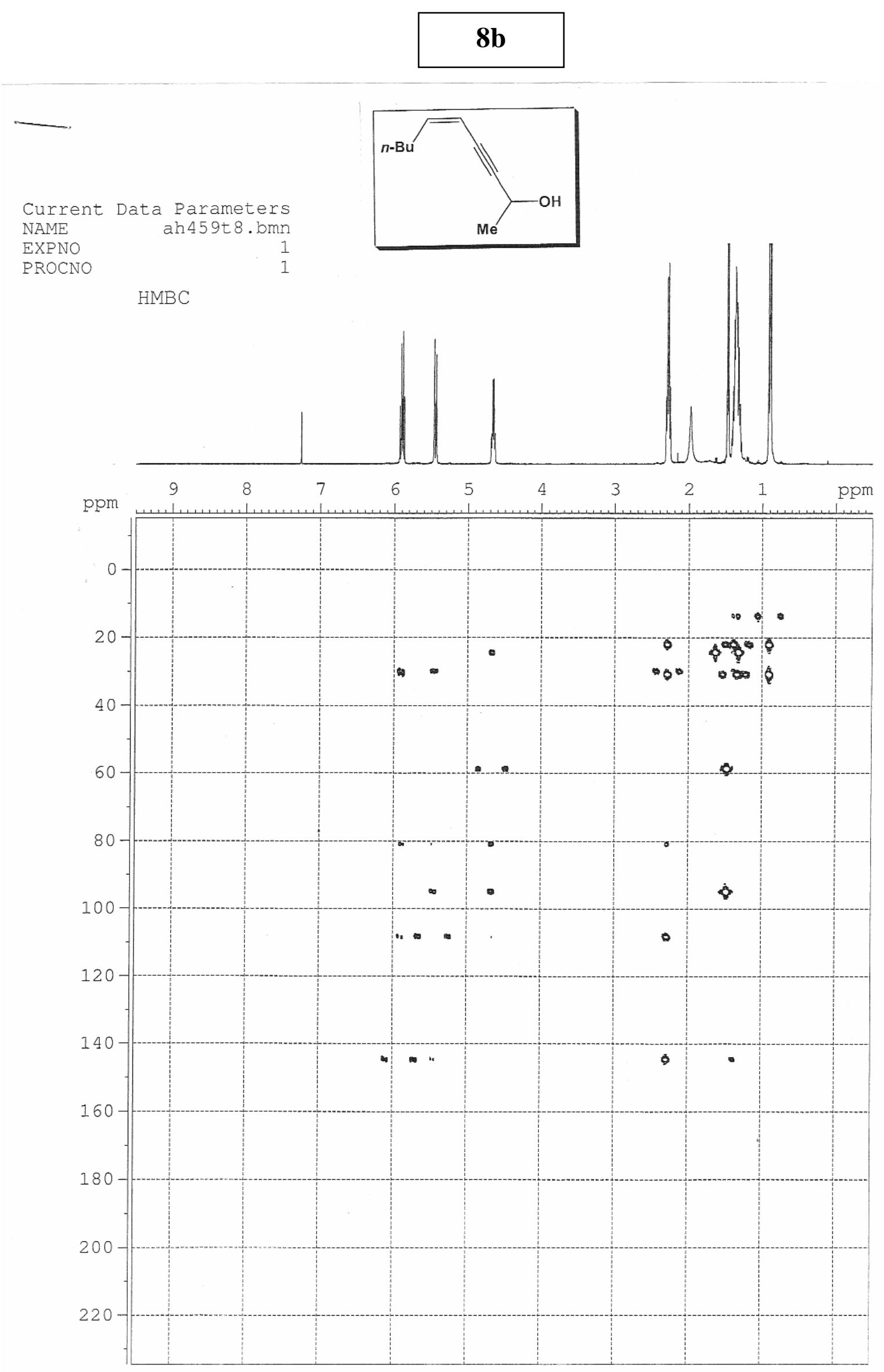



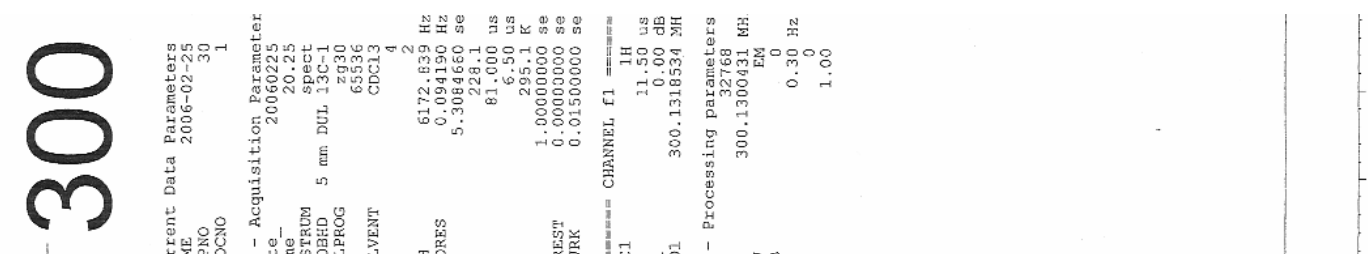

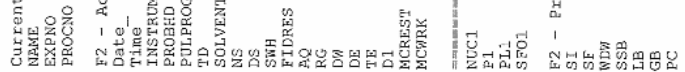

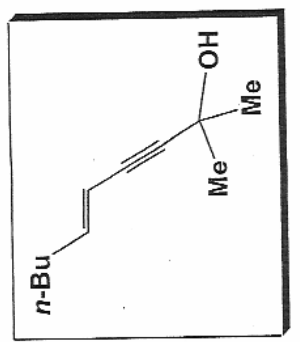

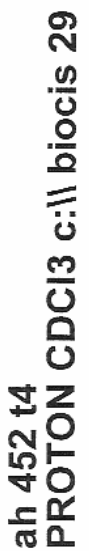




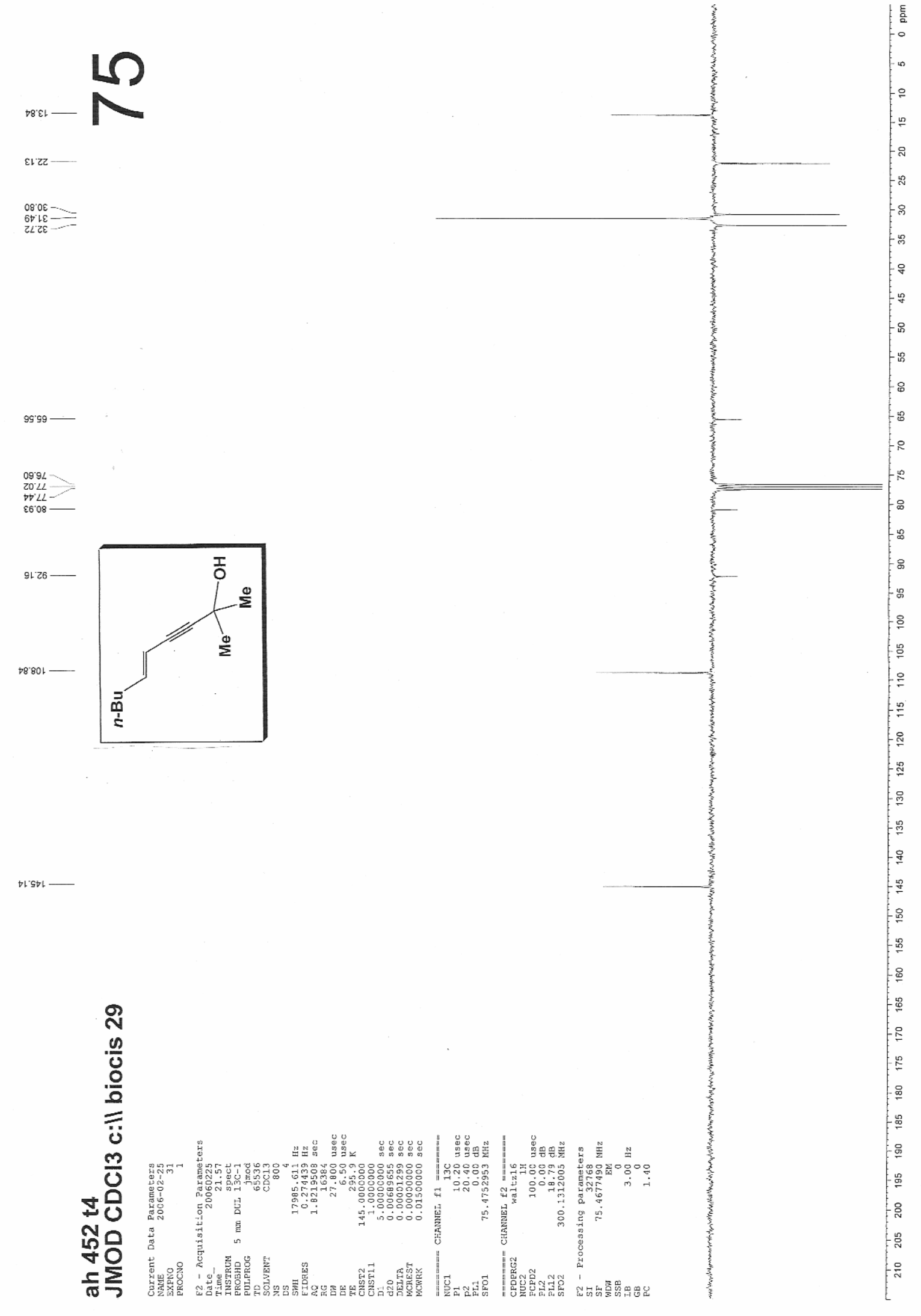


6b

Current Data parameters

NAME ah452t4.bmn

EXPNO

PROCNO

1
1

HMBC
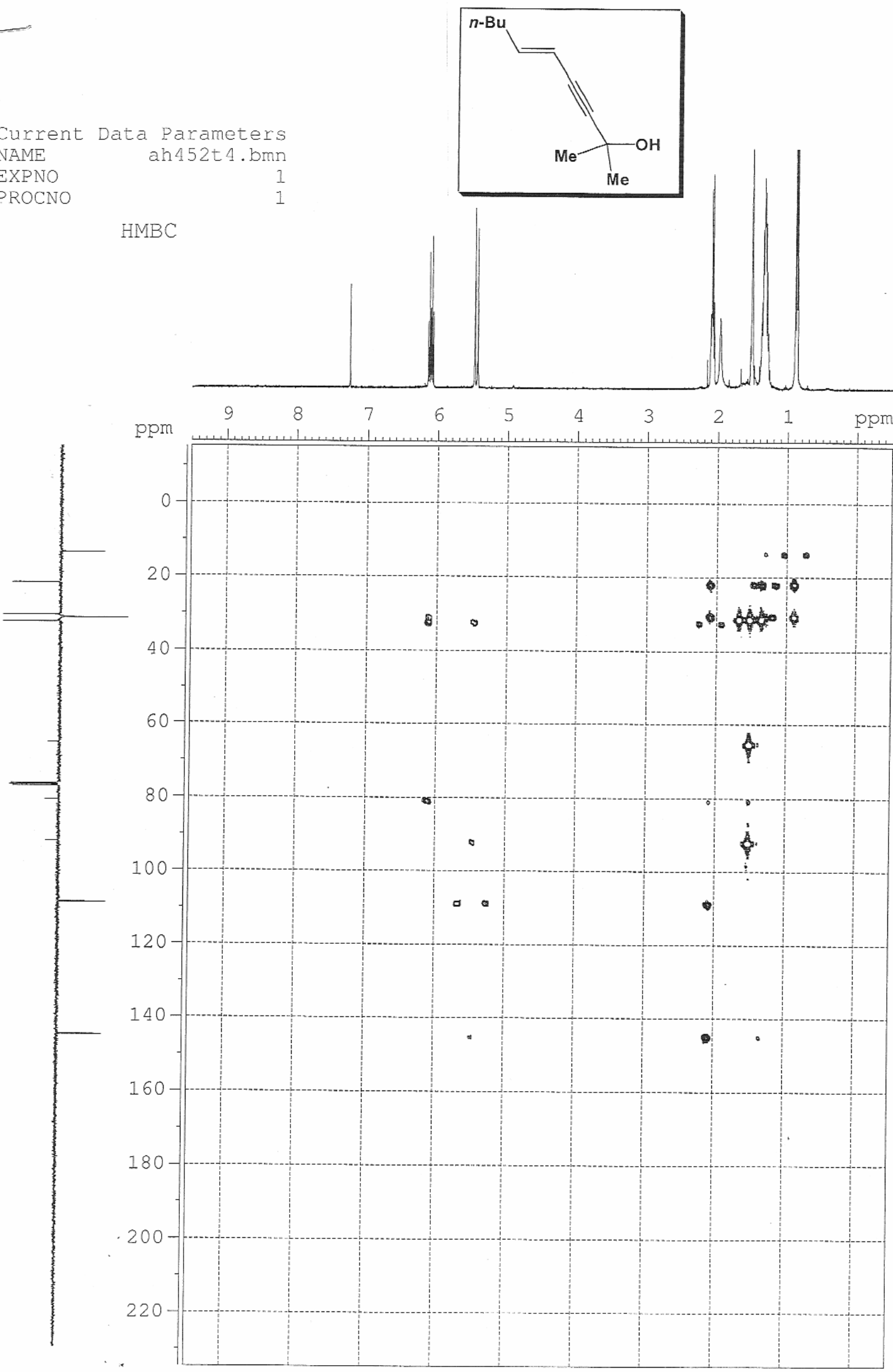


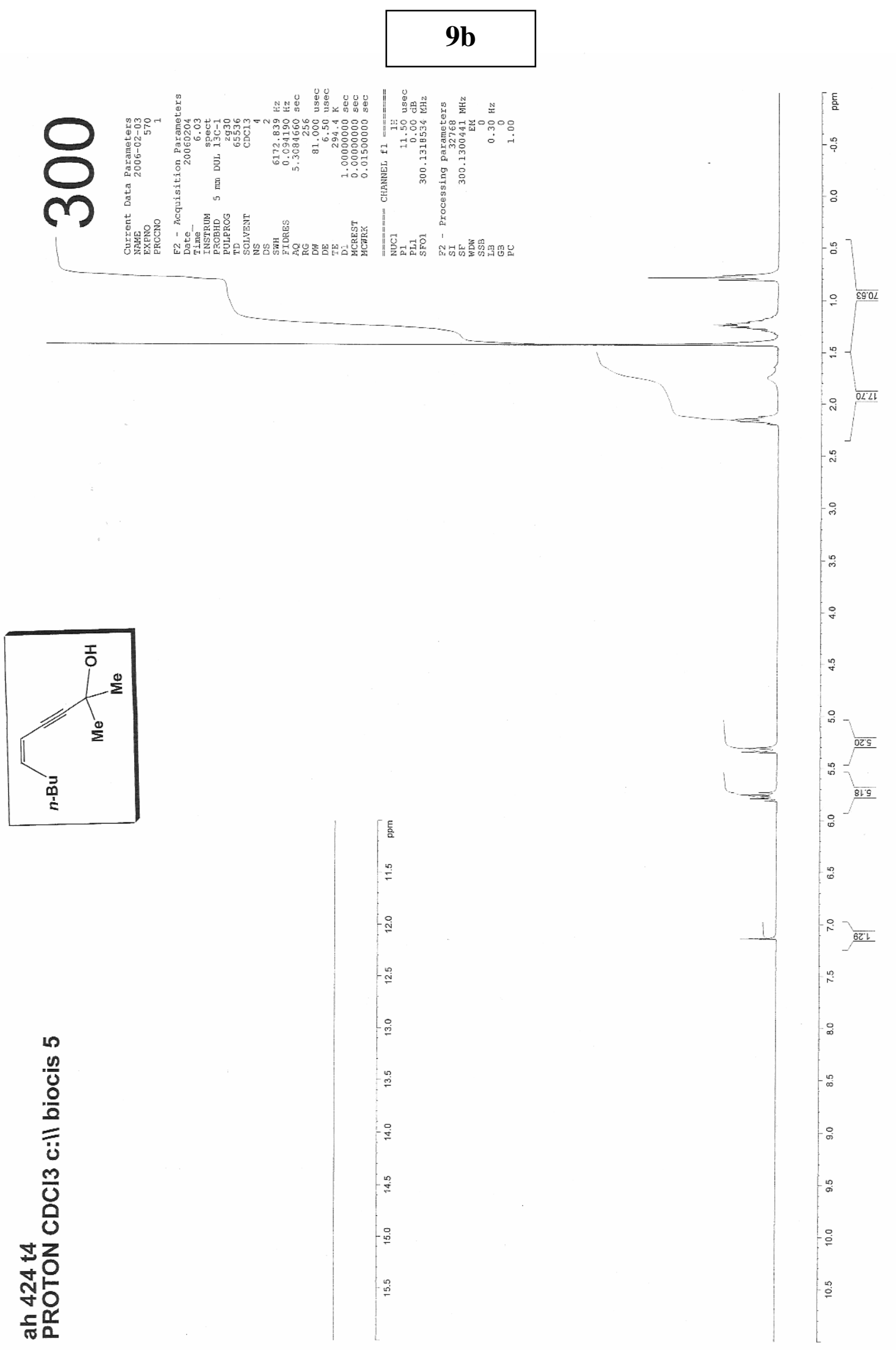




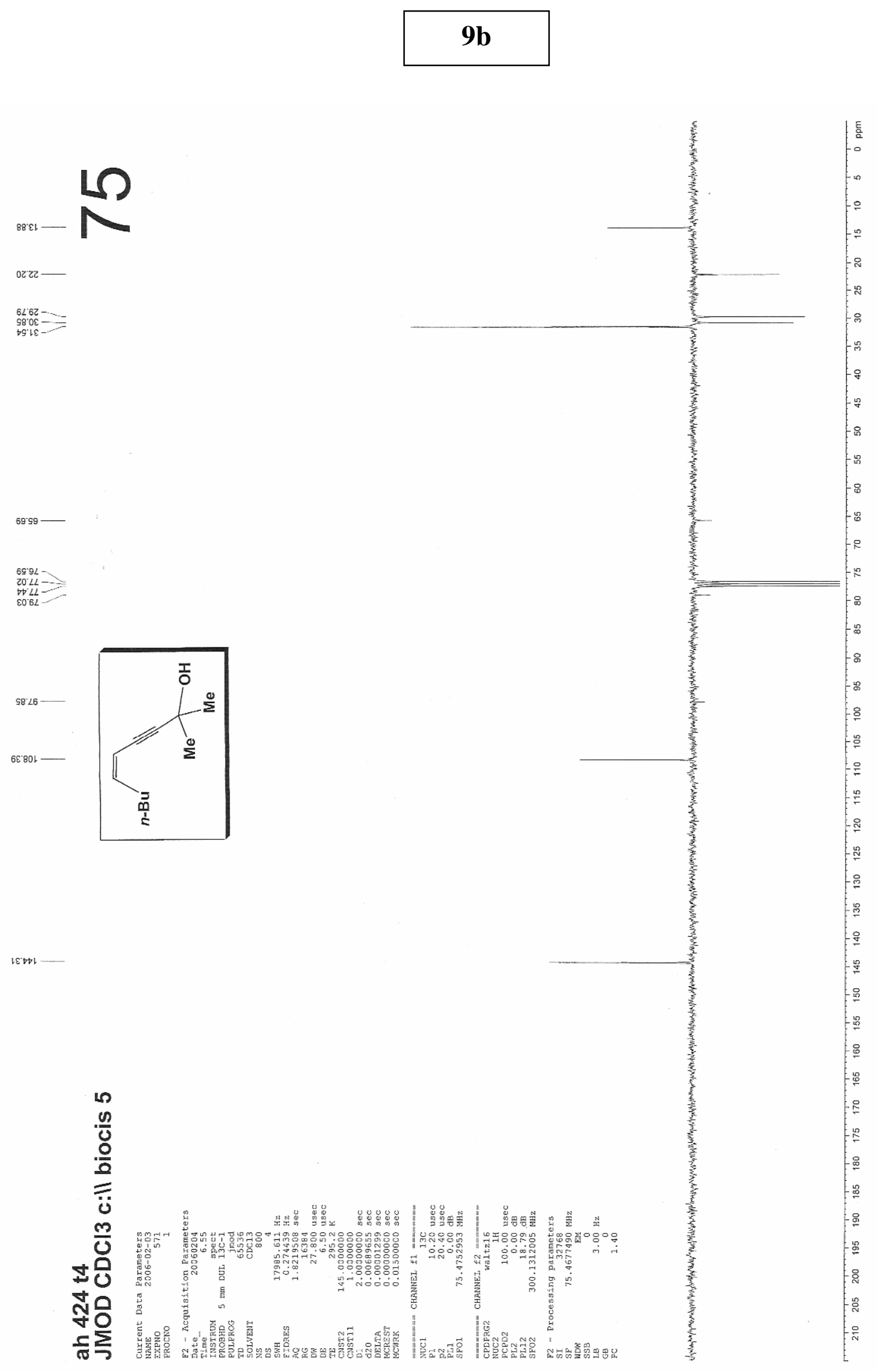




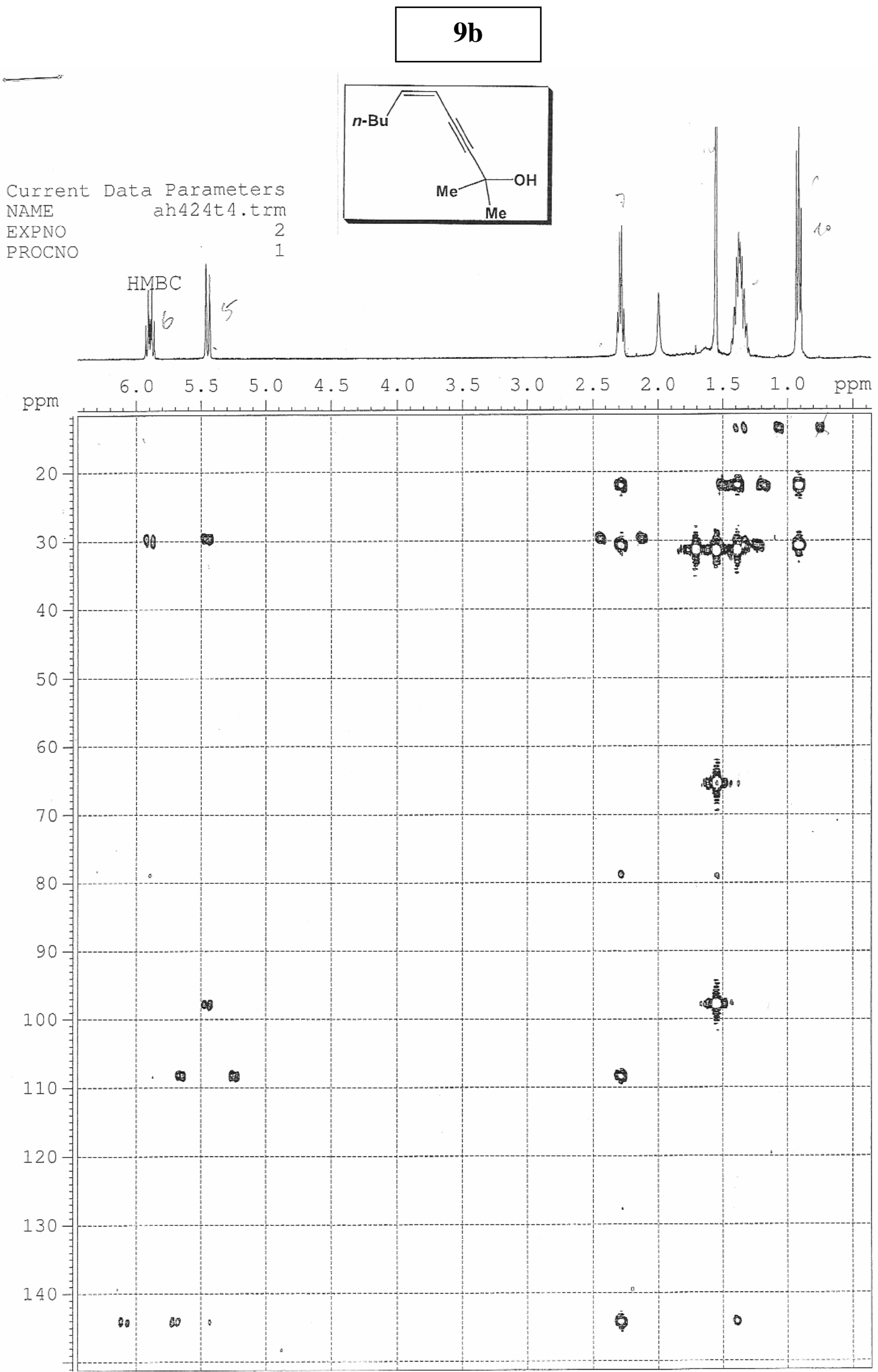




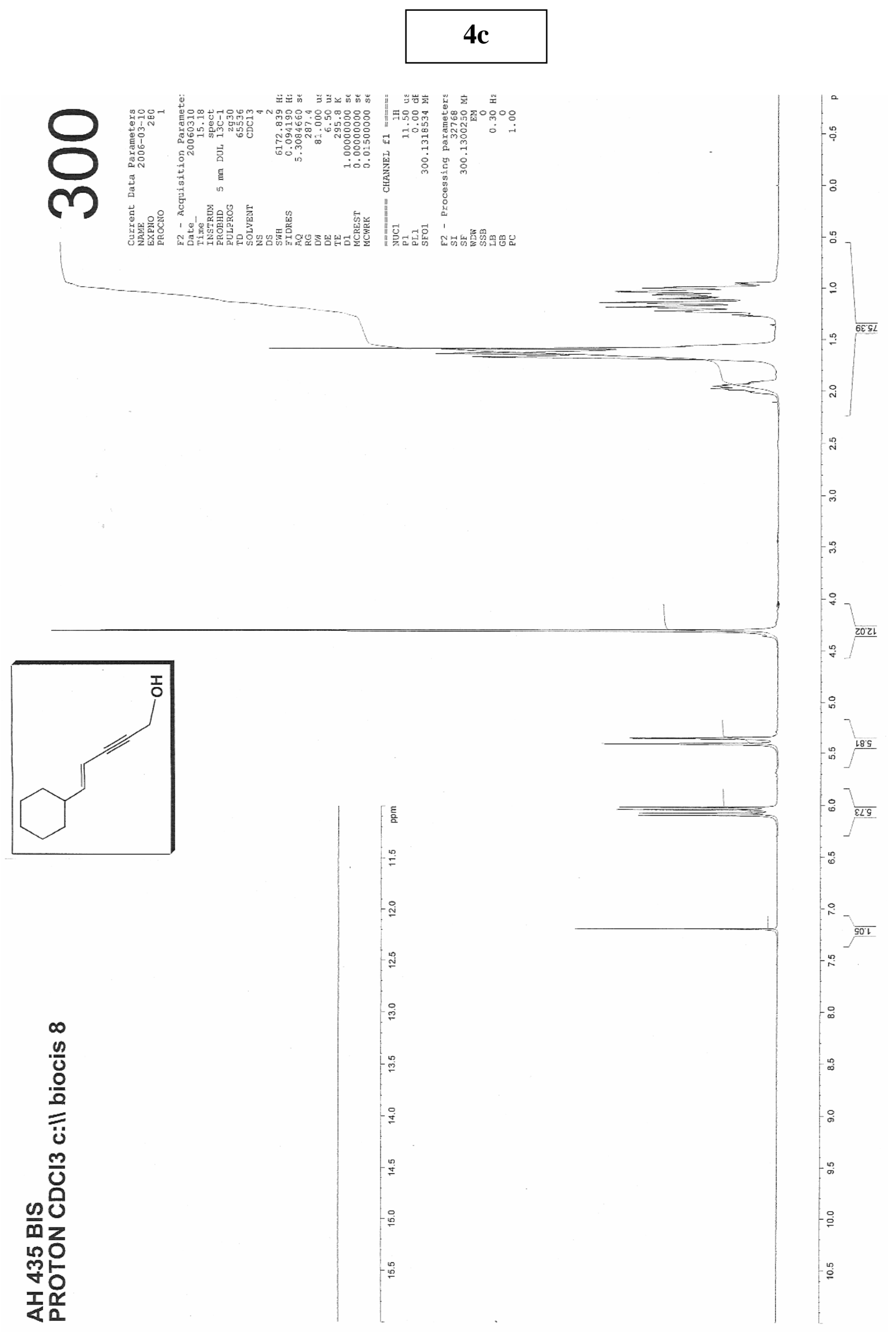




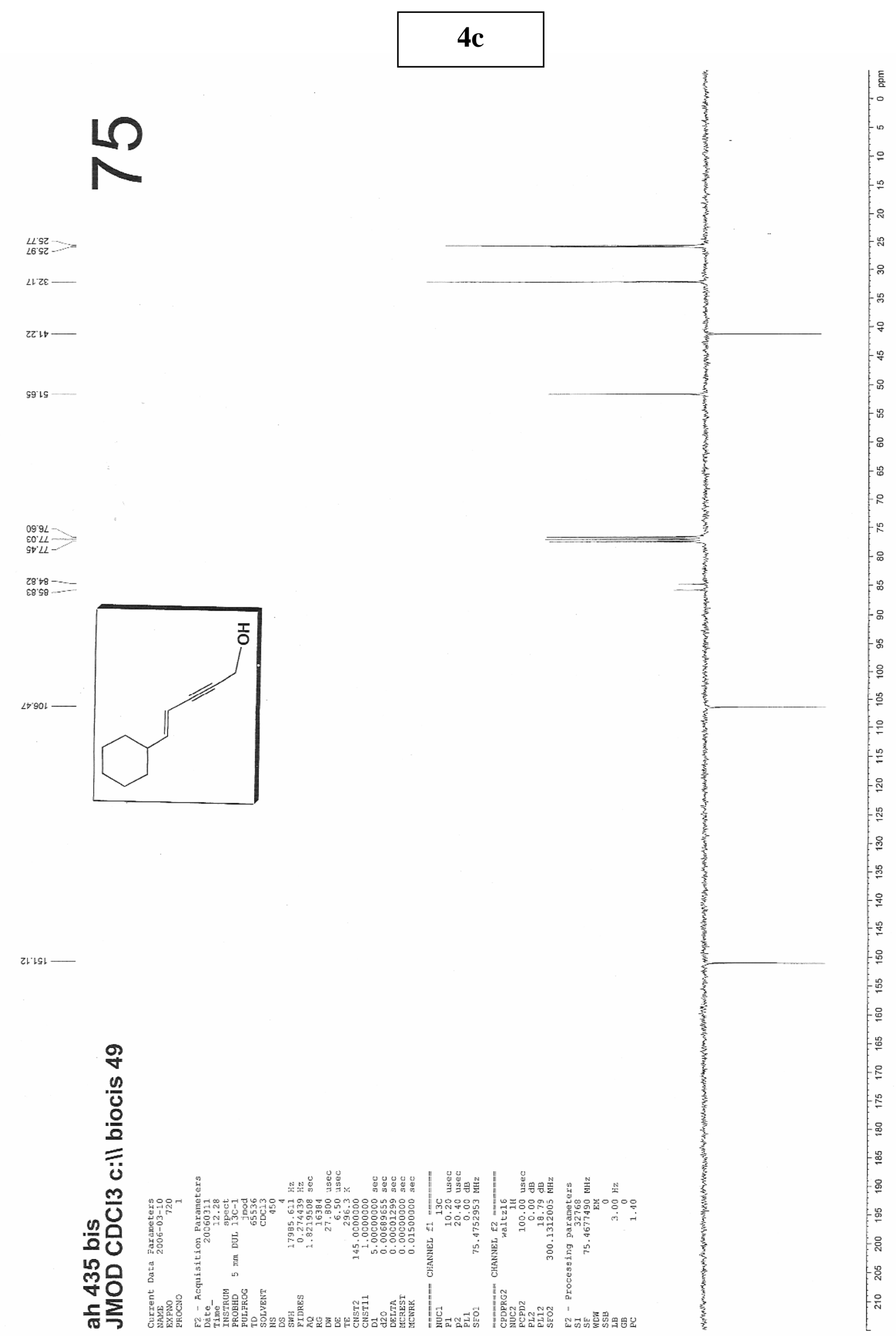




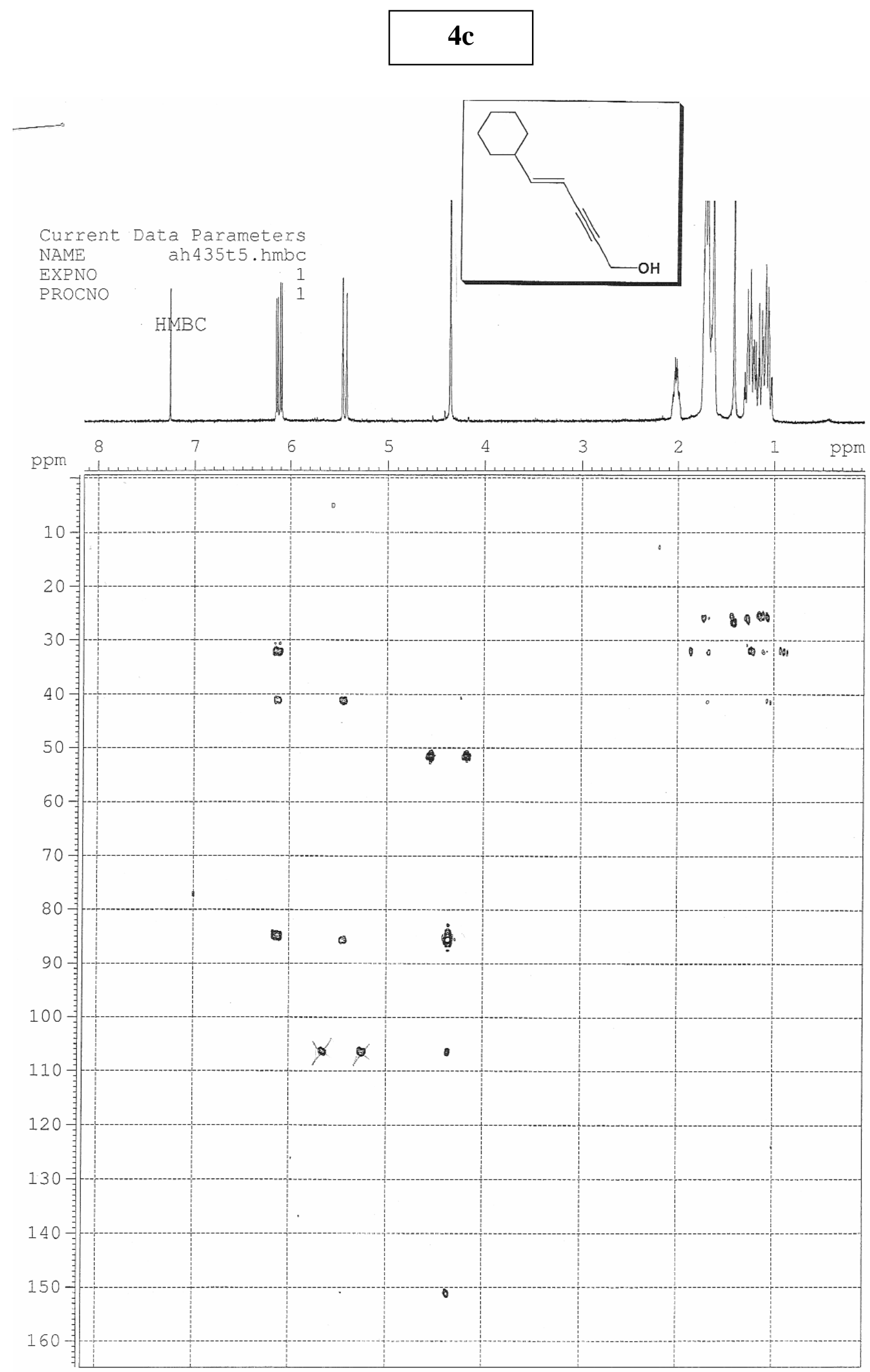




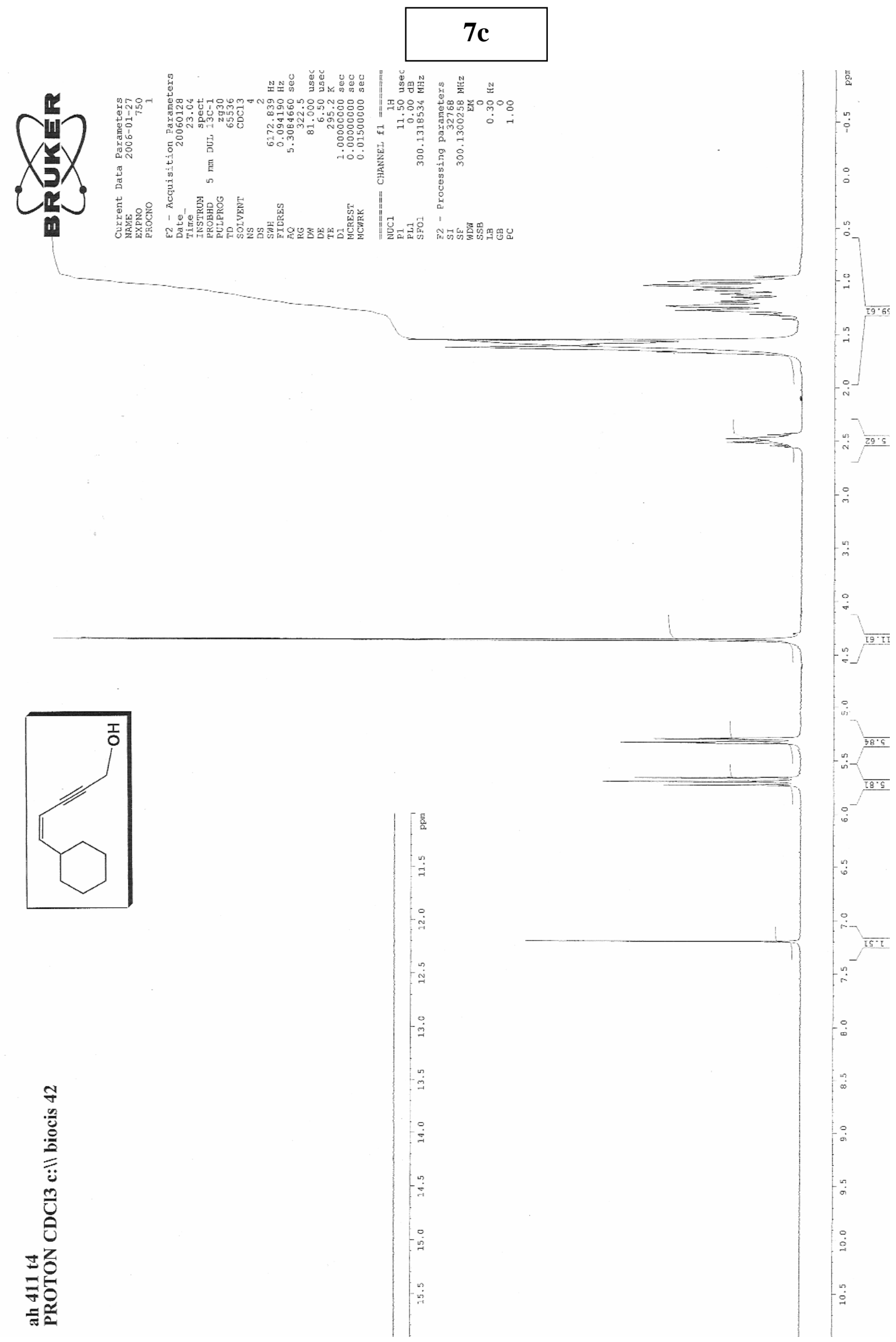




\section{7c}
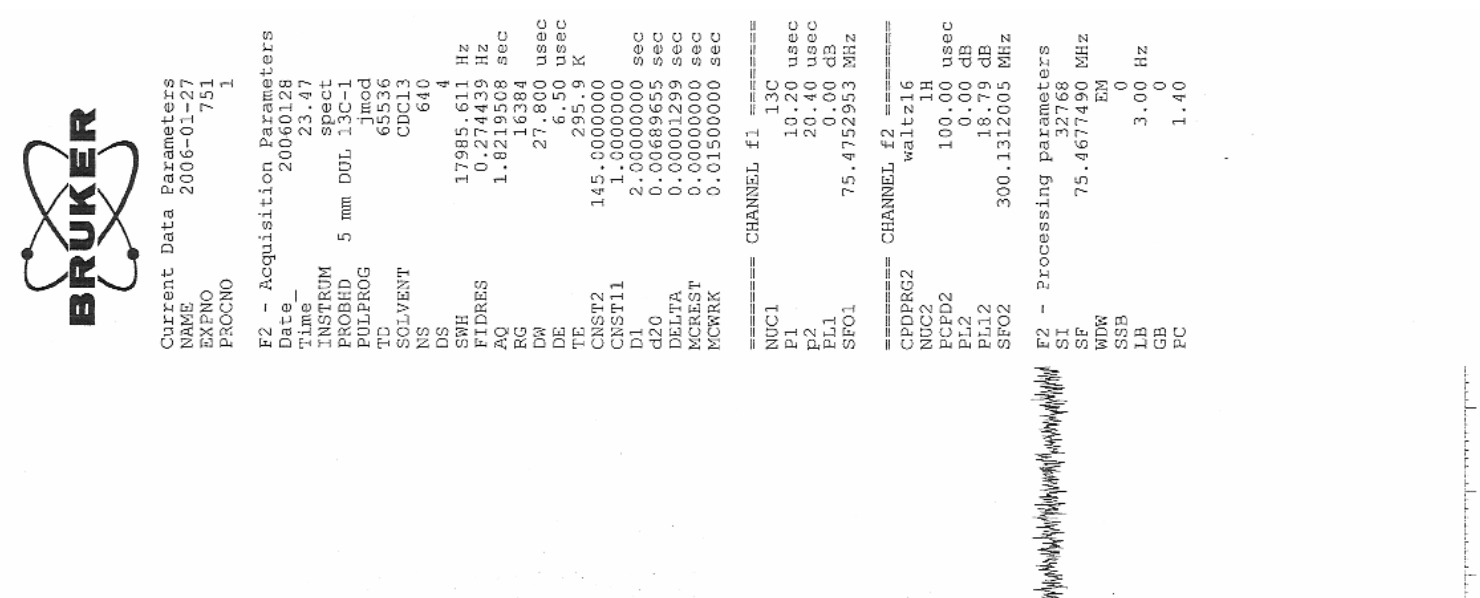

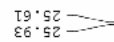

$9 z \cdot z \varepsilon-$

$9 Z \cdot 6 \varepsilon$

6L'TS

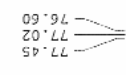

nat

...

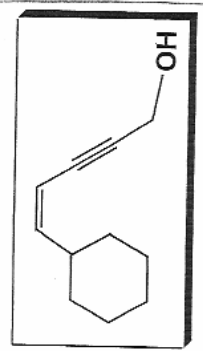

s2. ost

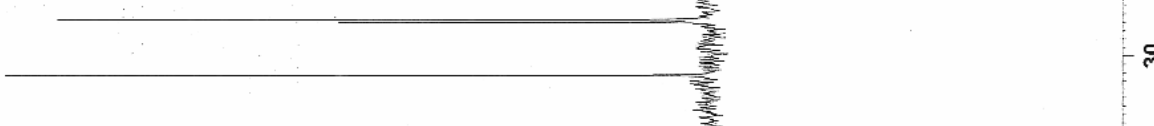

grear
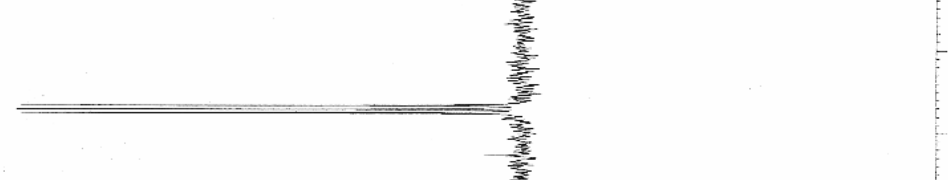

웅

움 


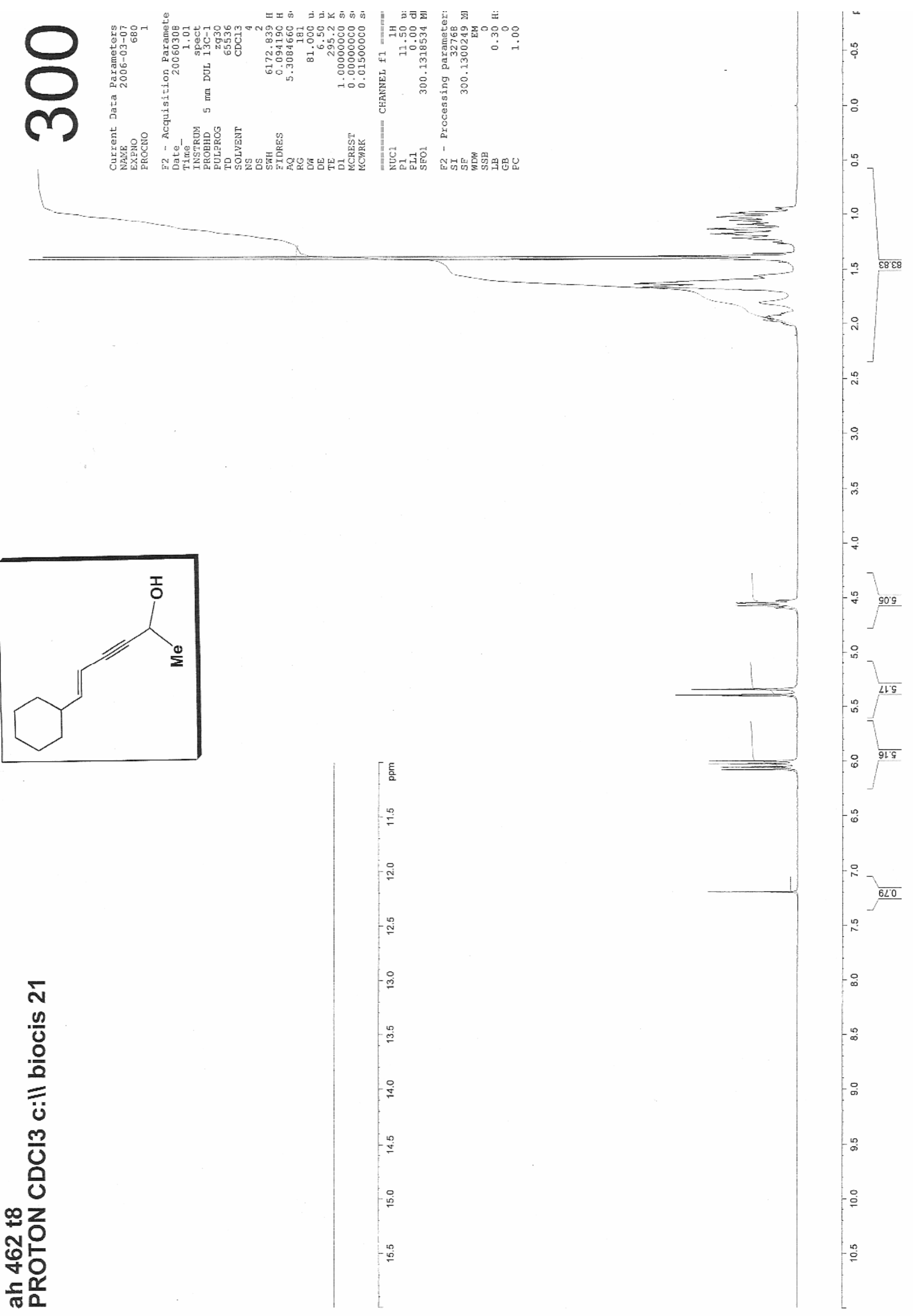




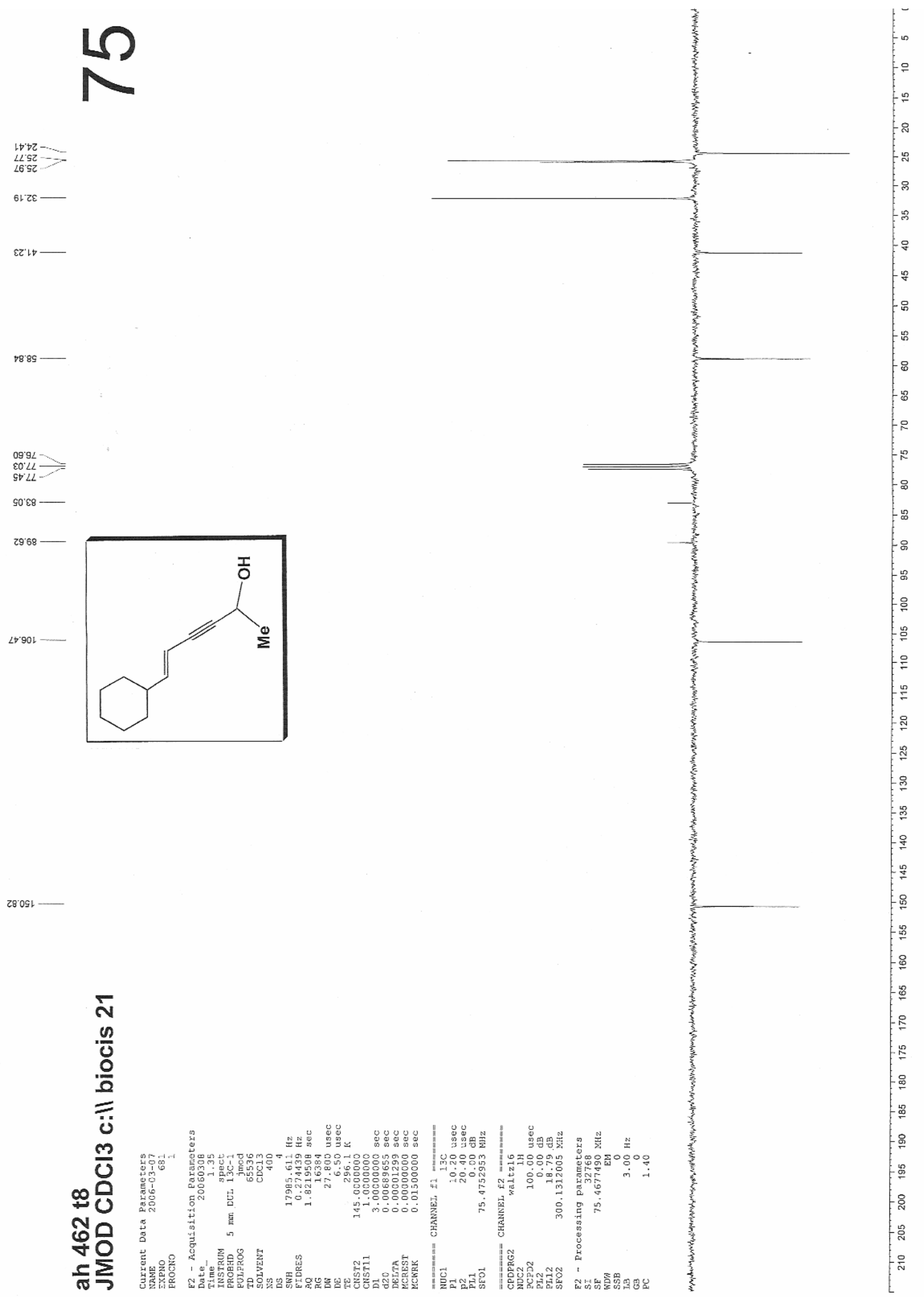




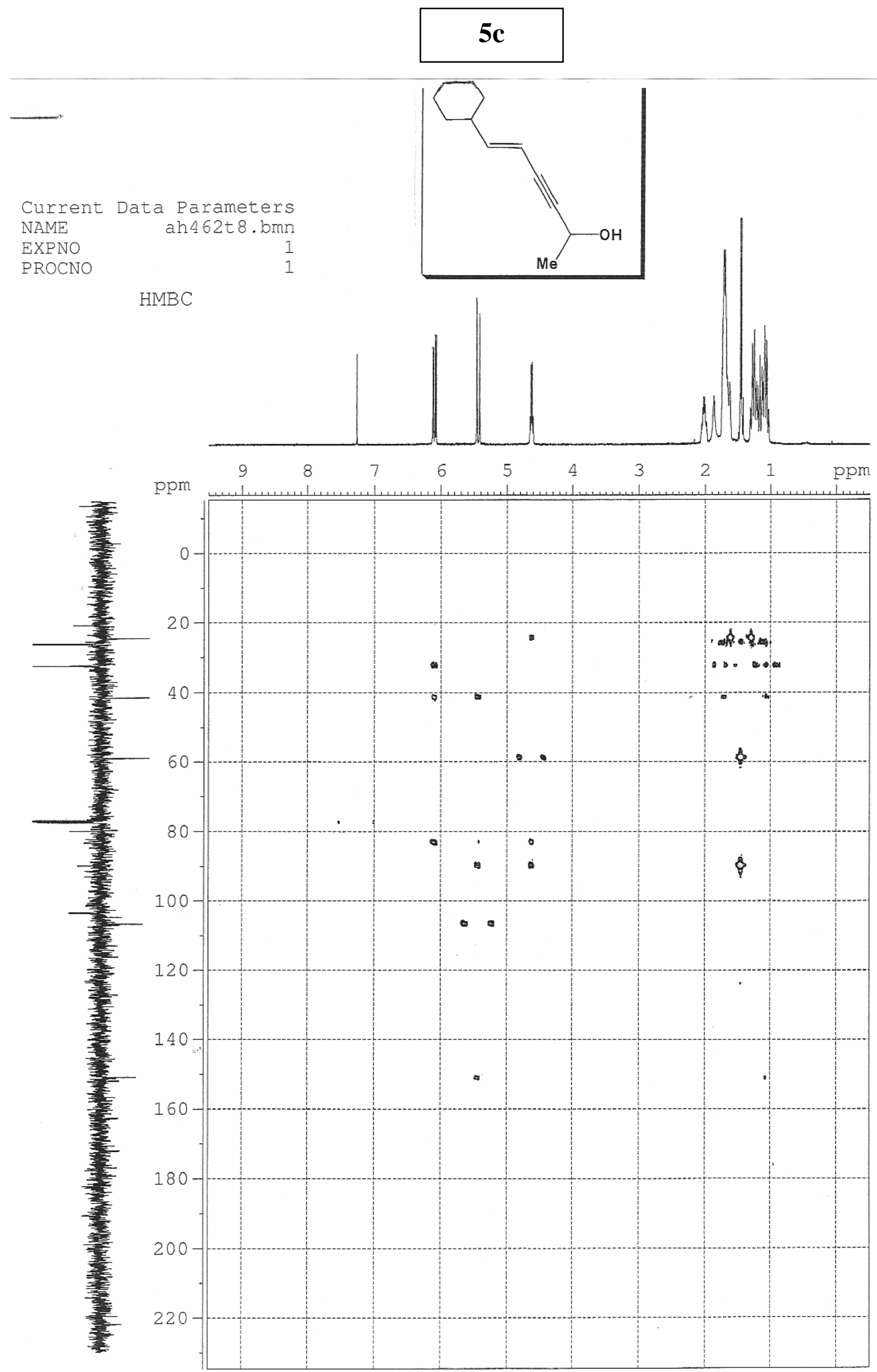




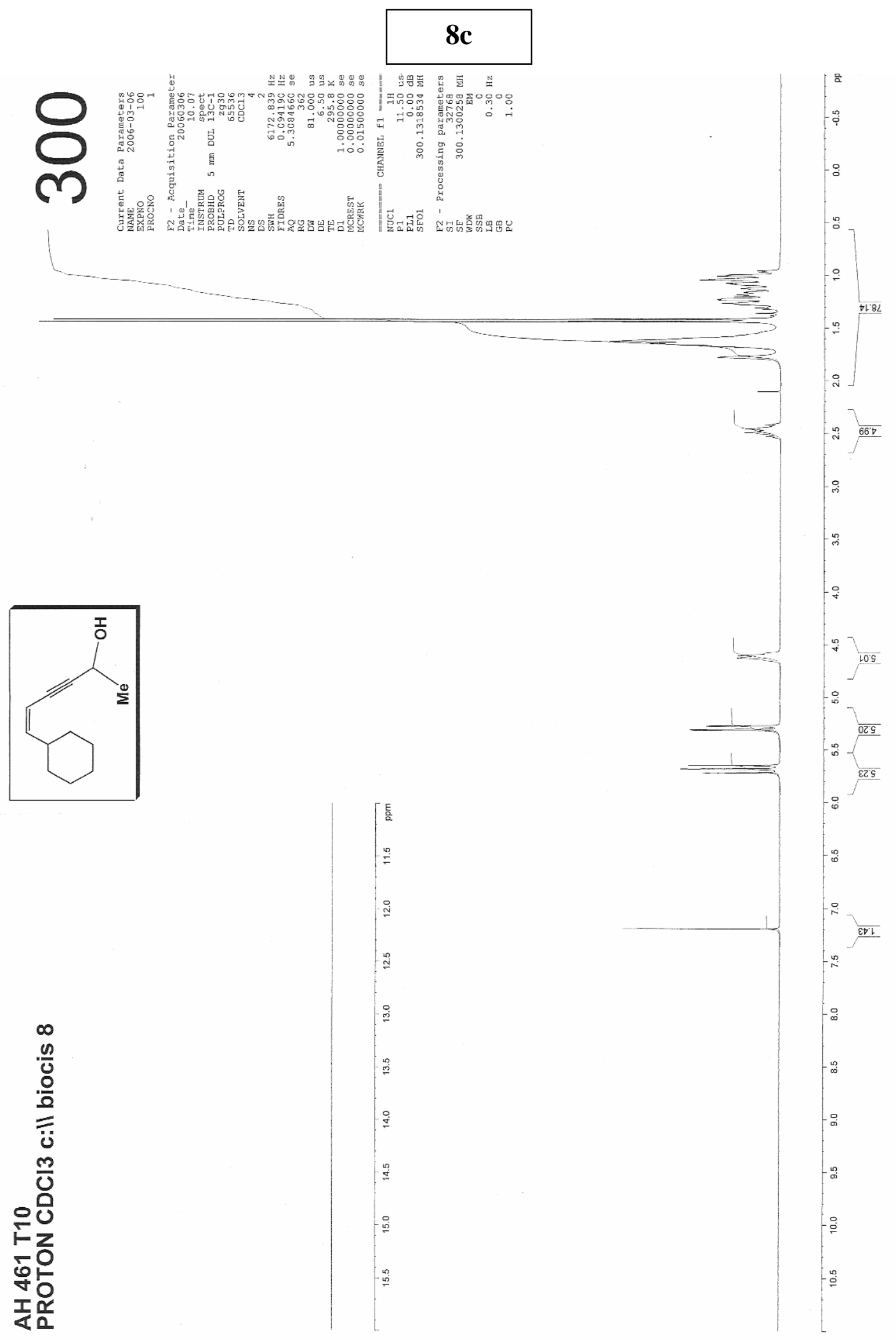




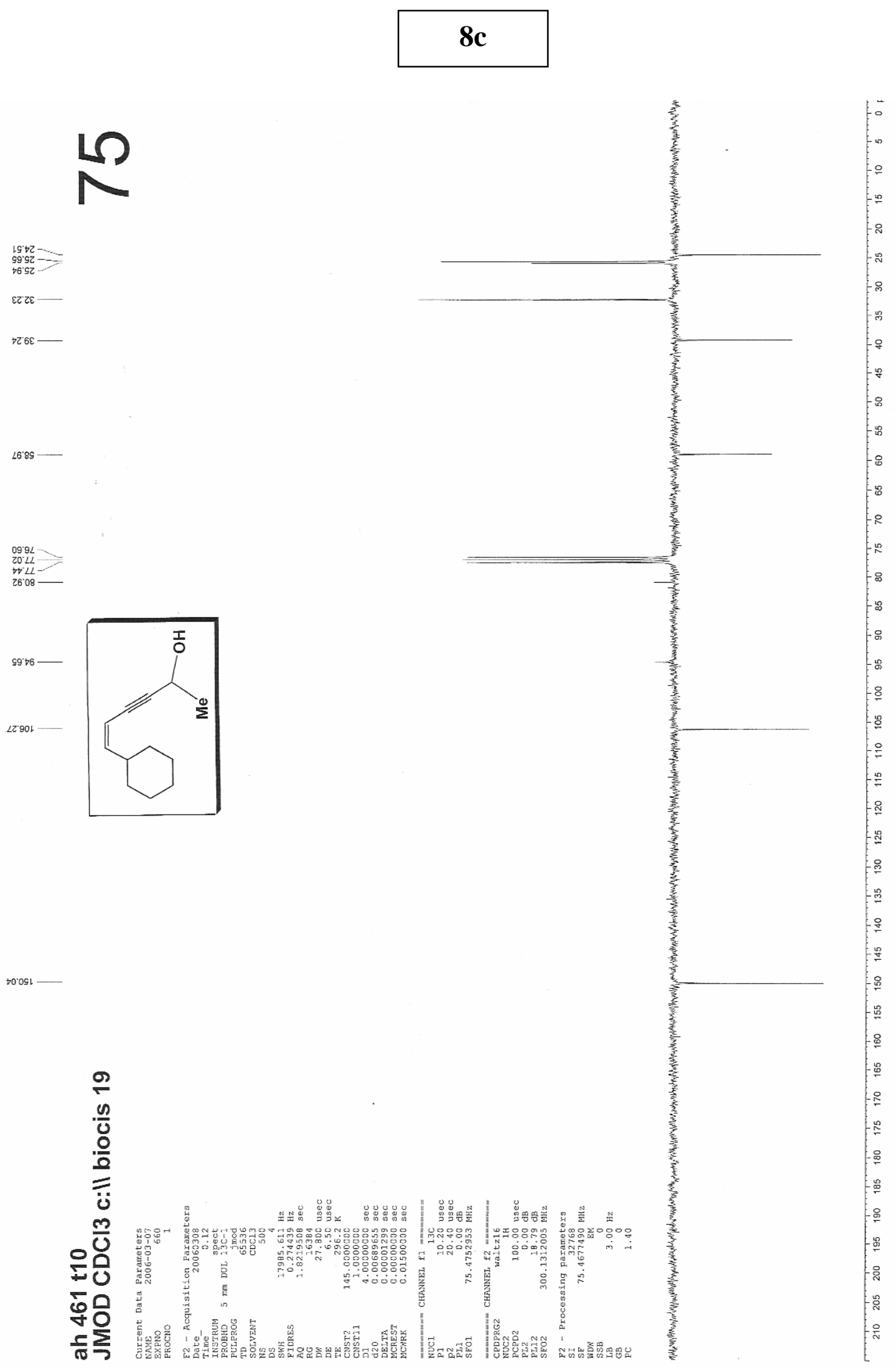


Current Data Parameters

NAME

EXPNO

PROCNO

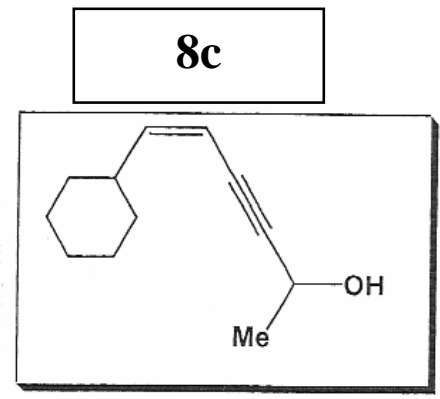

HMBC
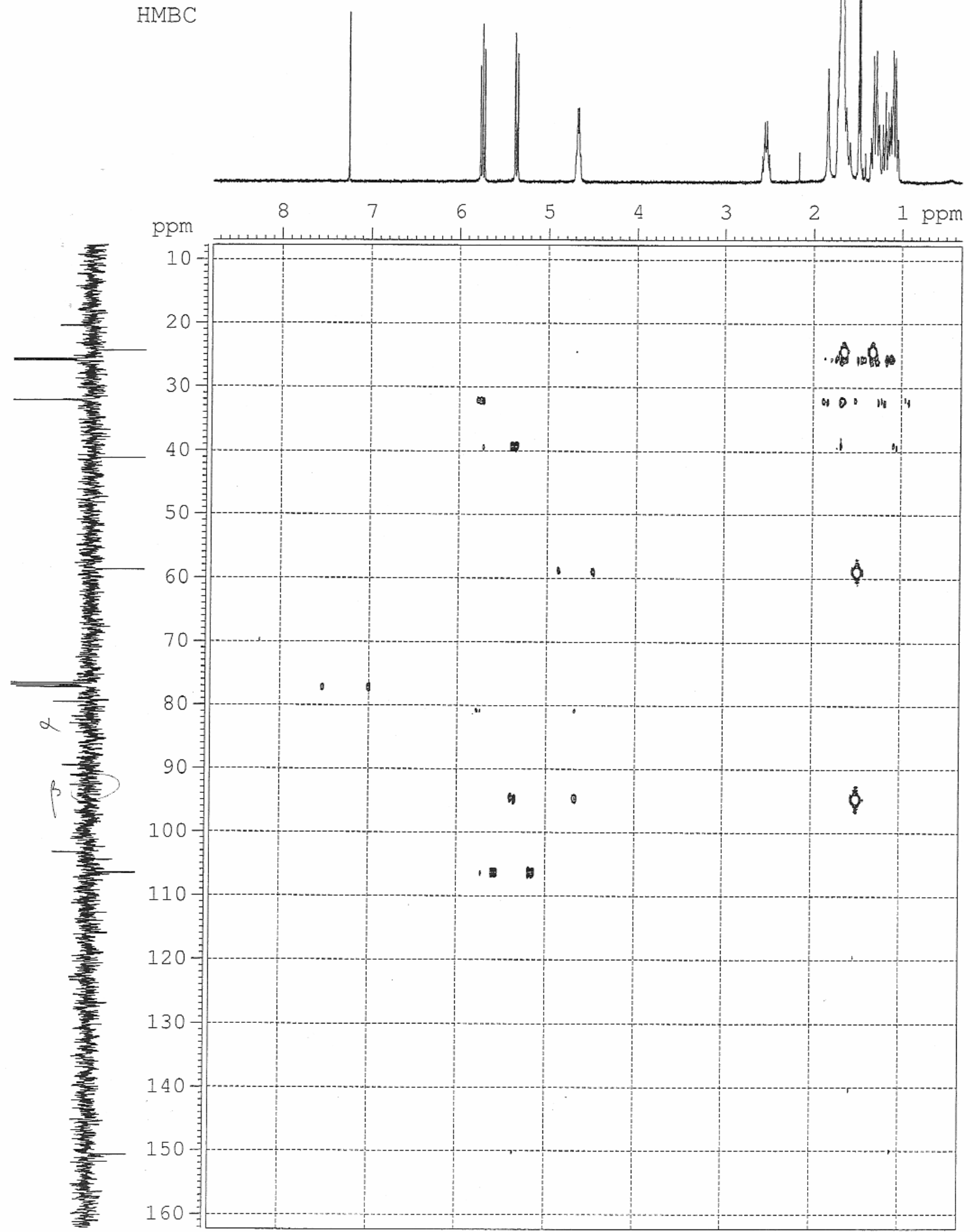

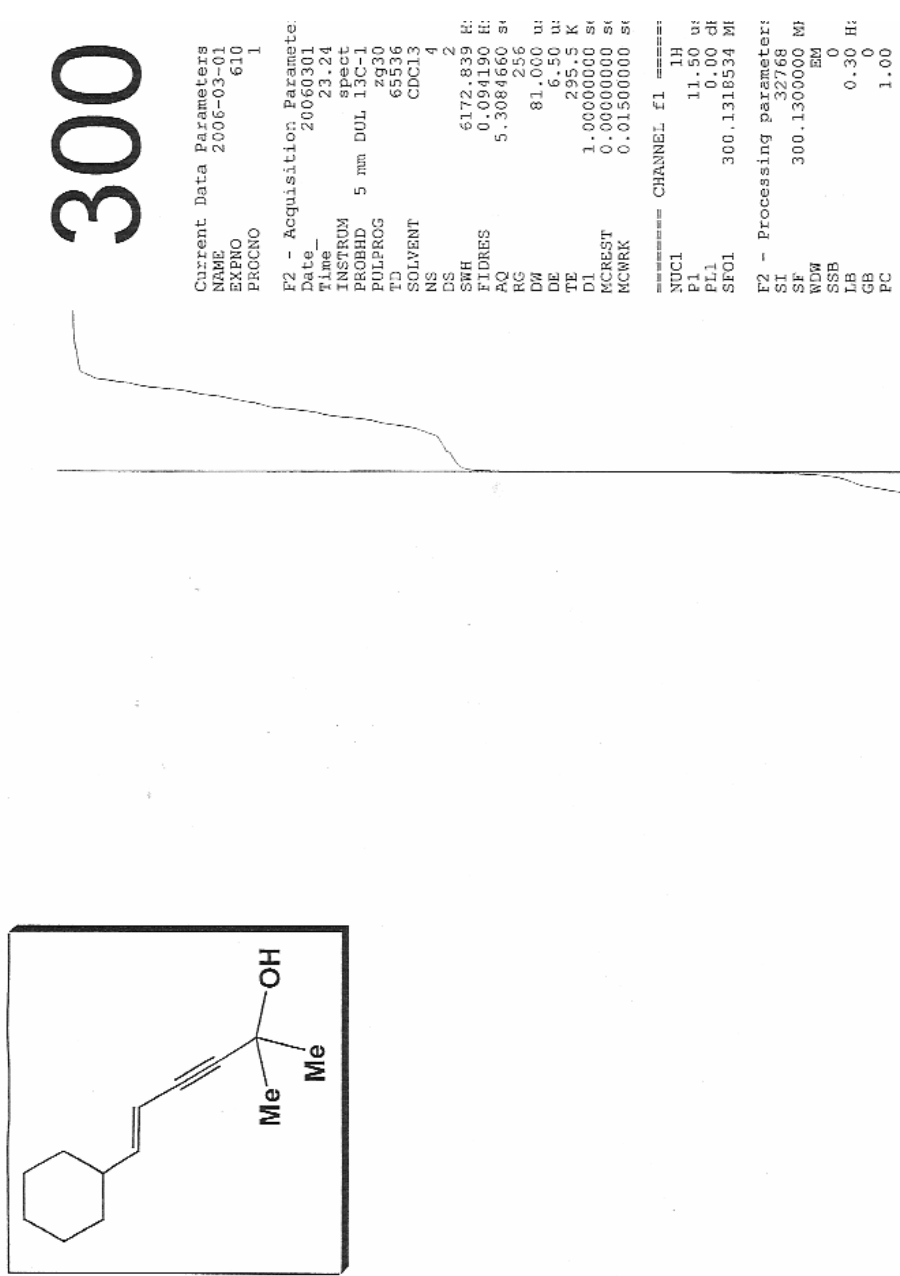

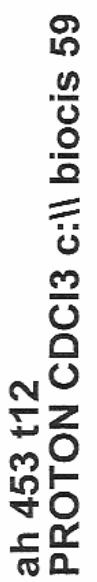




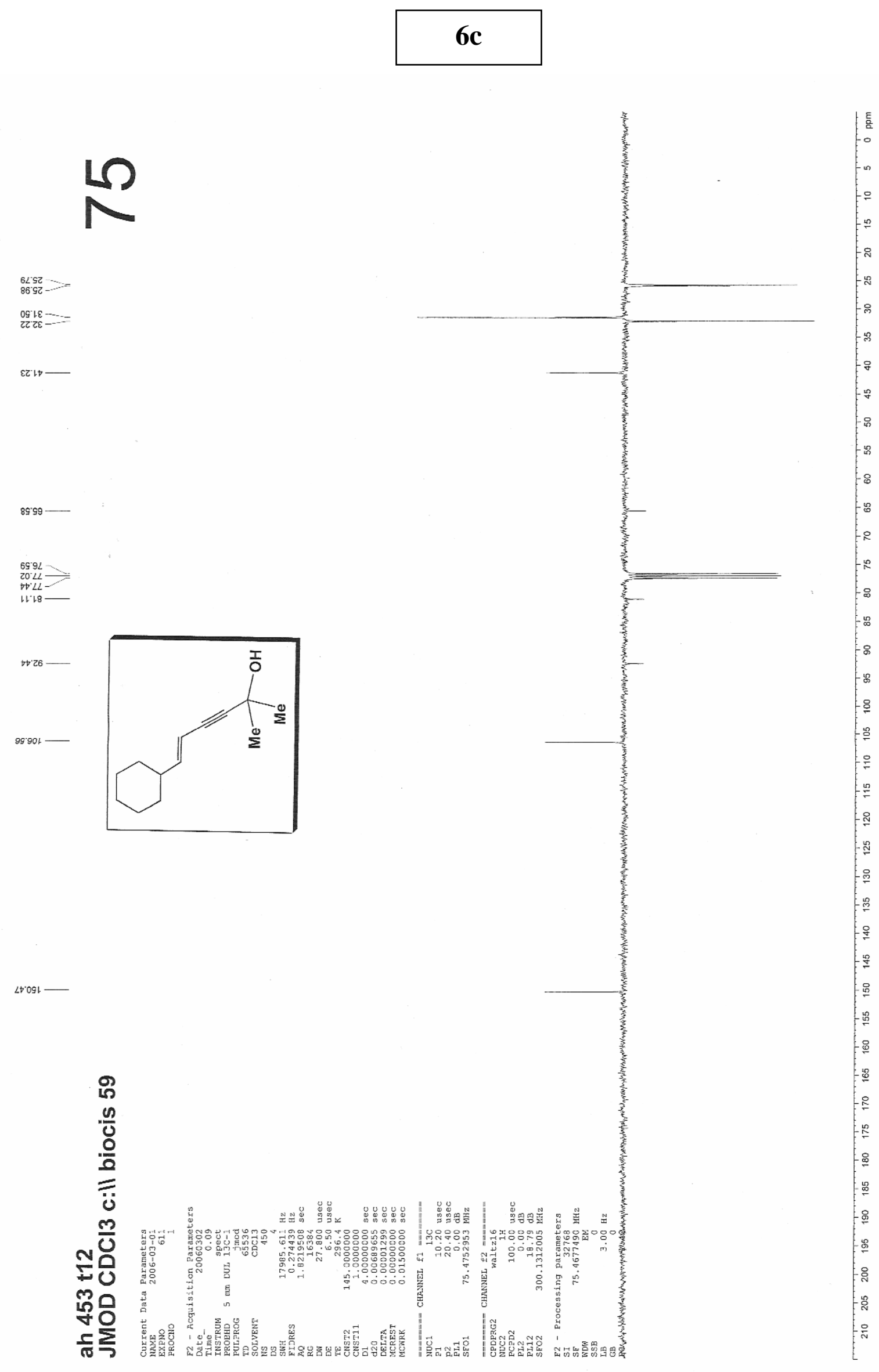



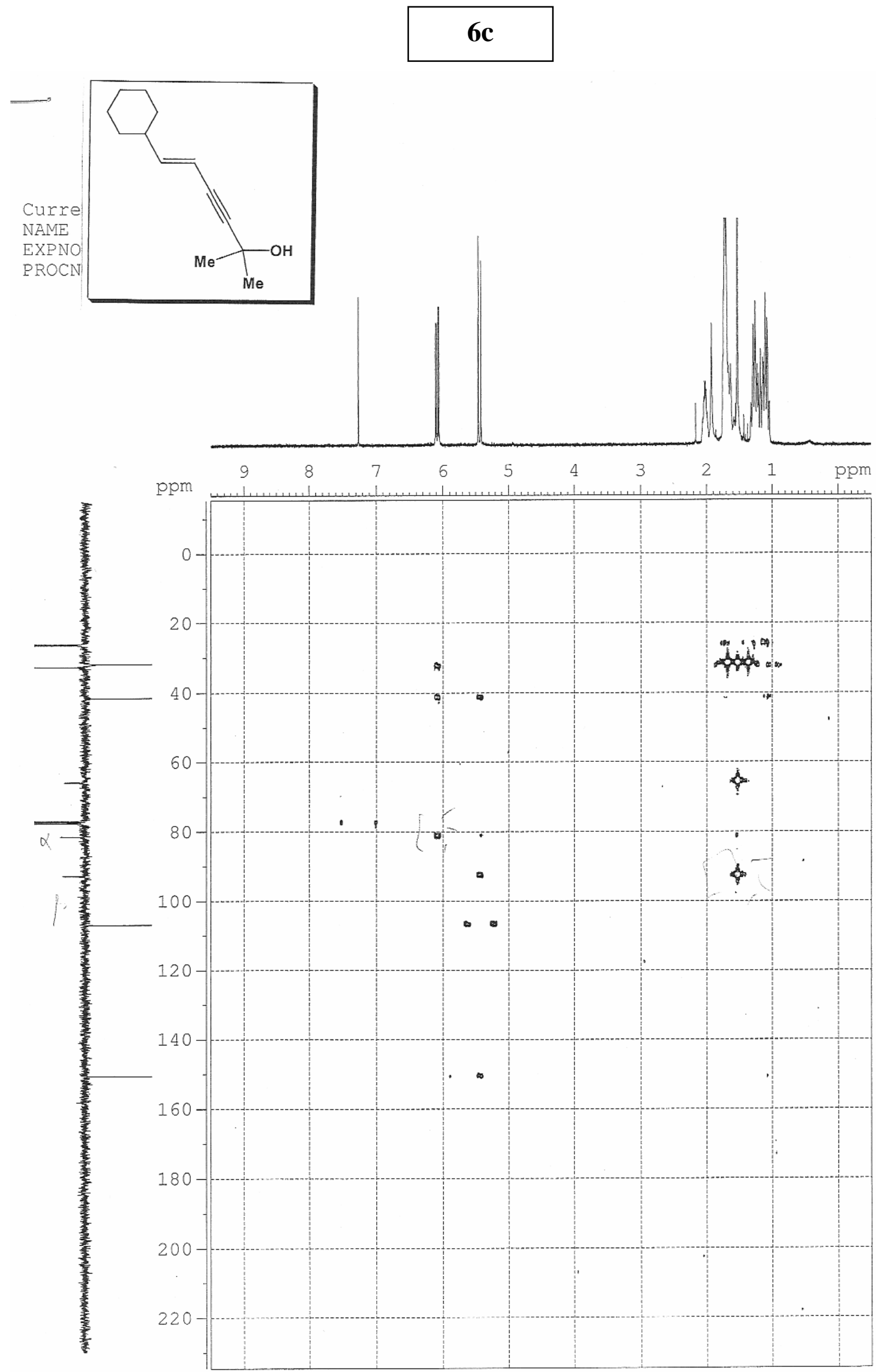


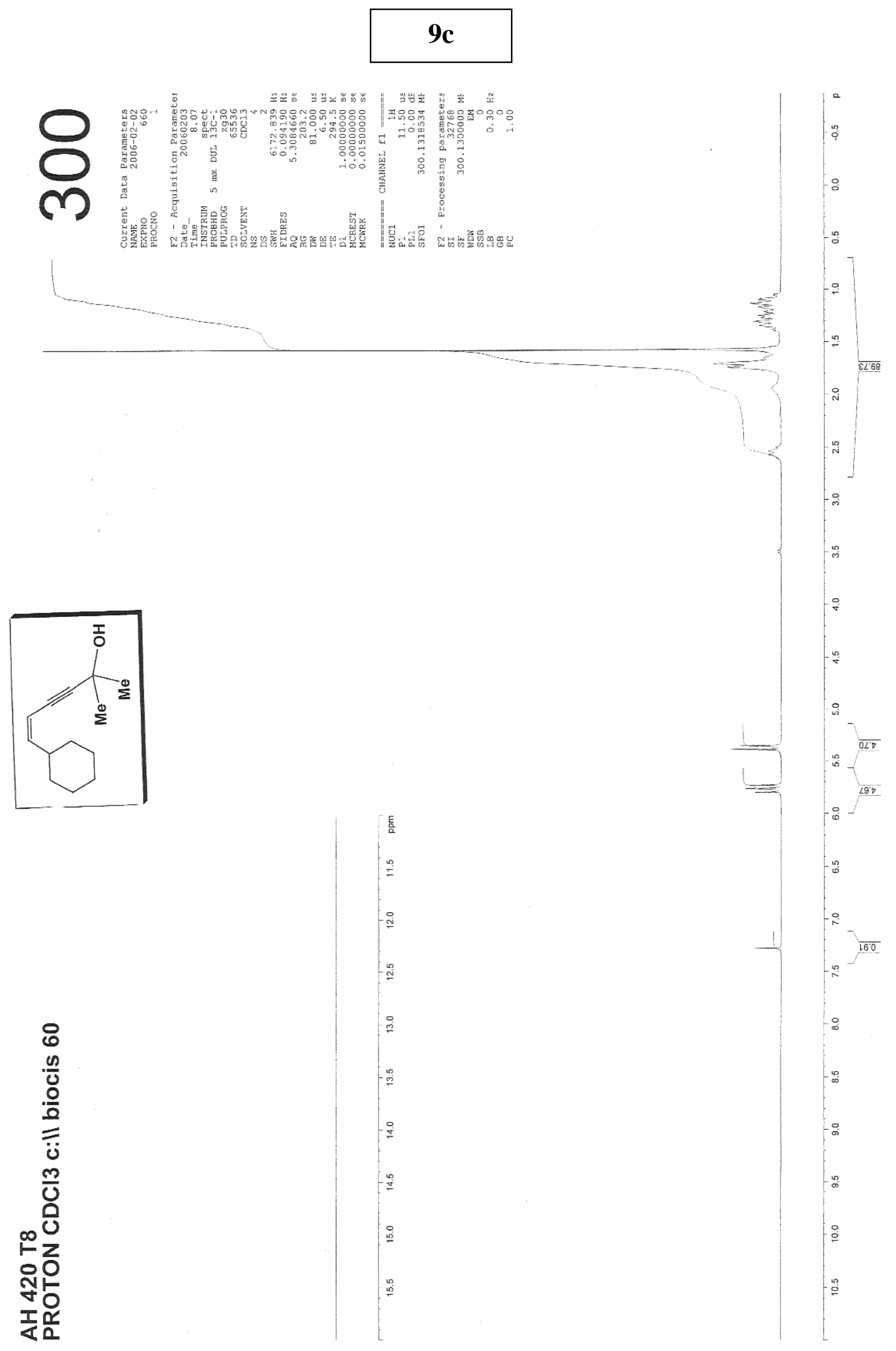




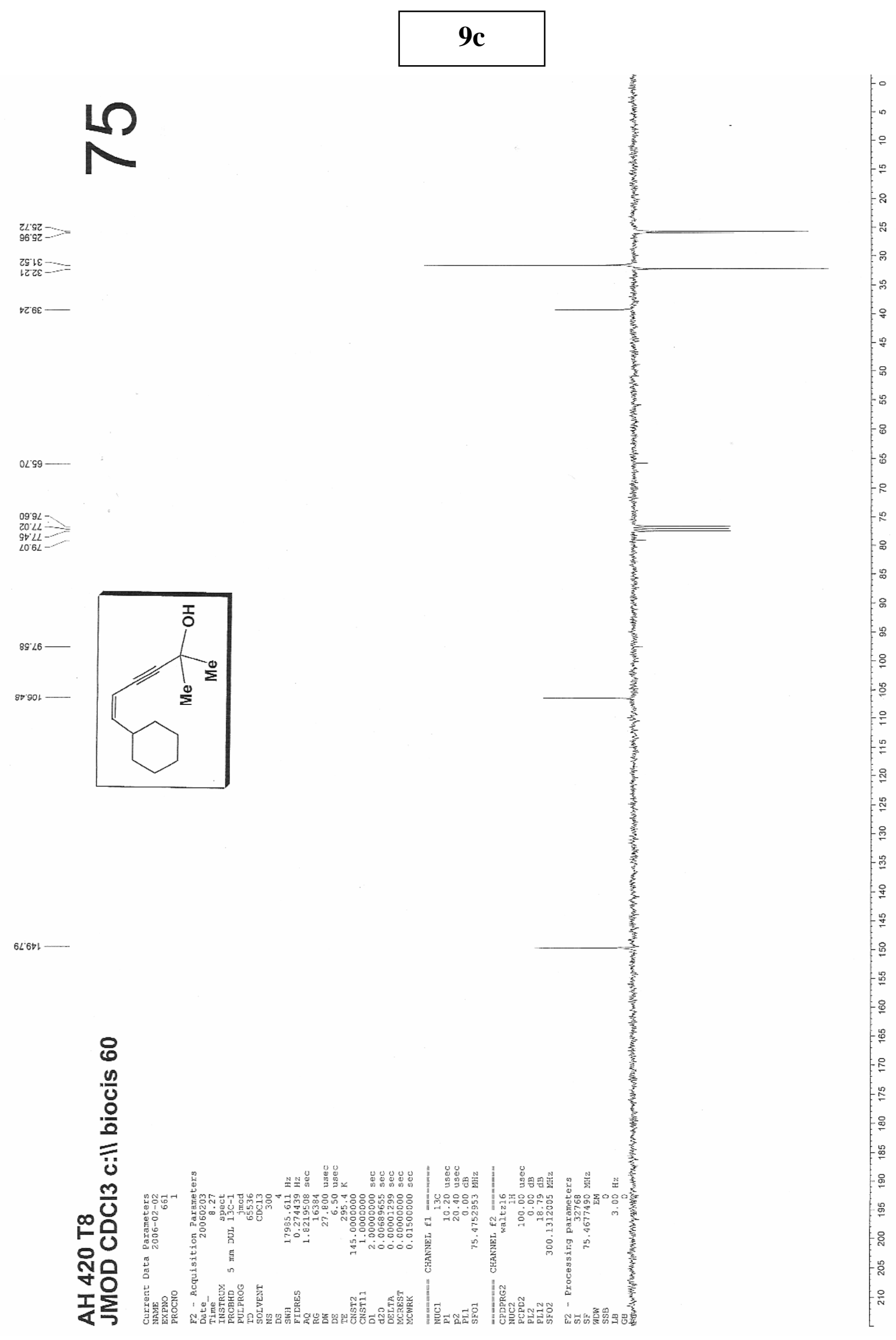




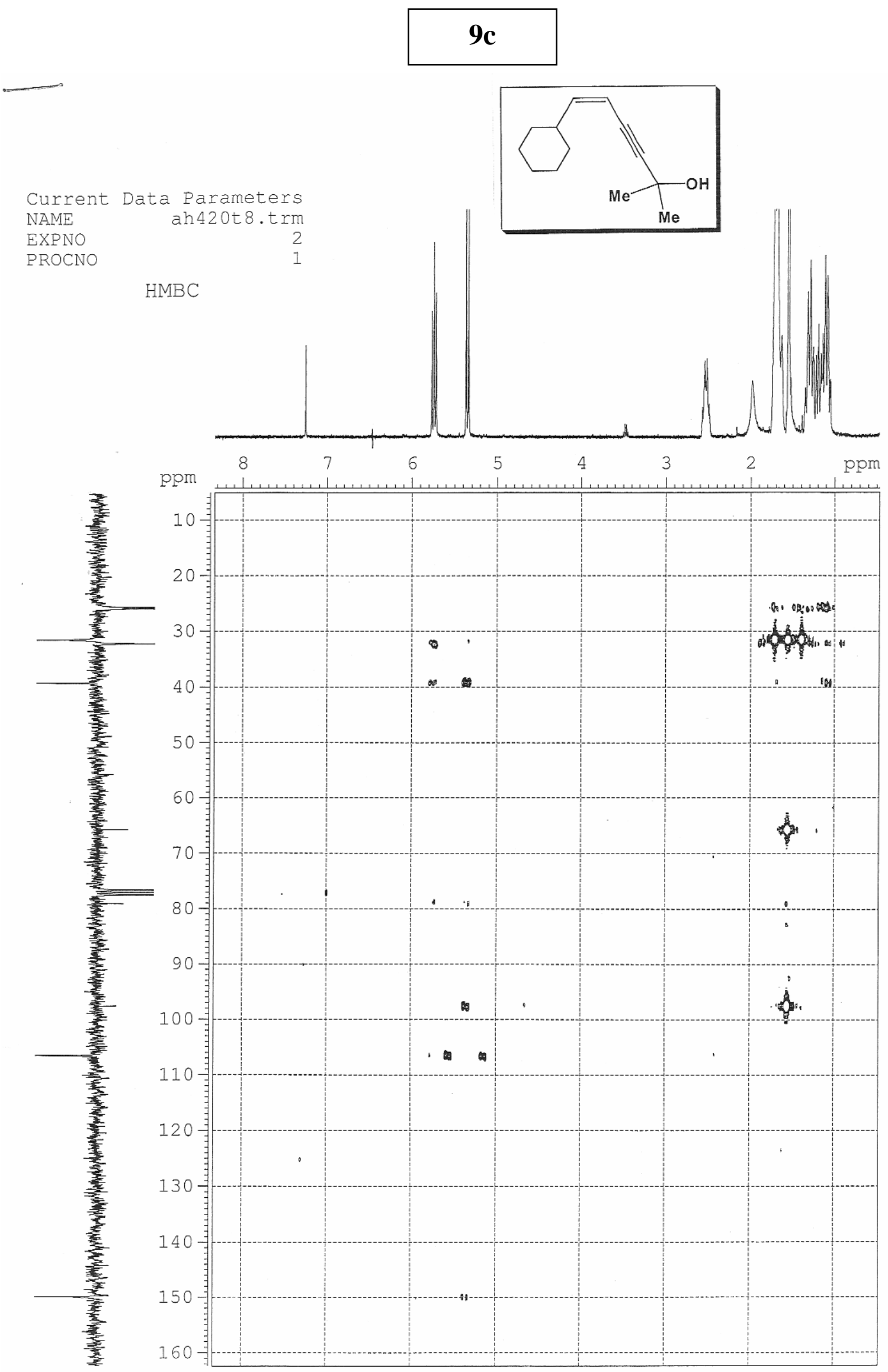




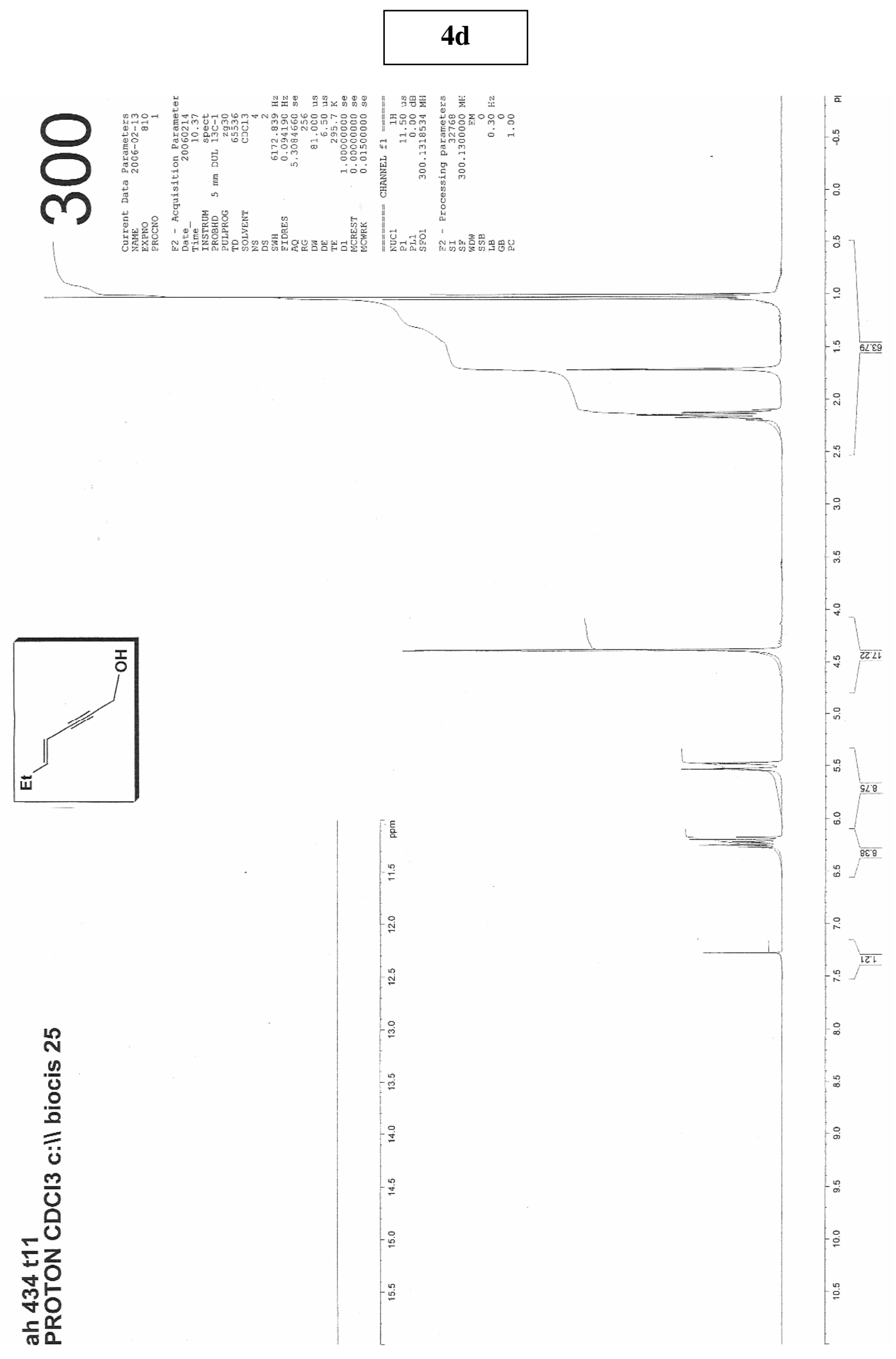




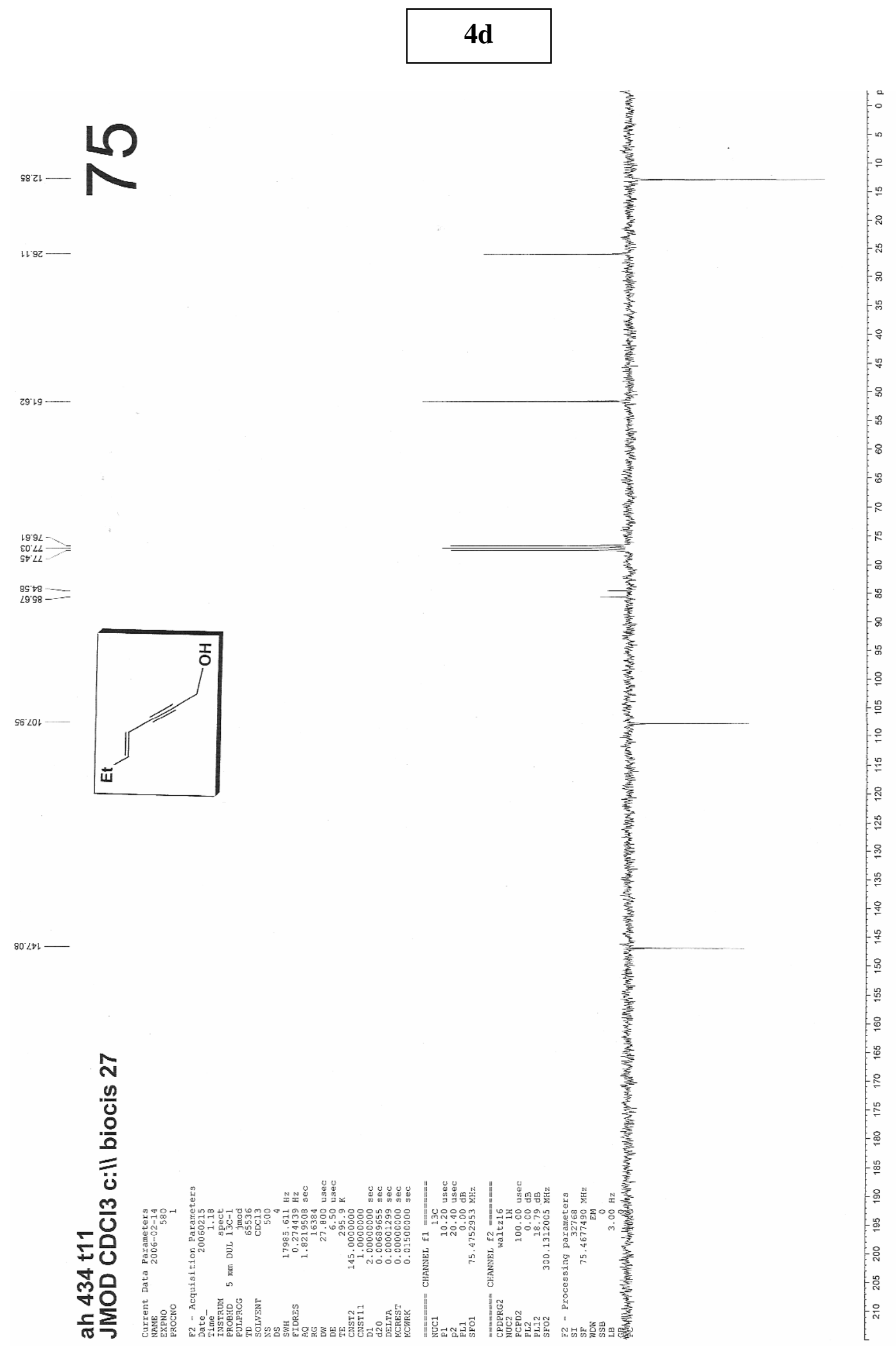




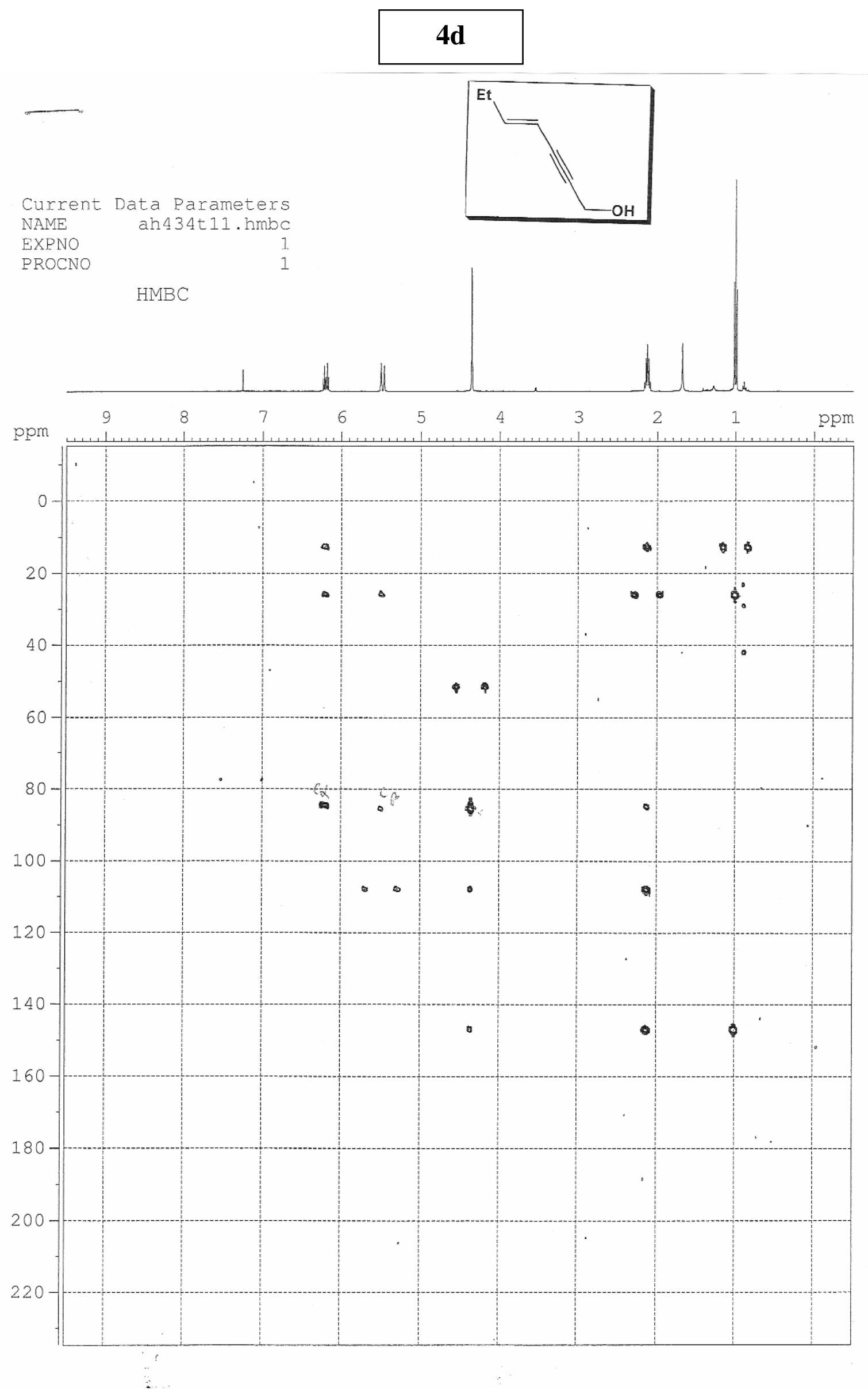




\section{7d}
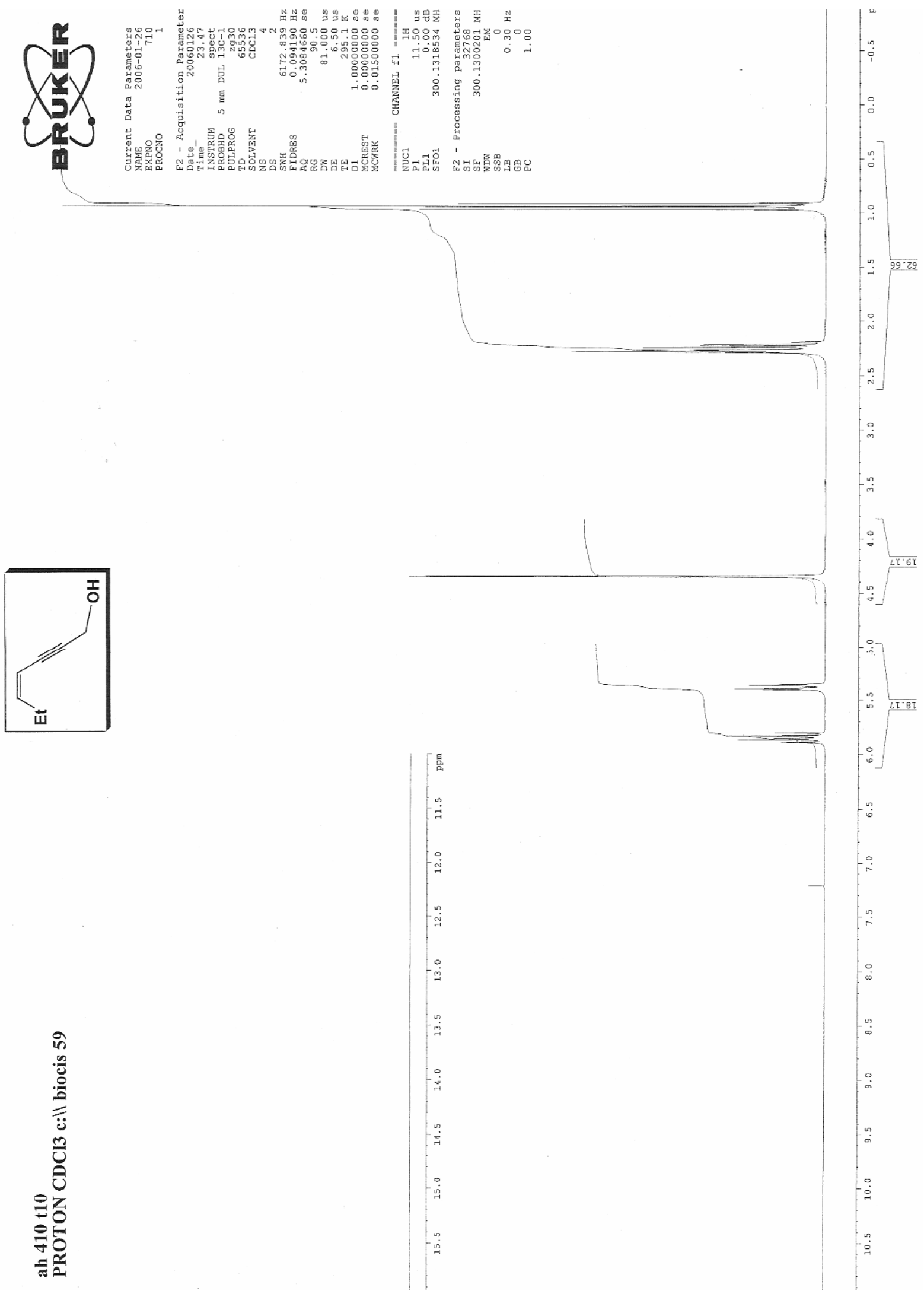

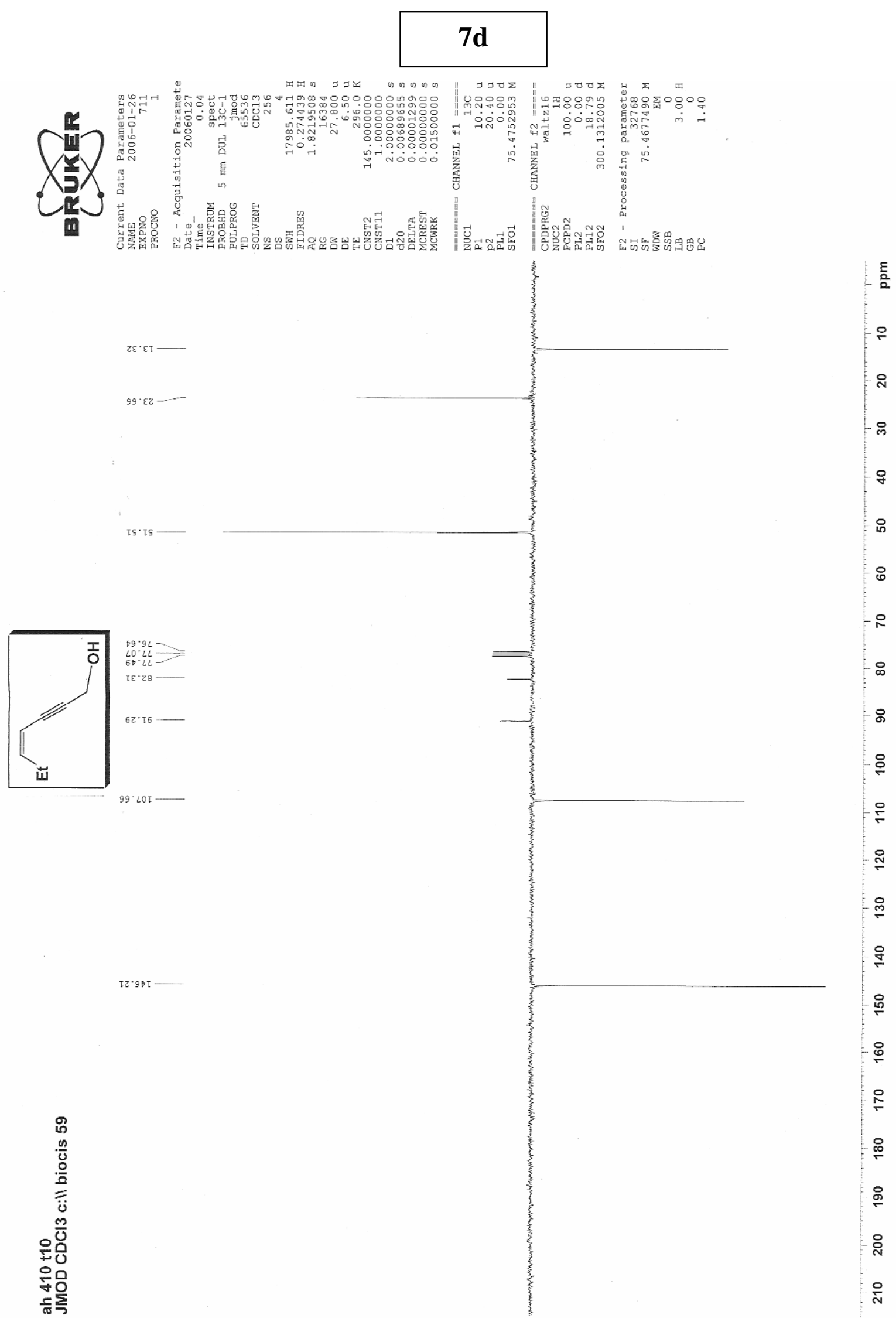


\section{$4 e$}

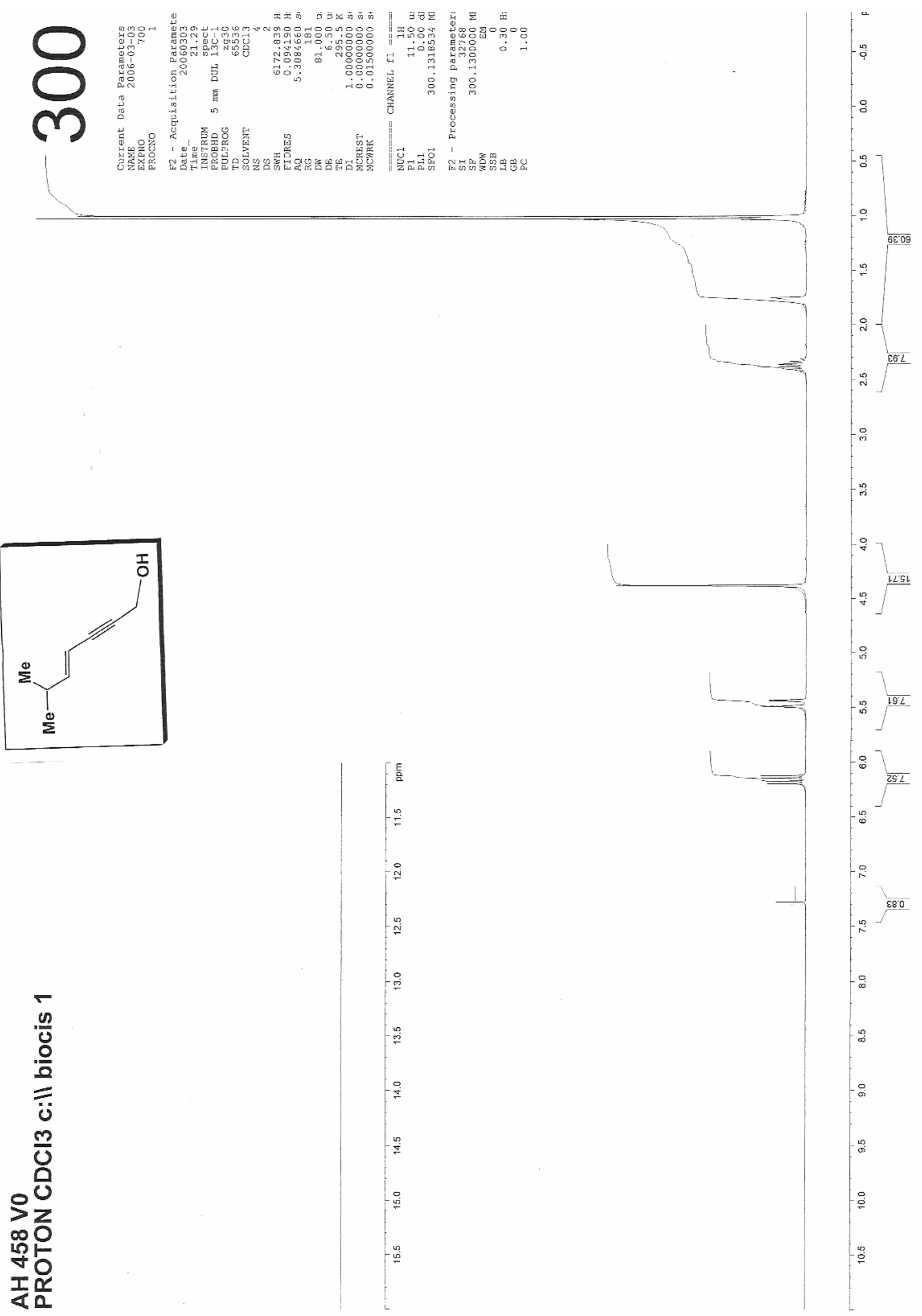




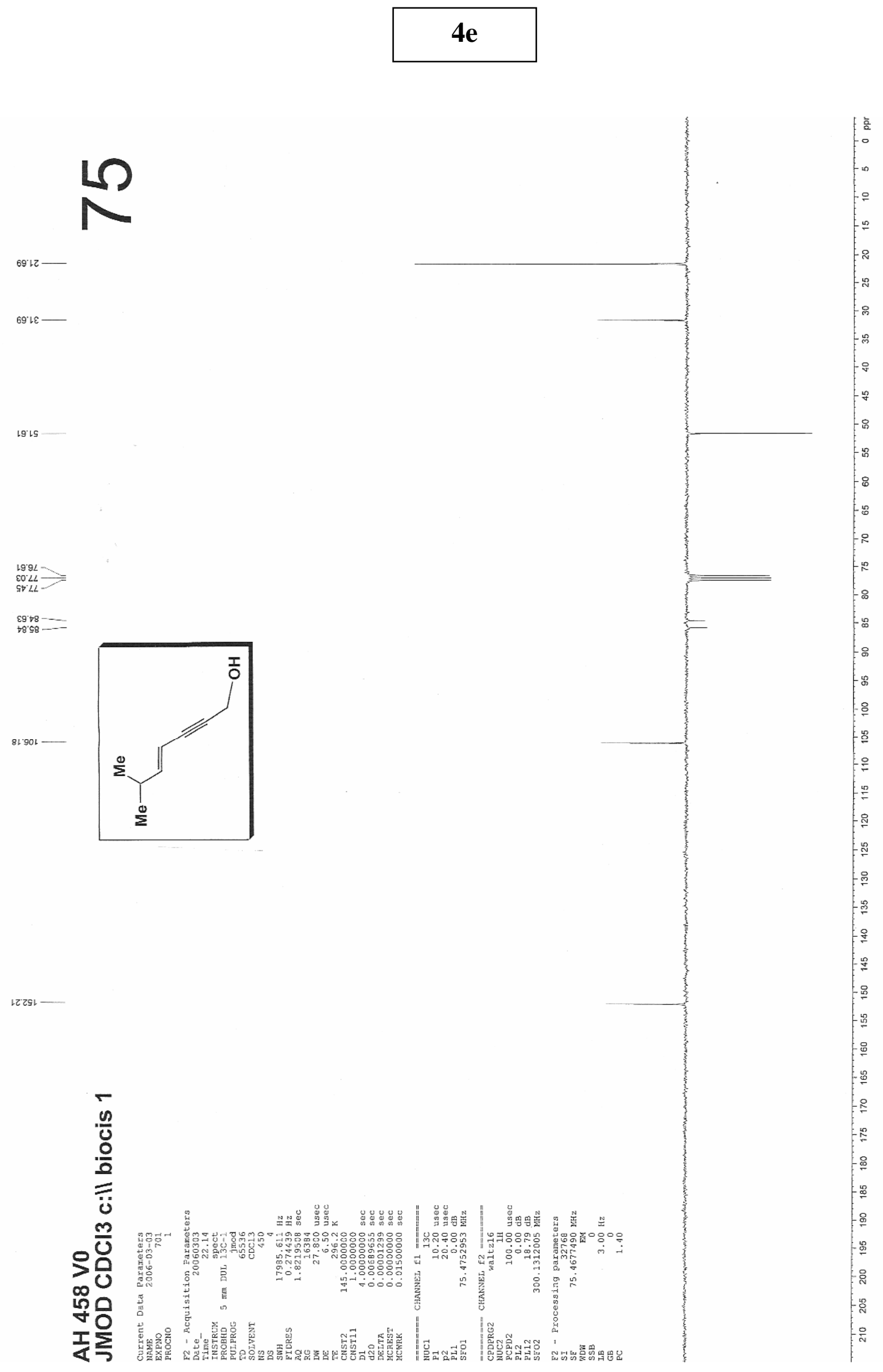



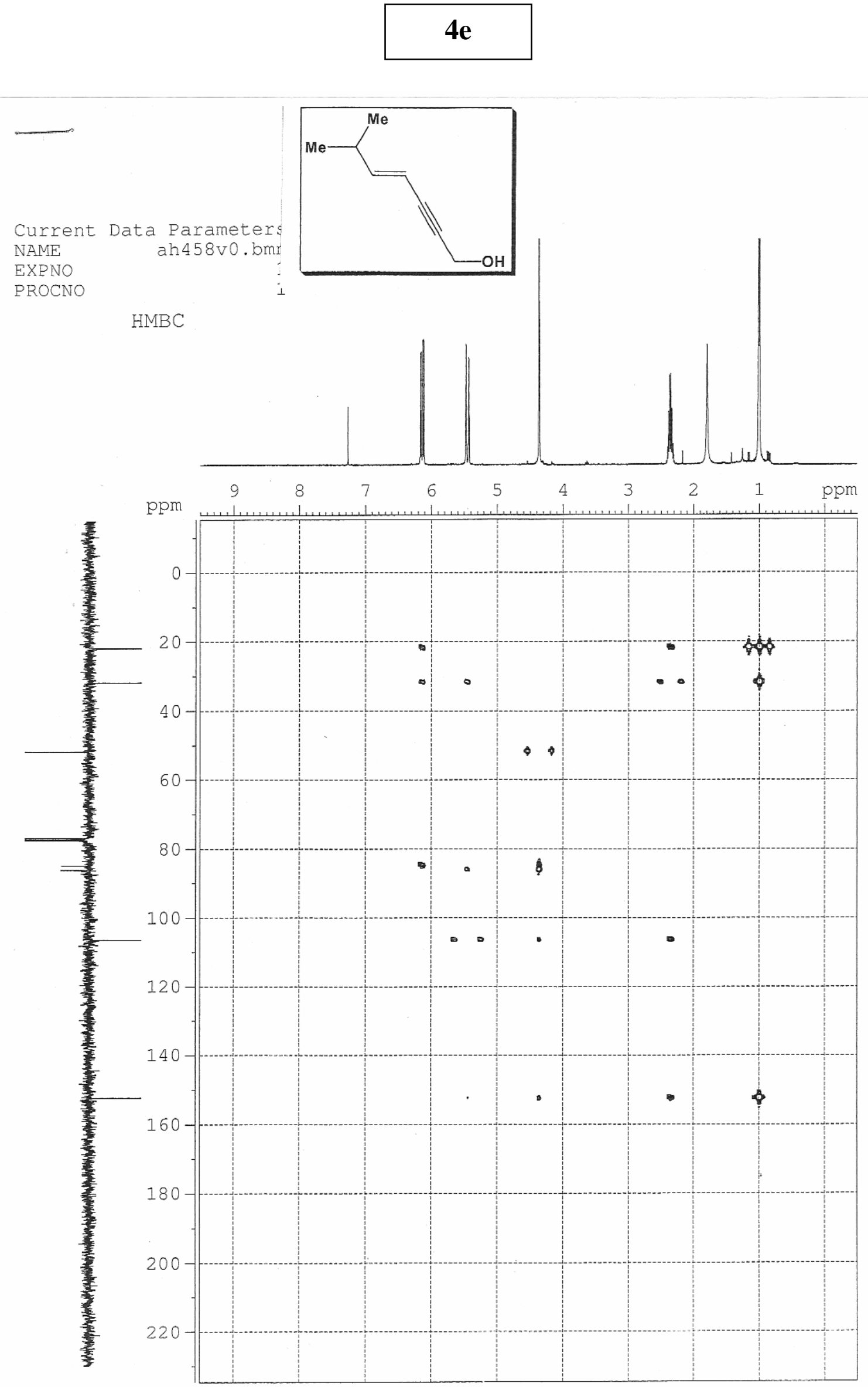


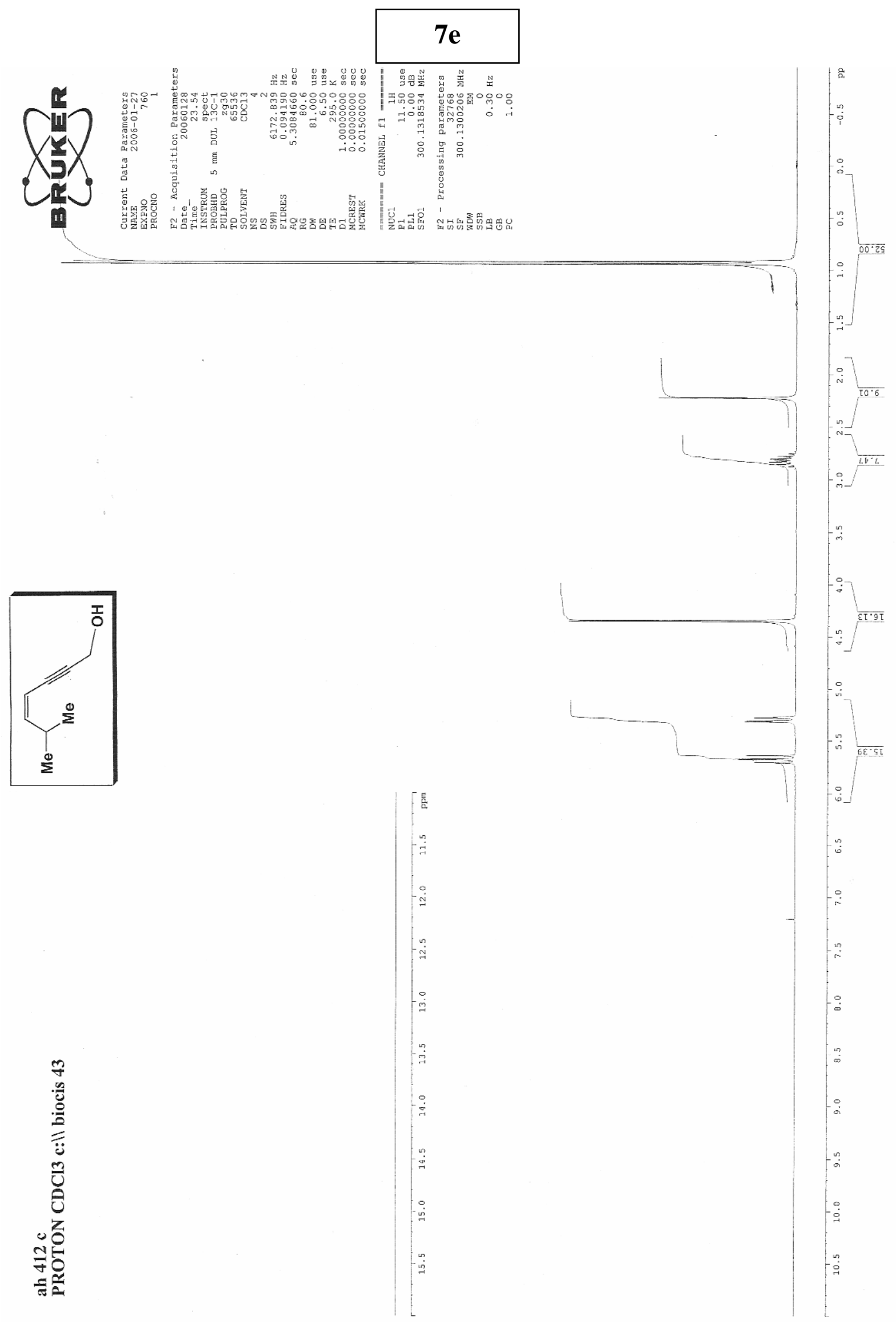




\section{$7 e$}
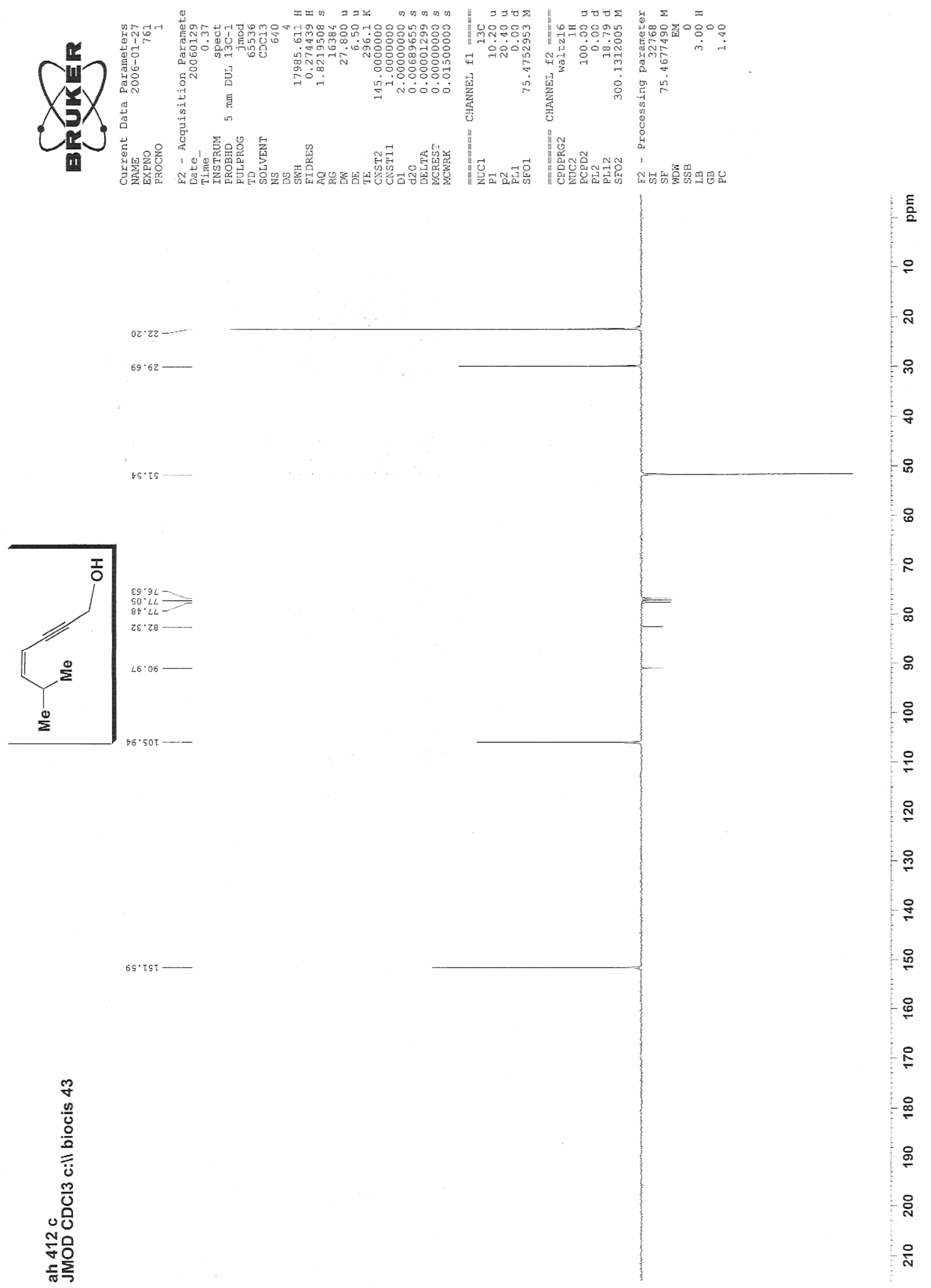


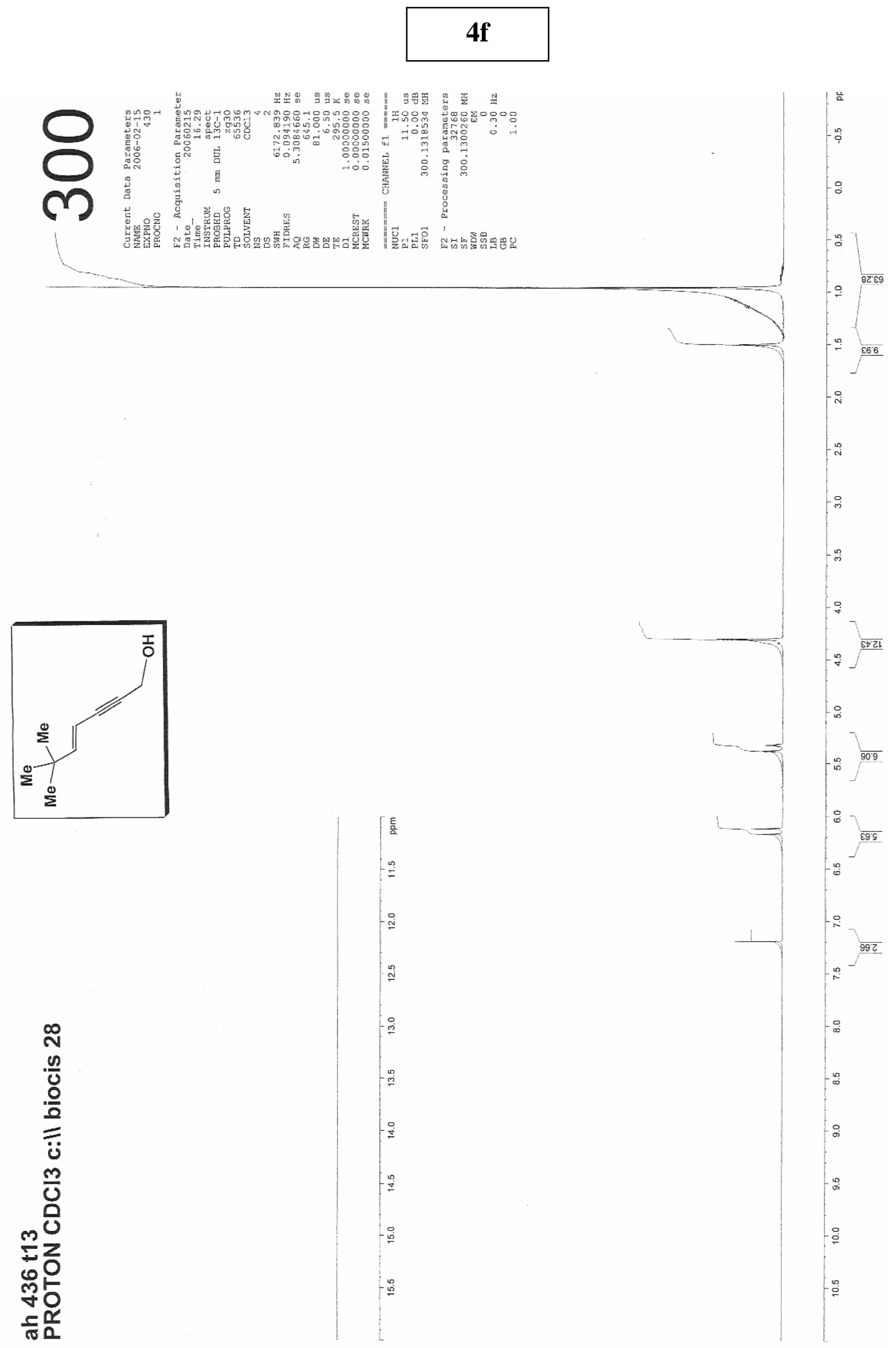




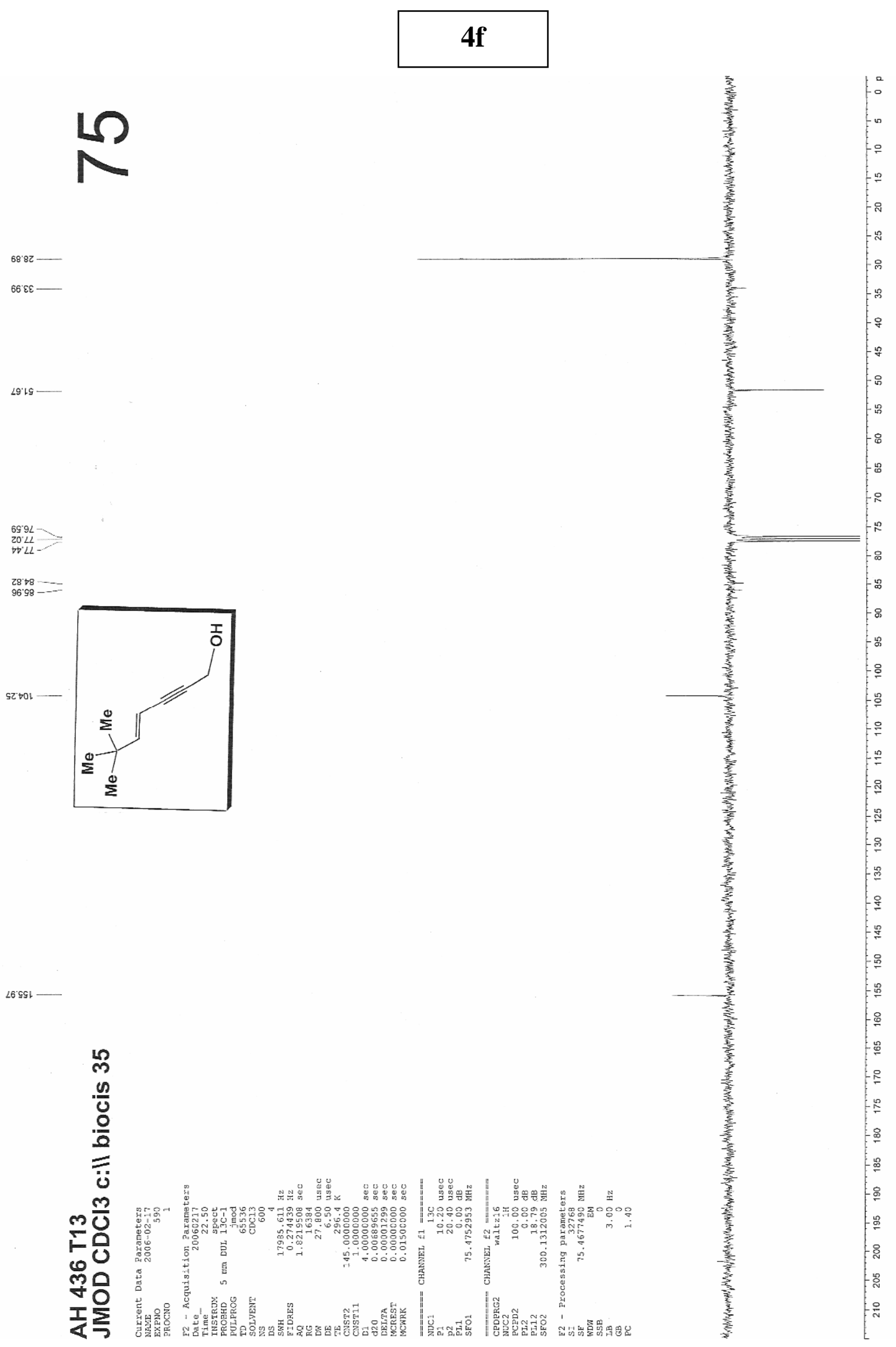



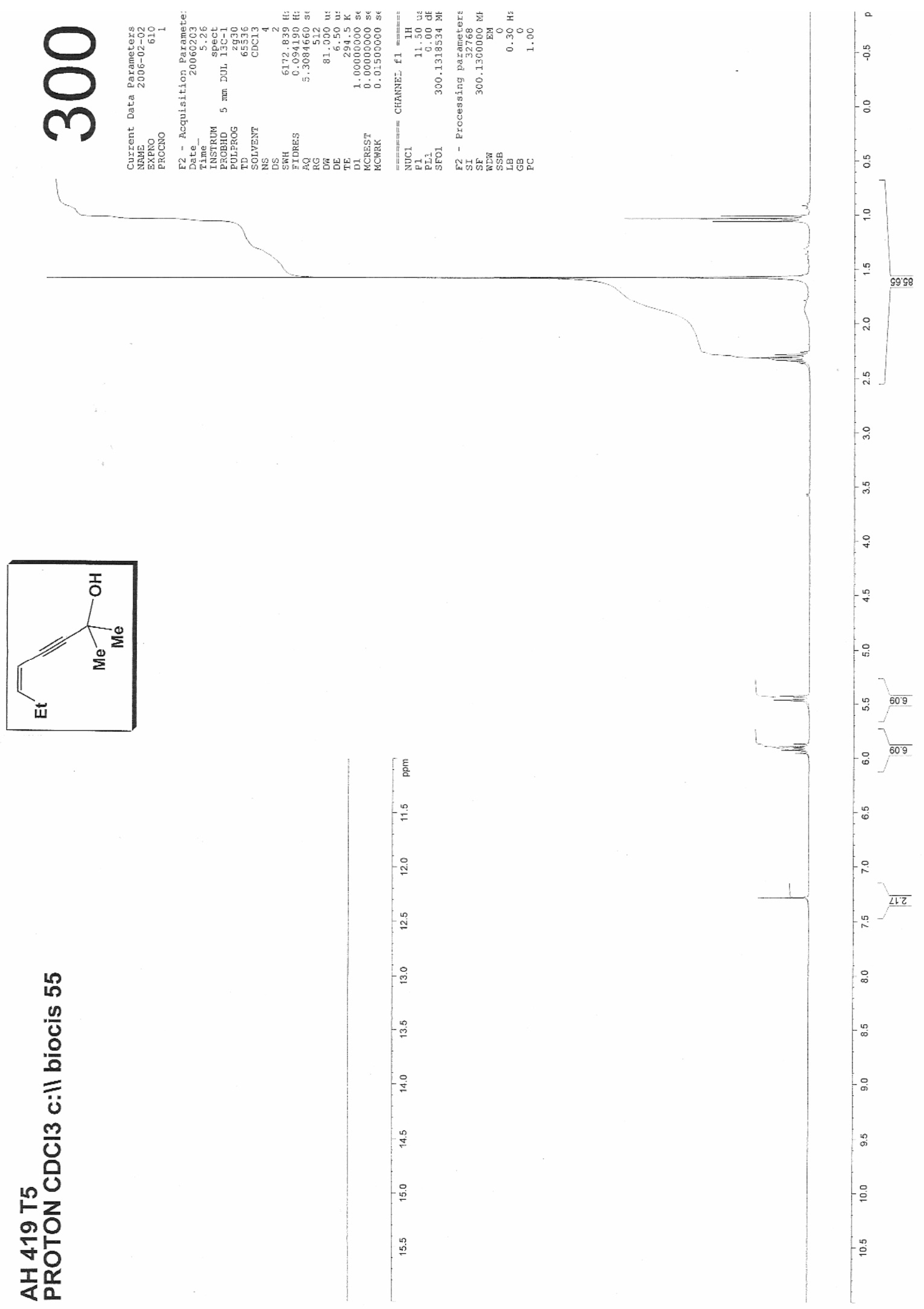


$$
\text { 9d }
$$

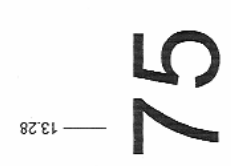

9ร ६z - -

$\rightarrow \mathfrak{s} 1 \varepsilon$
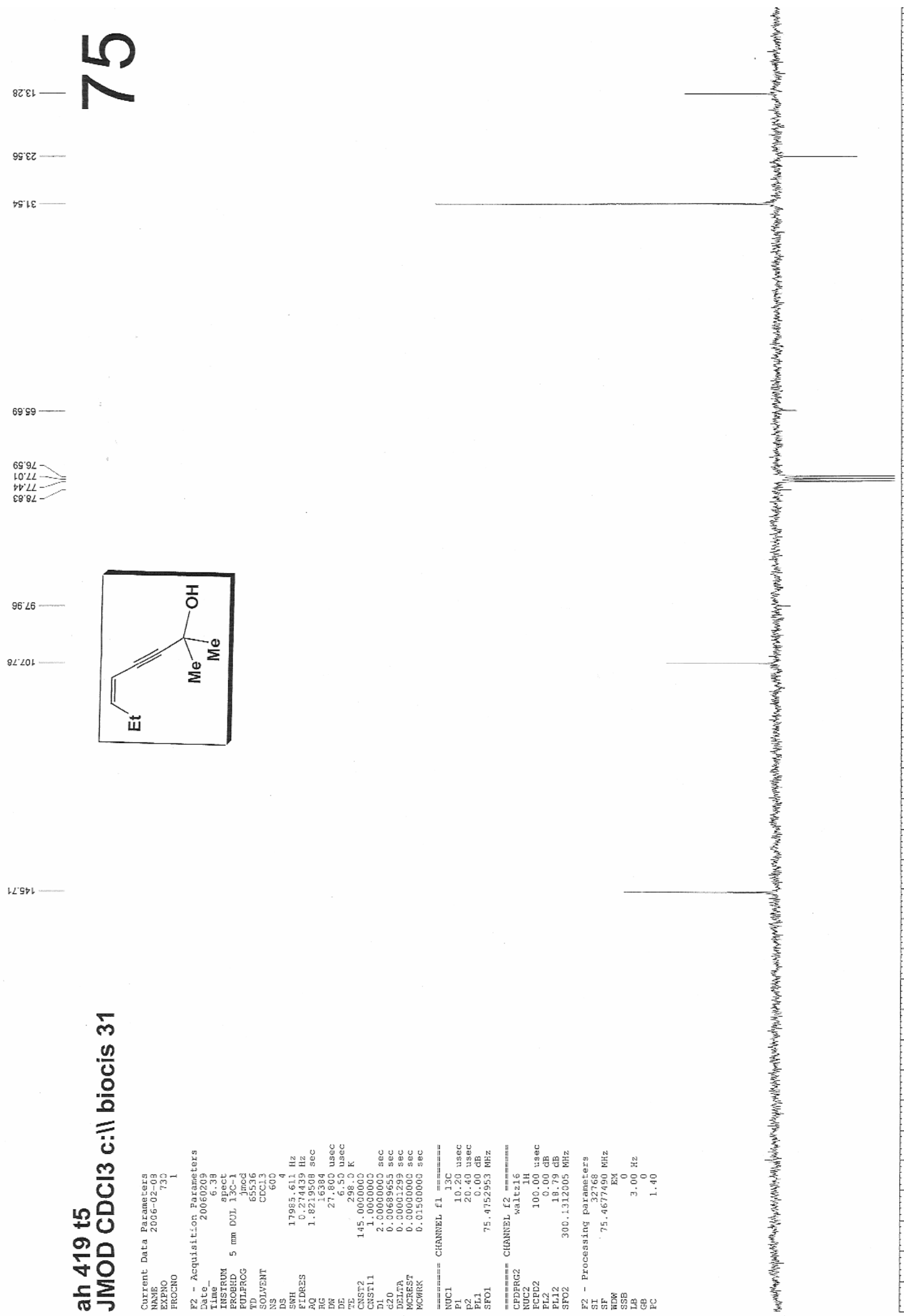

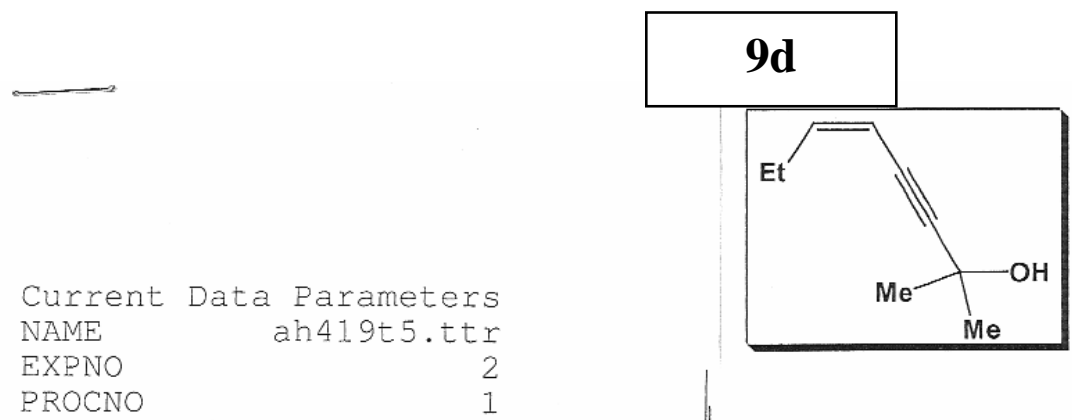

HMBC
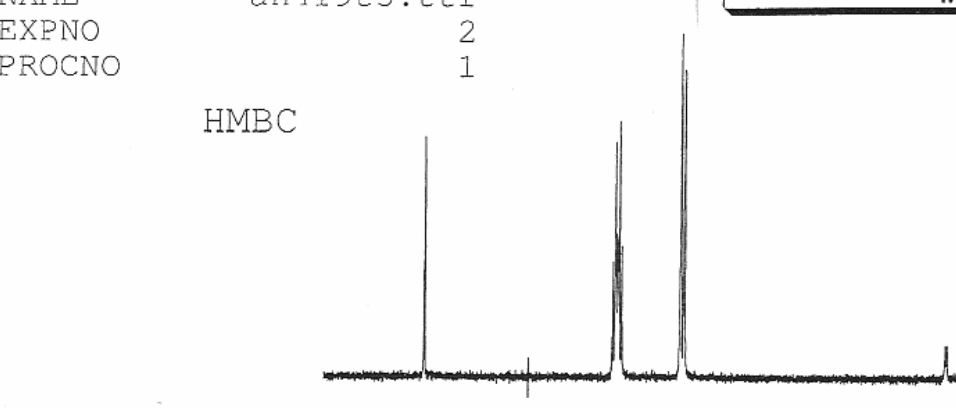

Me

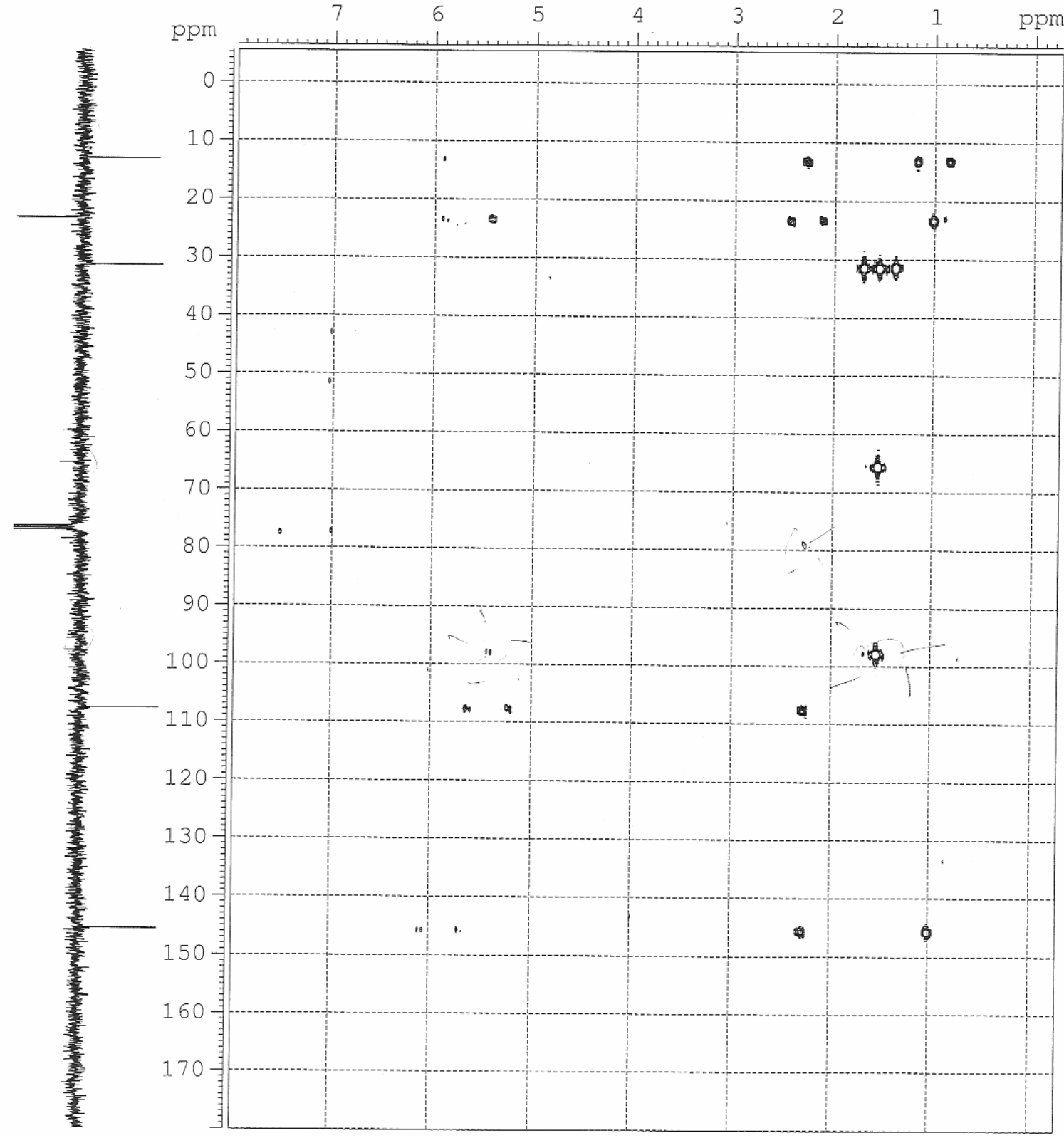




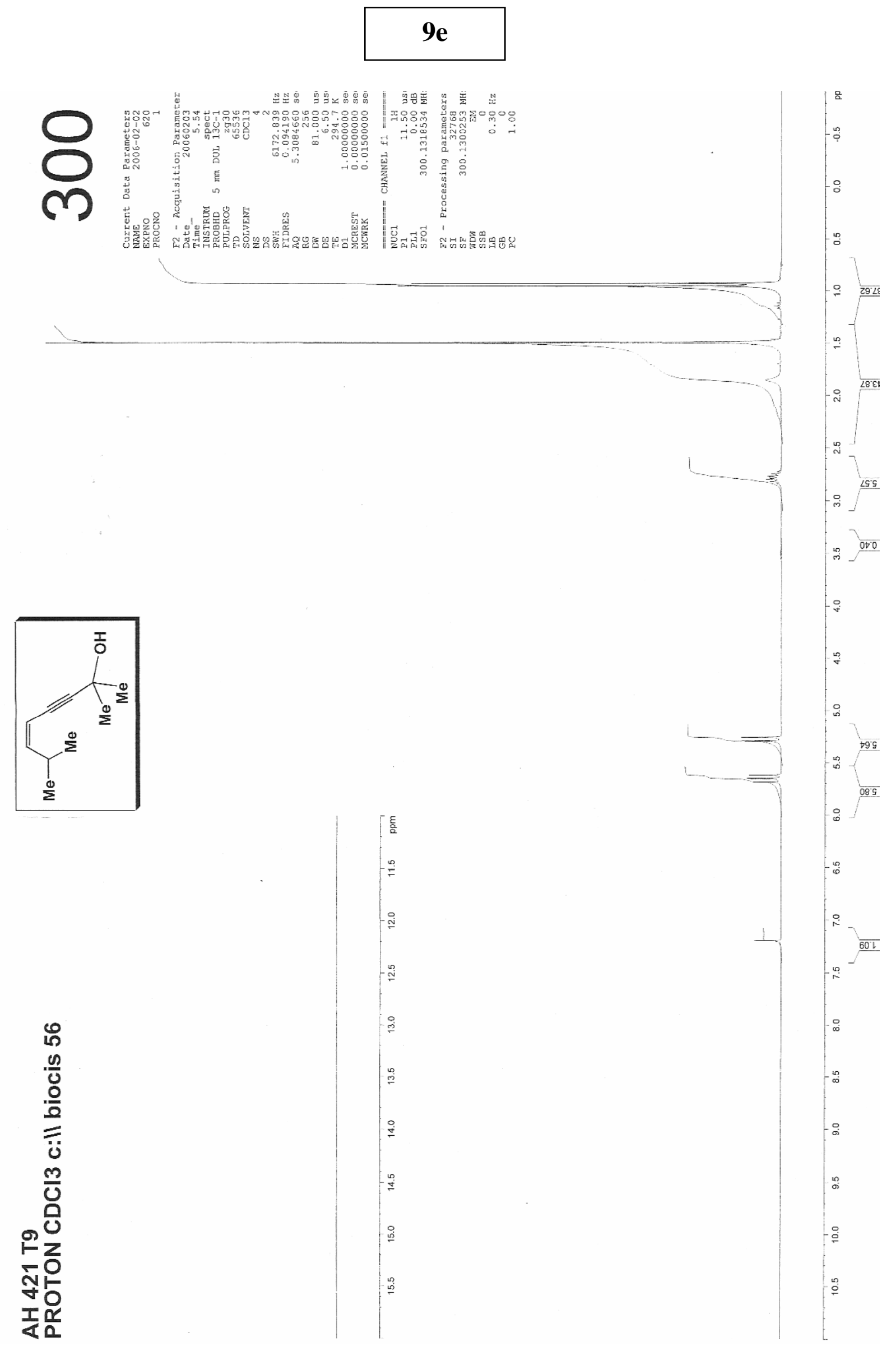




\section{9e}
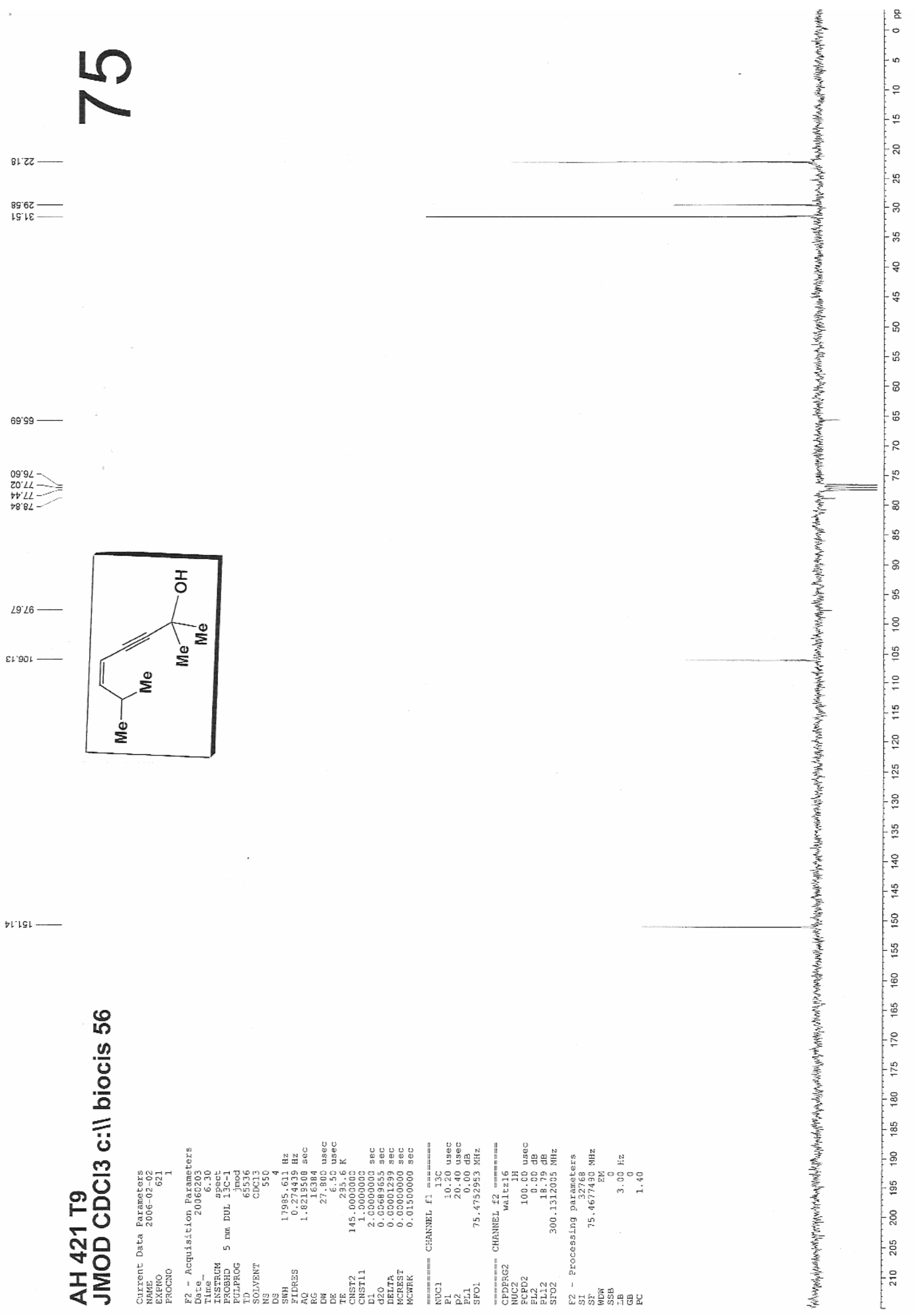
Current Data Parameters NAME ah421t9.ttr EXPNO

PROCNO

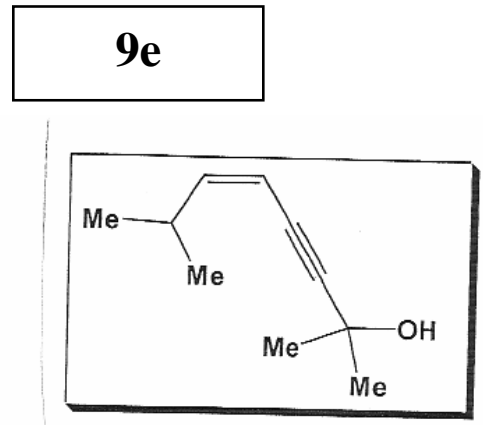

HMBC

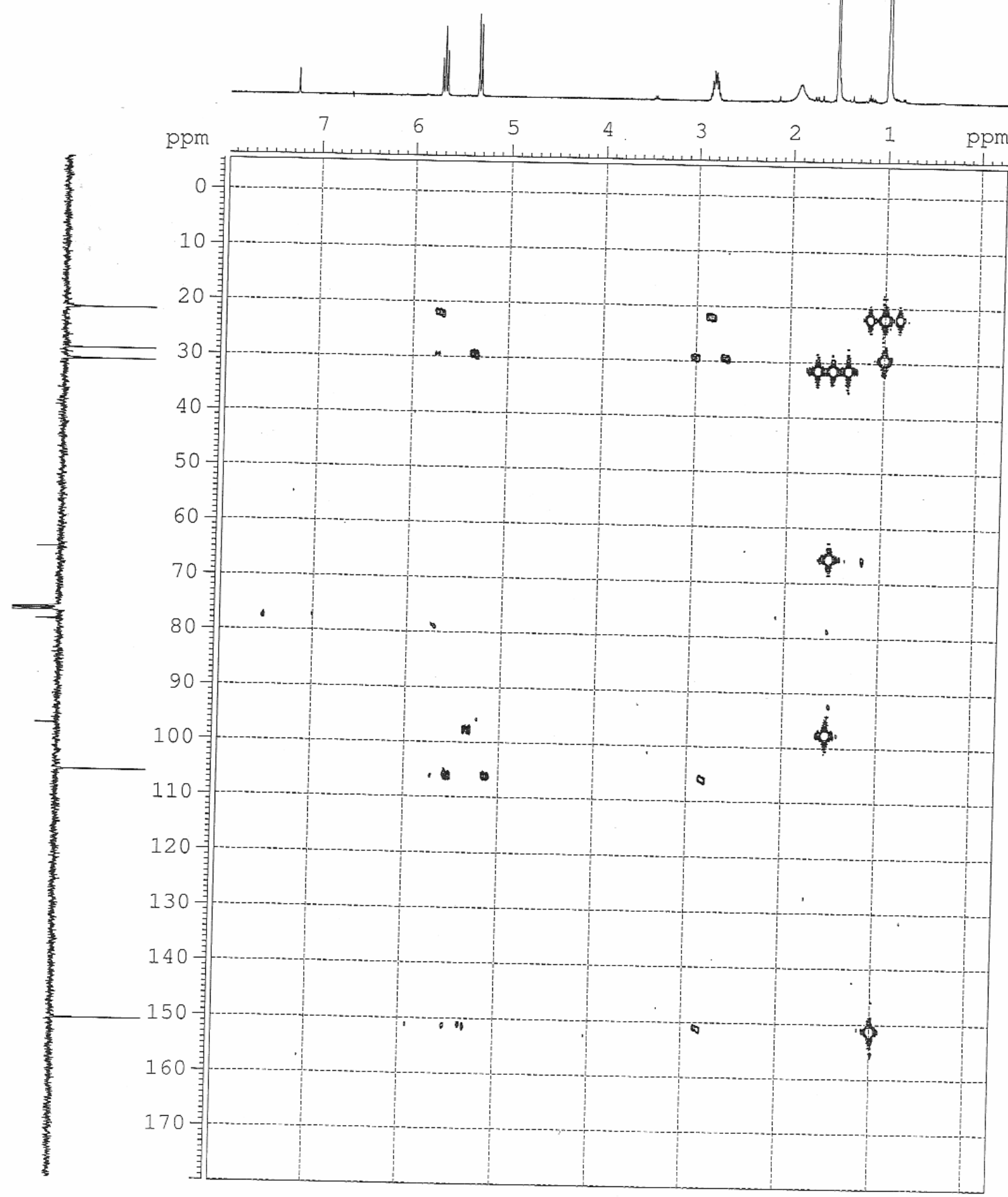




\section{$7 \mathrm{~g}$}

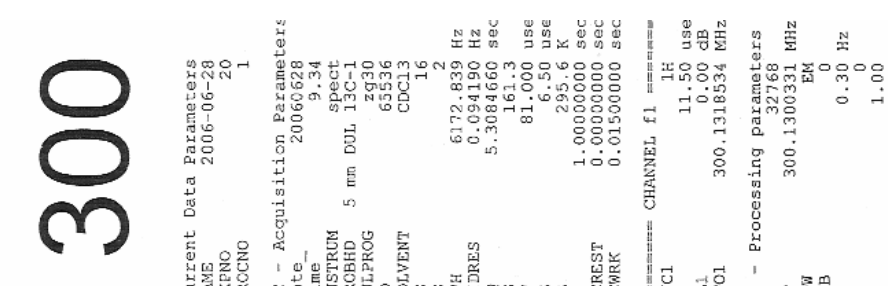

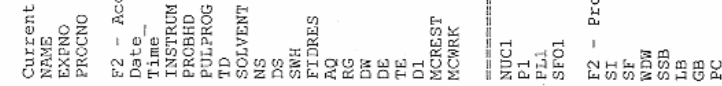
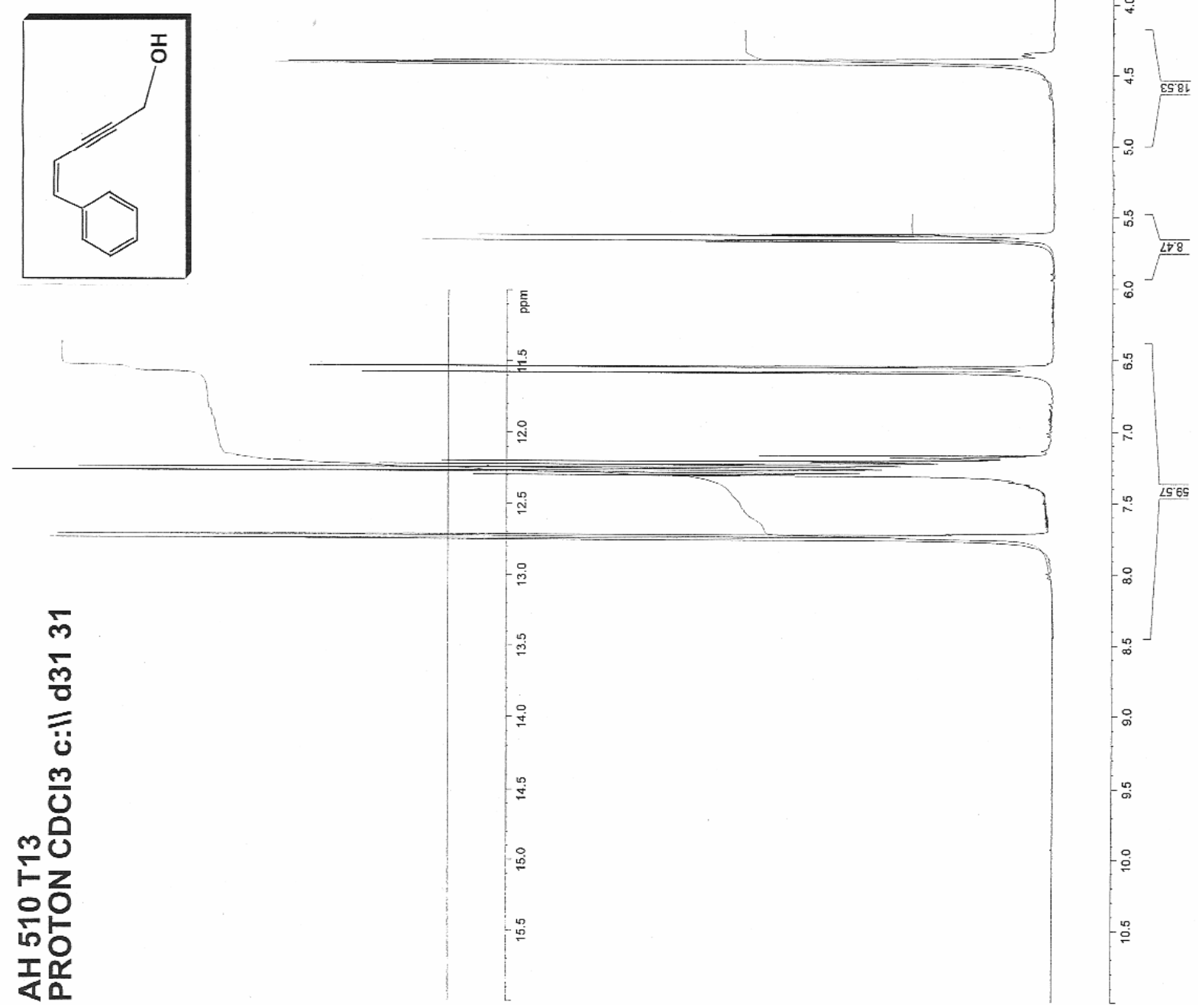
$\Omega$
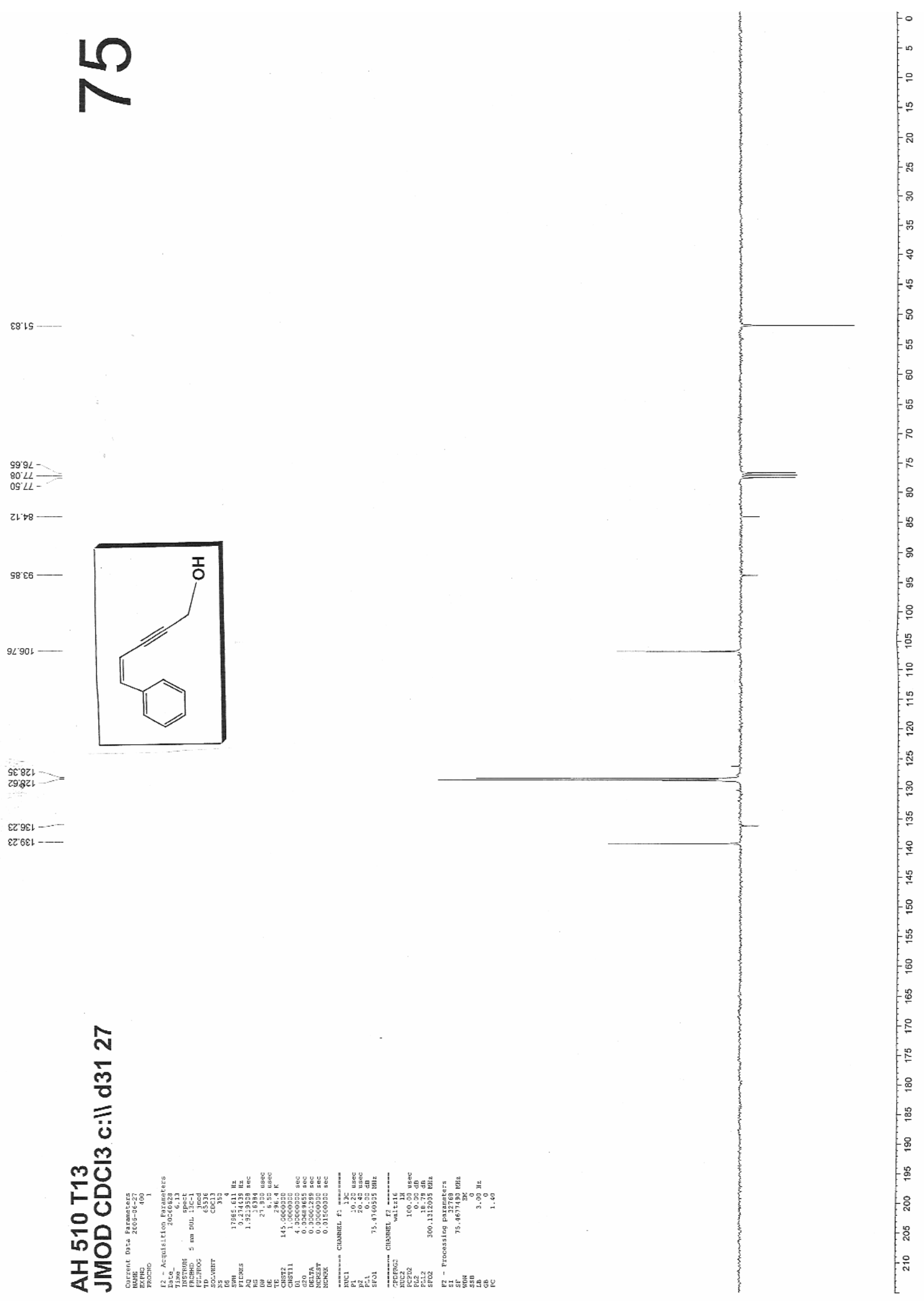


\section{2}

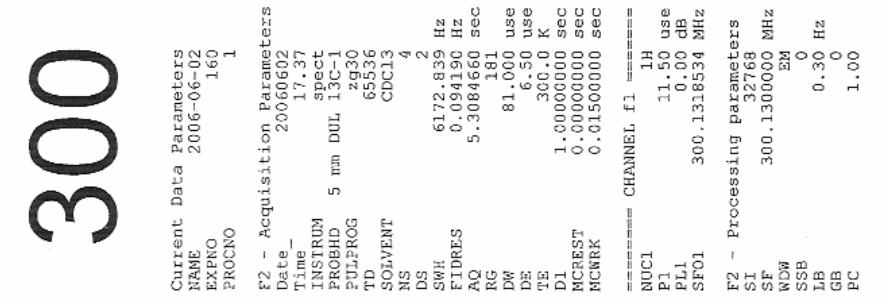

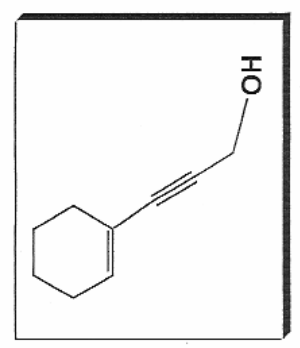

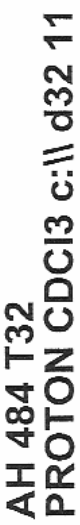
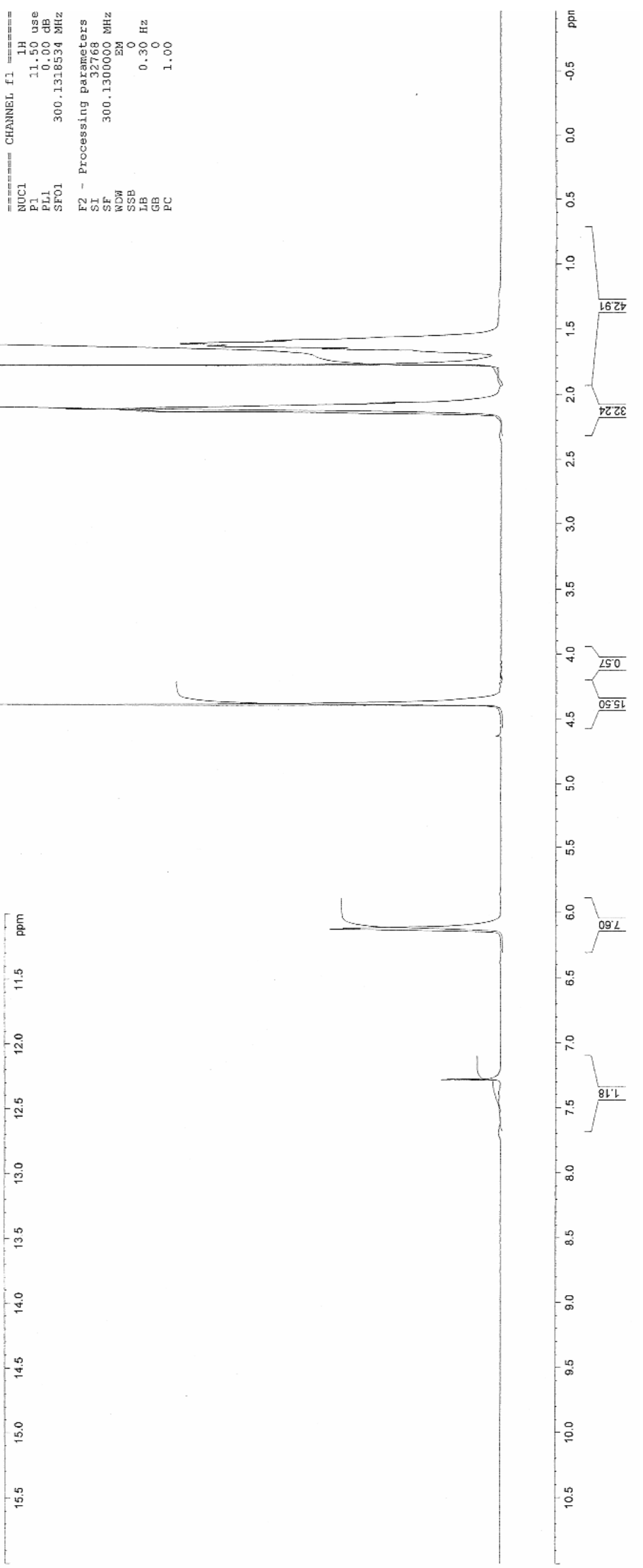


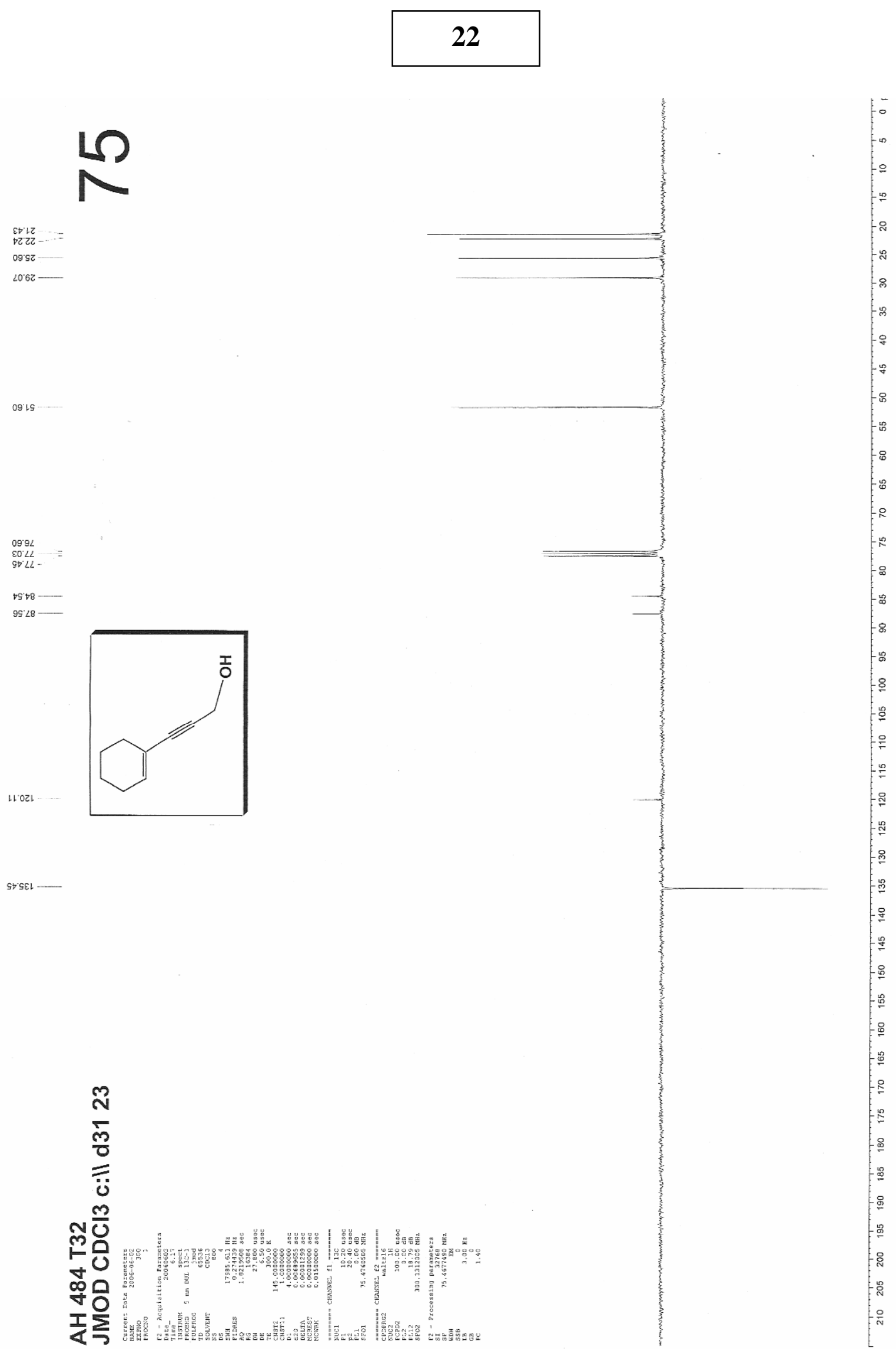




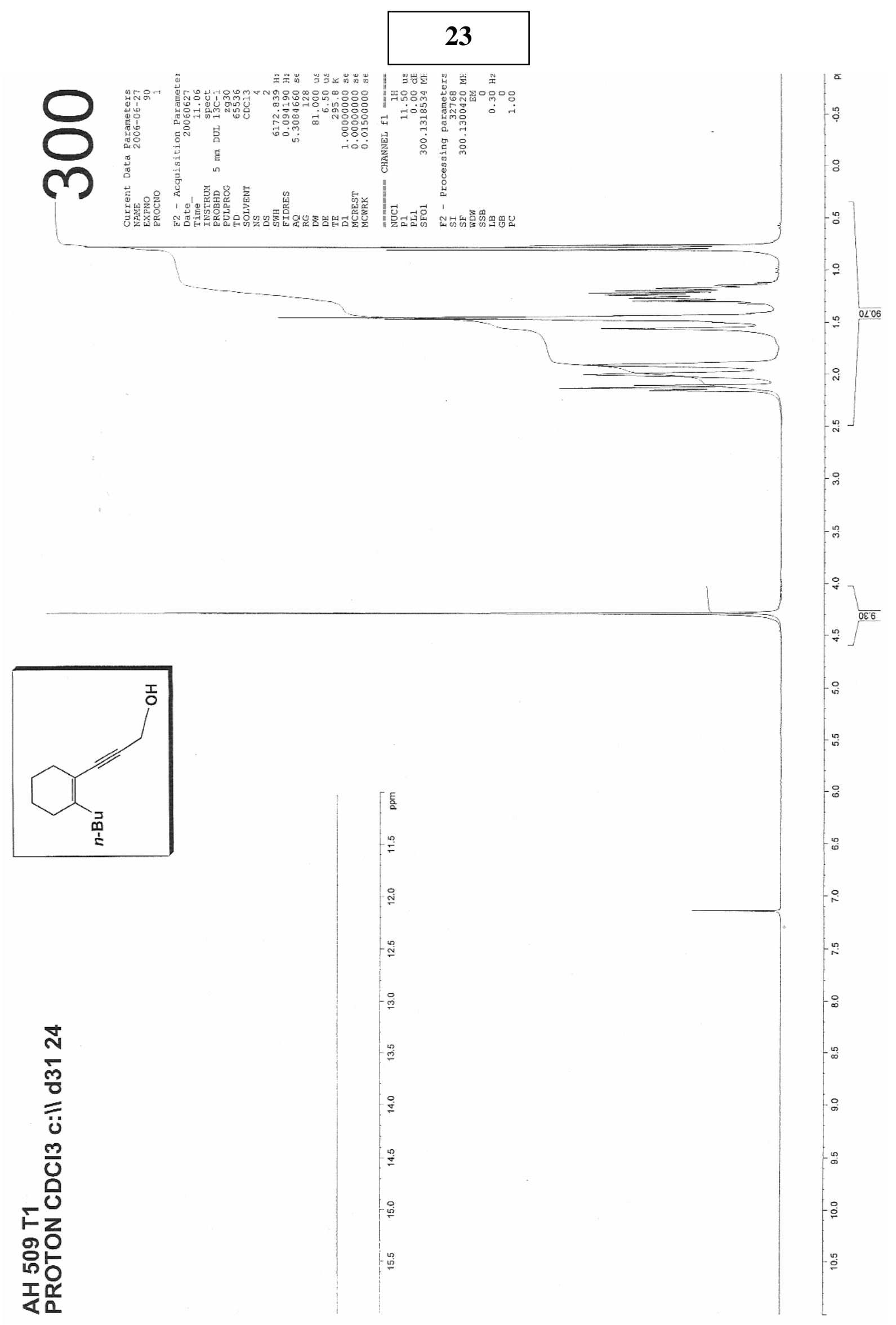



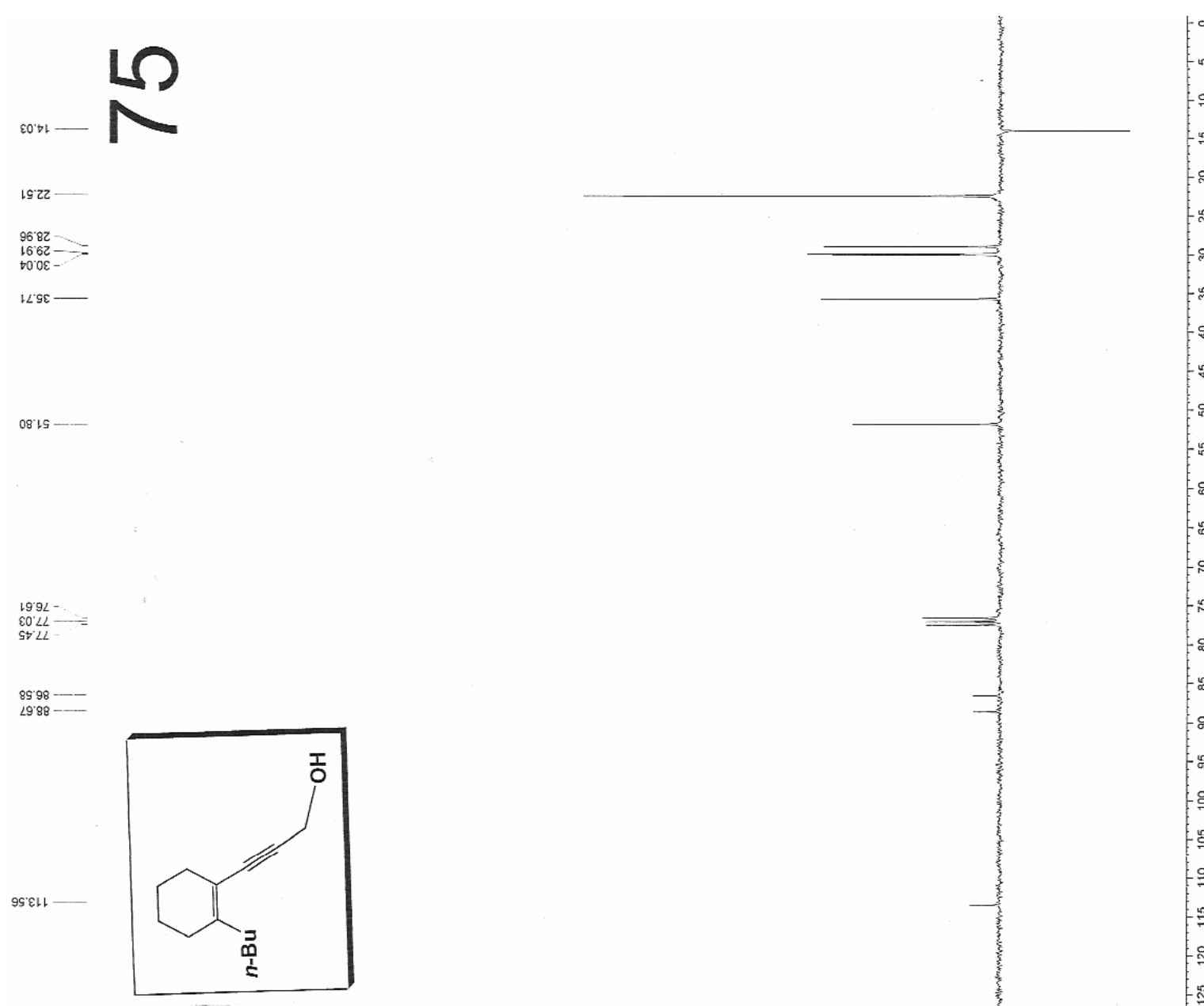

sList - . -

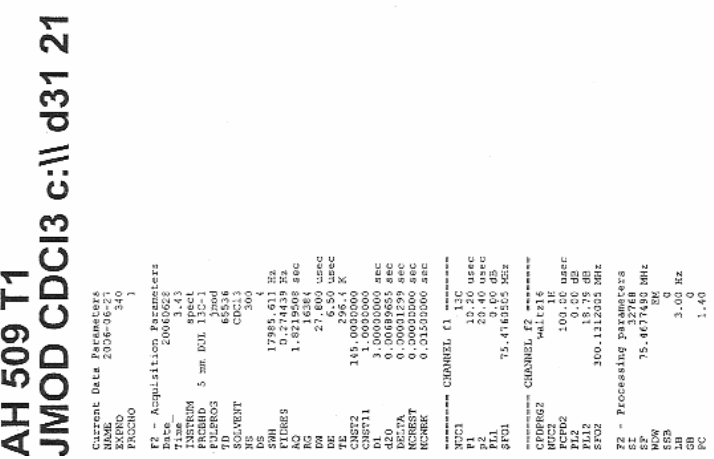




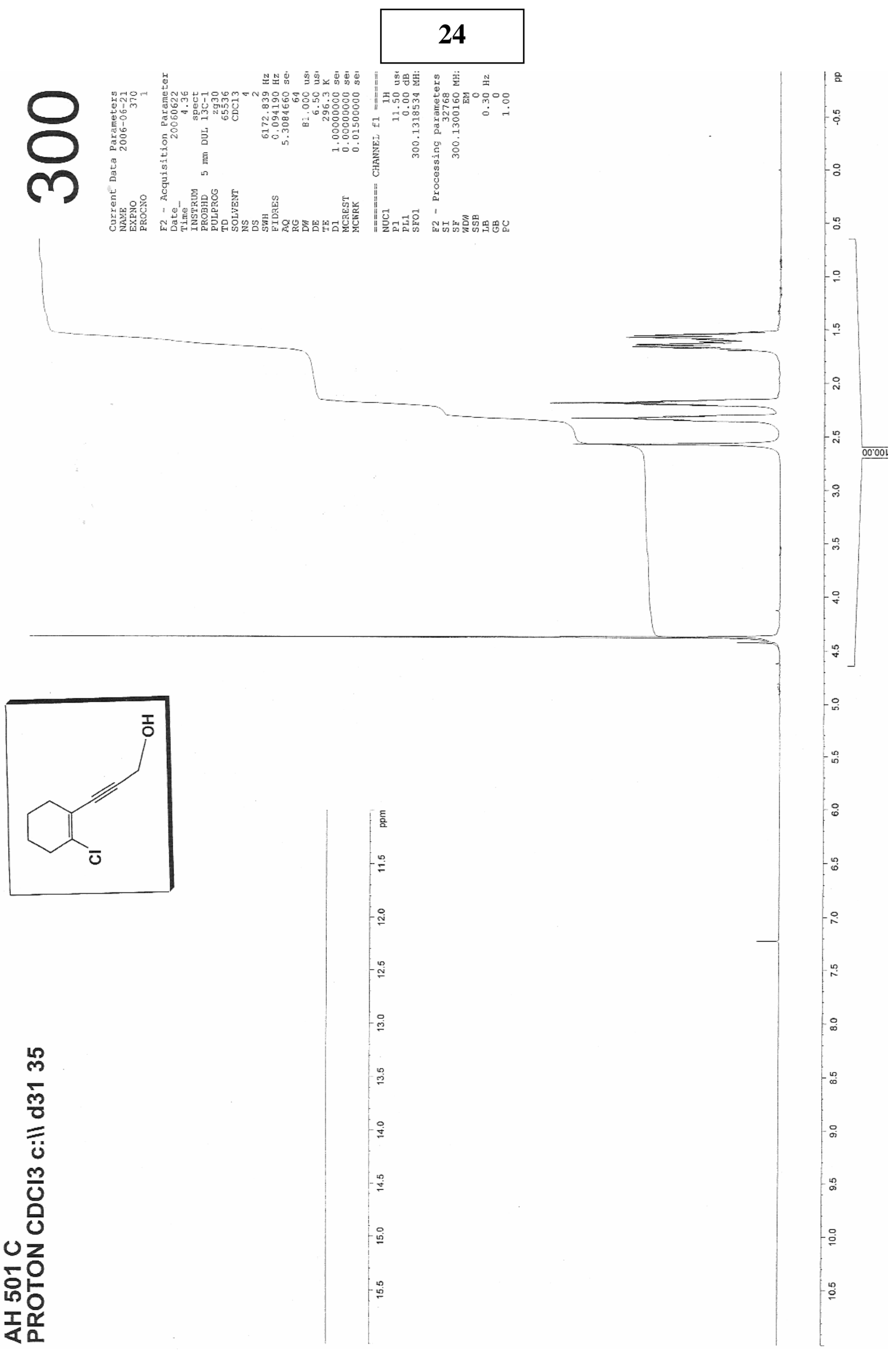




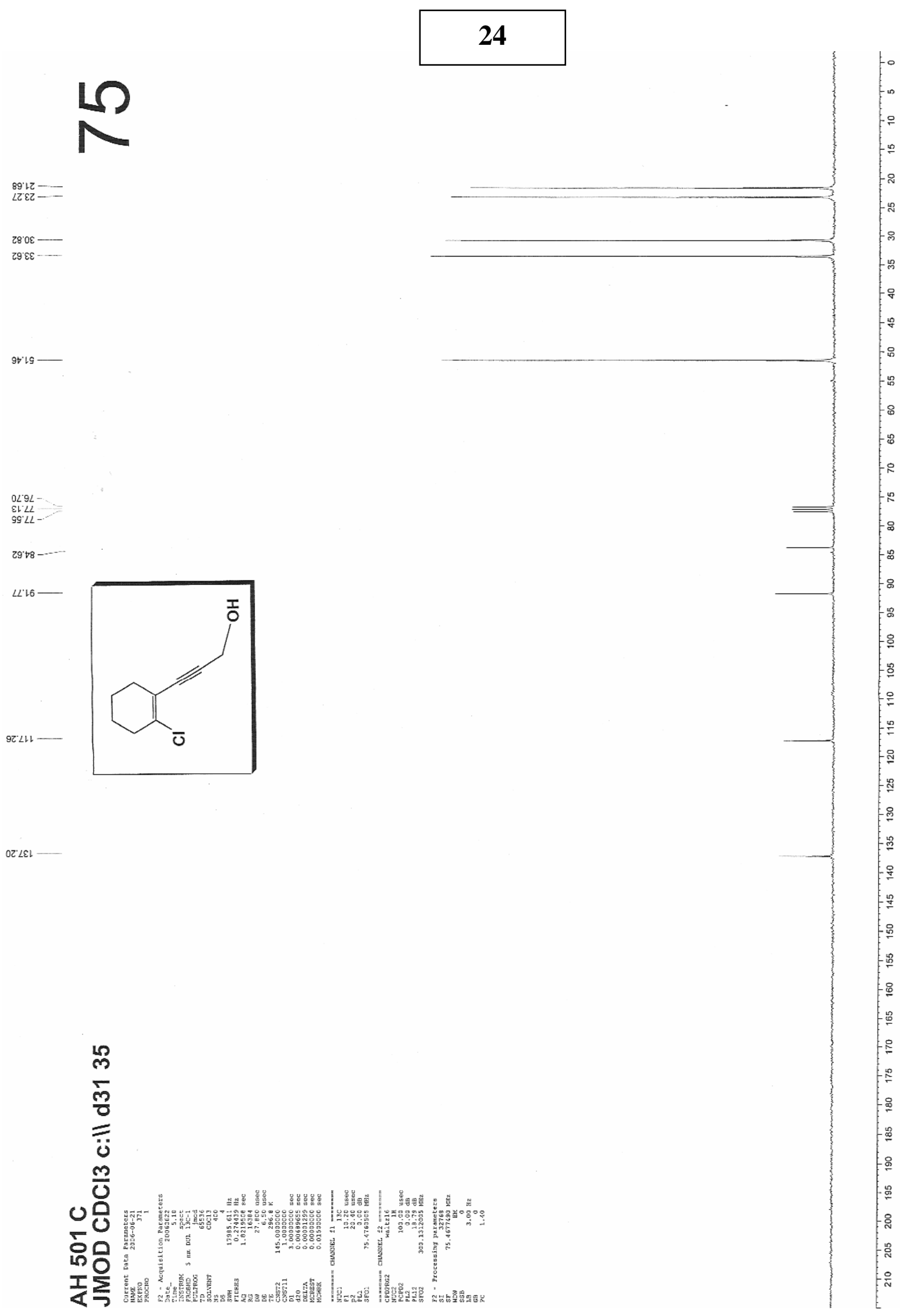




\section{5}

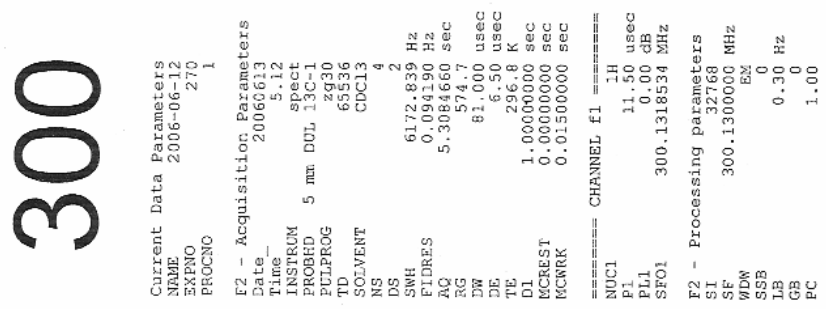

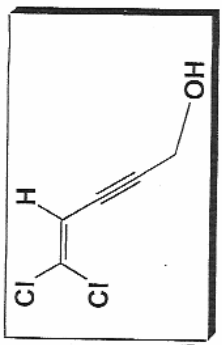

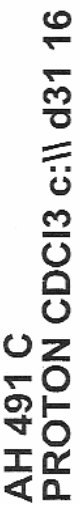




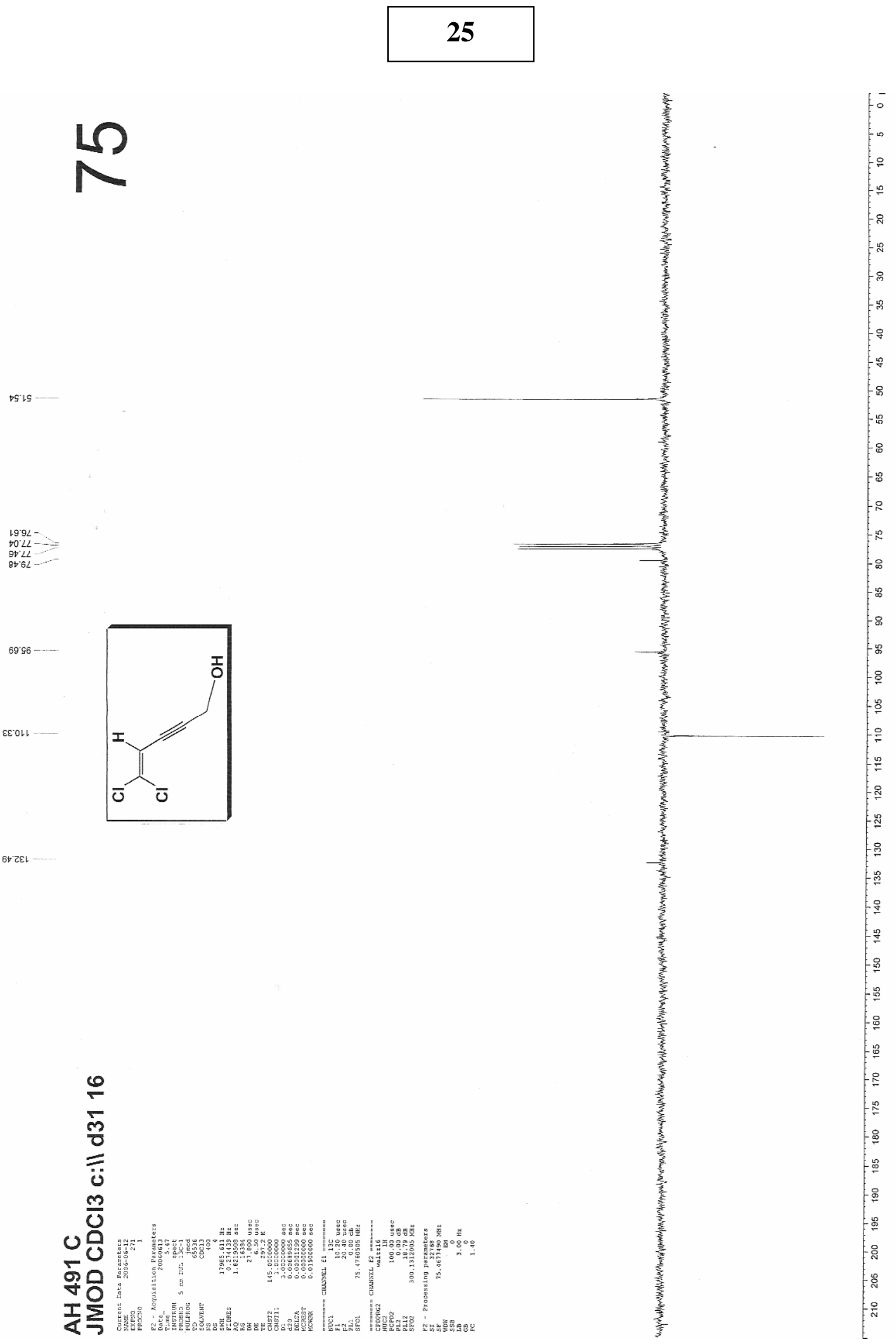




\section{6}
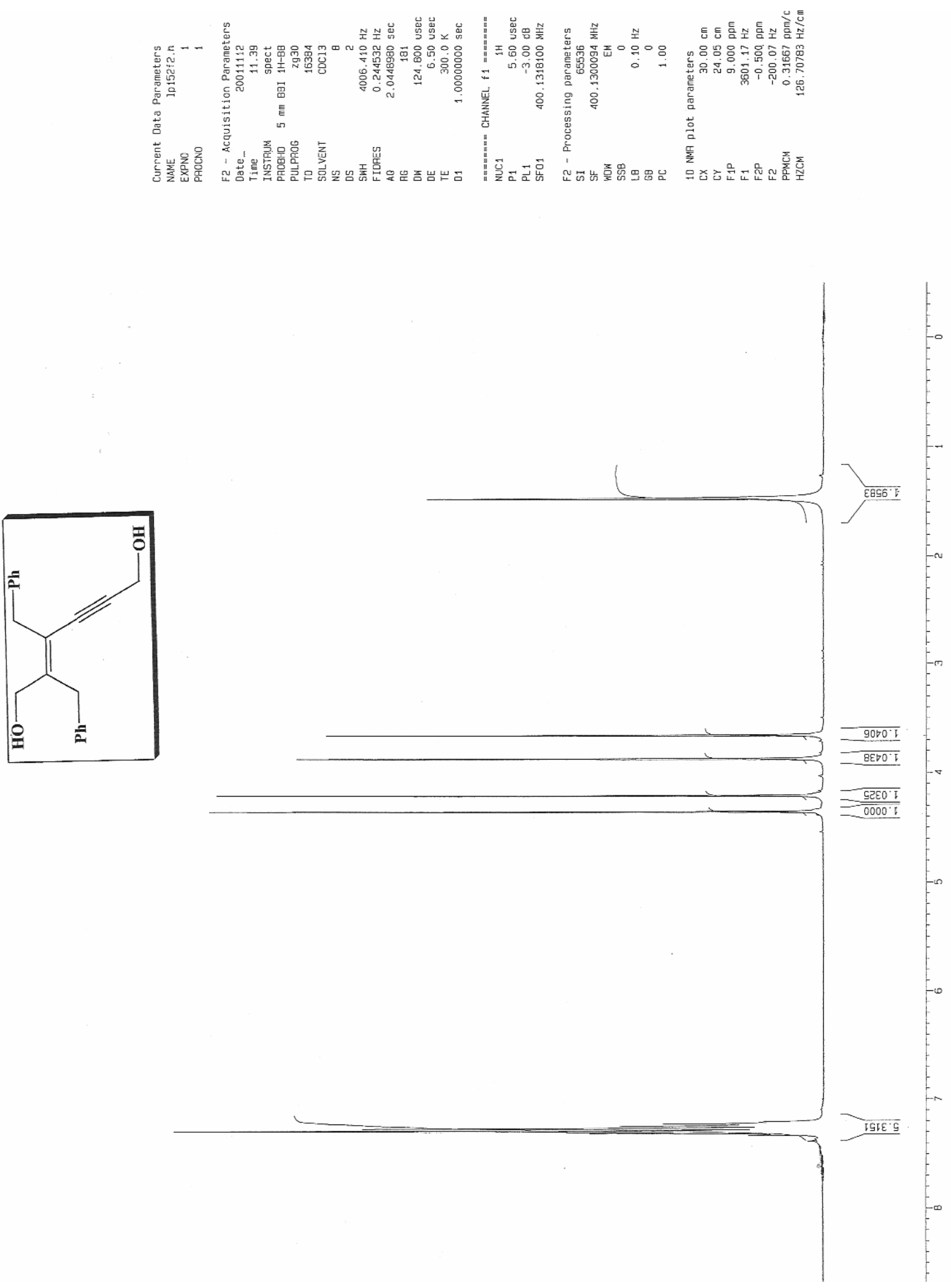


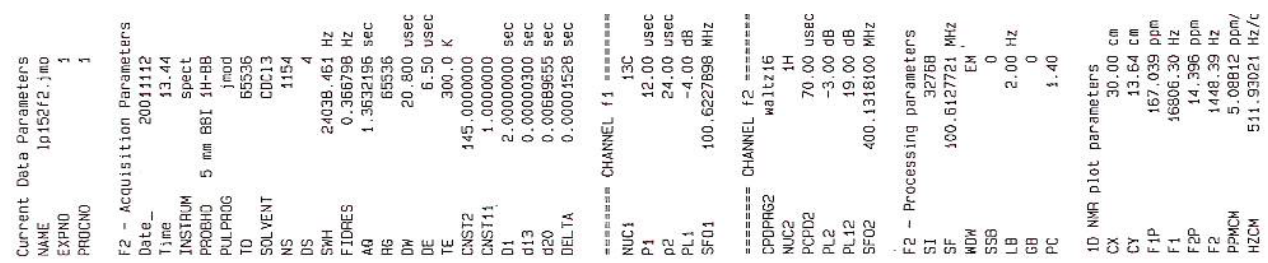

$\angle 68^{\circ} \angle E-$
$80 E^{\circ} 6 E$

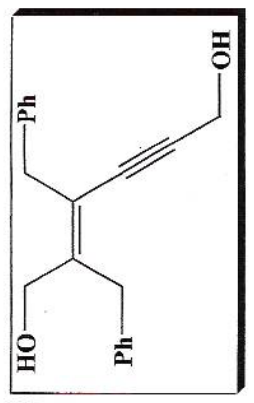

529.15

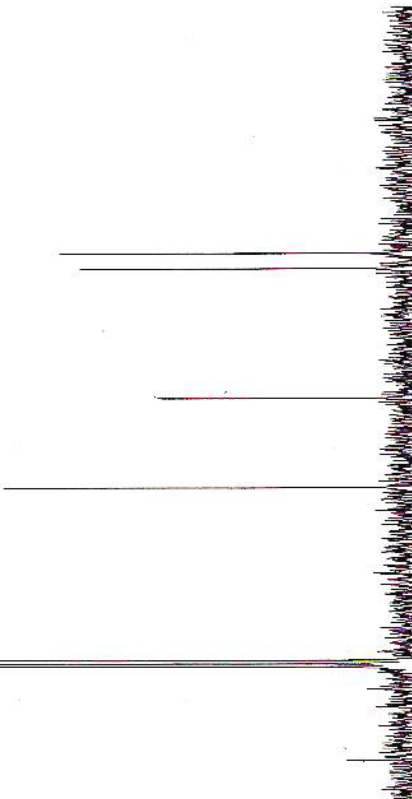

8IE I5 -

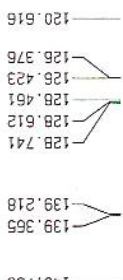

$85 L^{\circ} \mathrm{G} v 1$

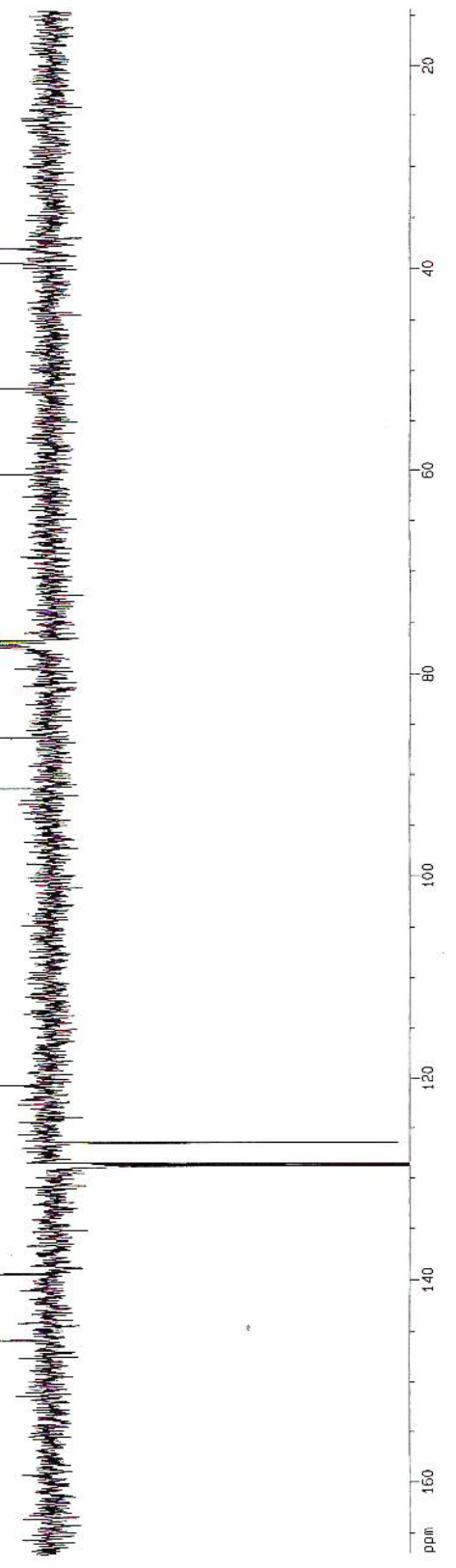




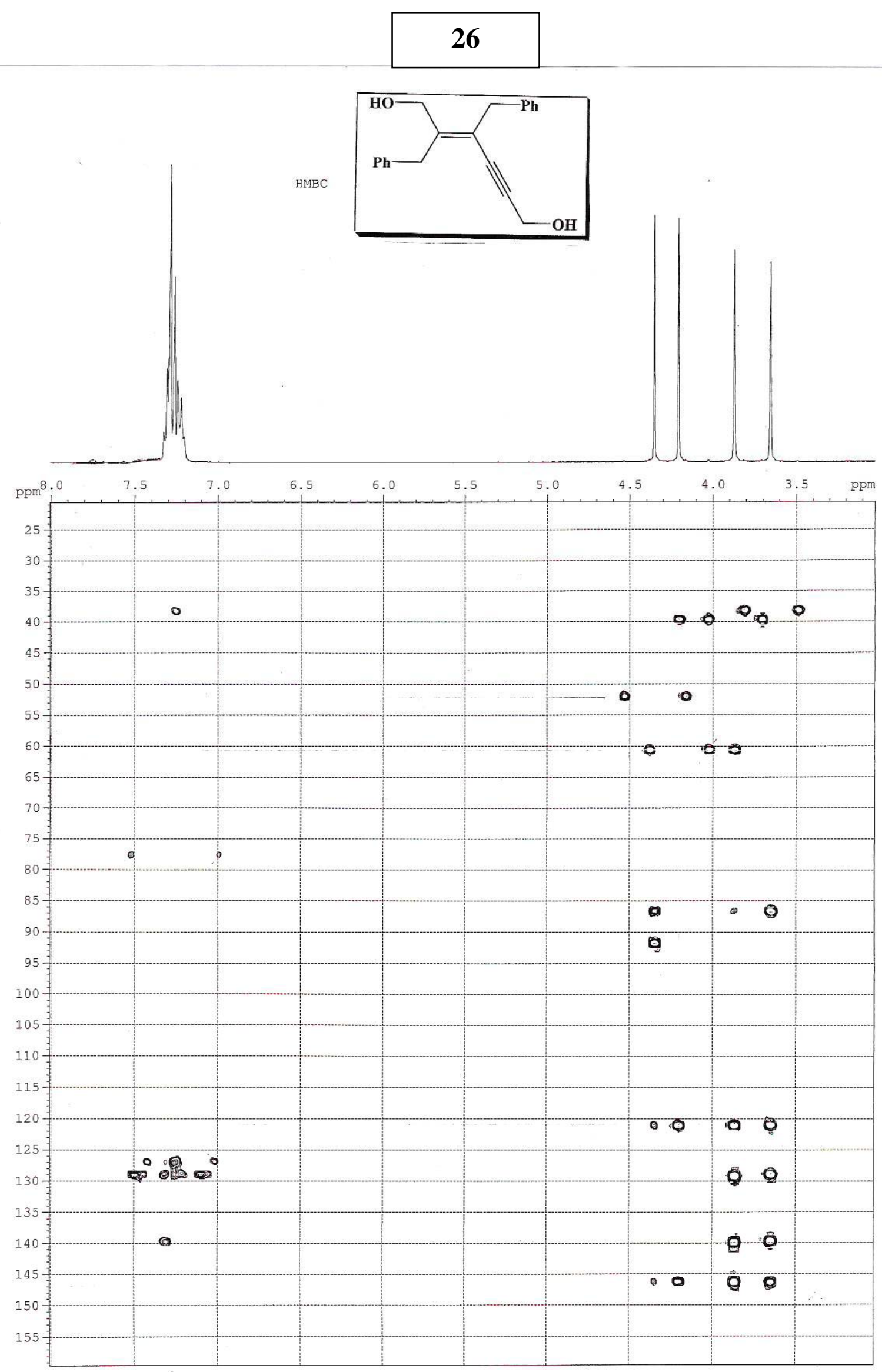




\section{7}
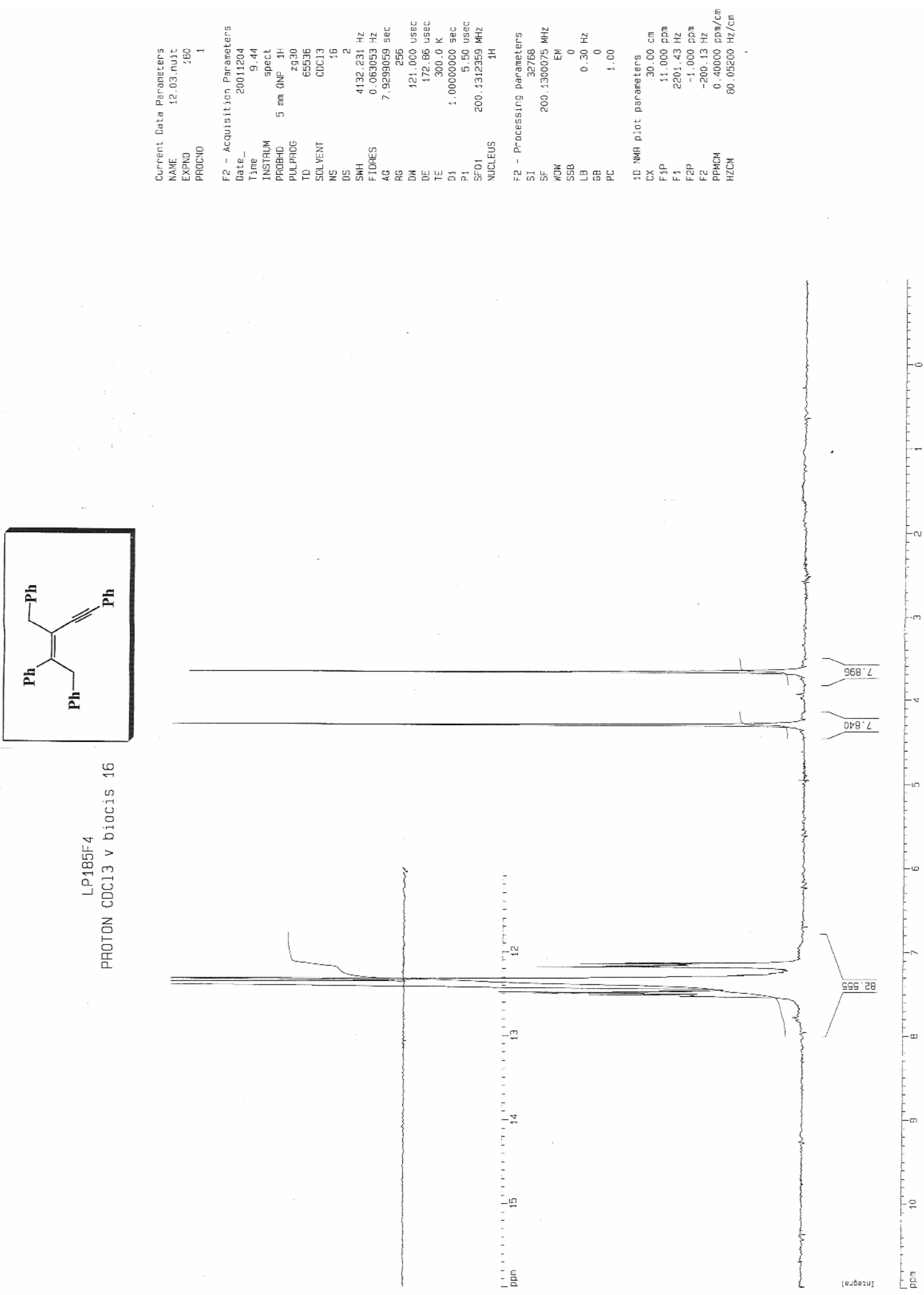

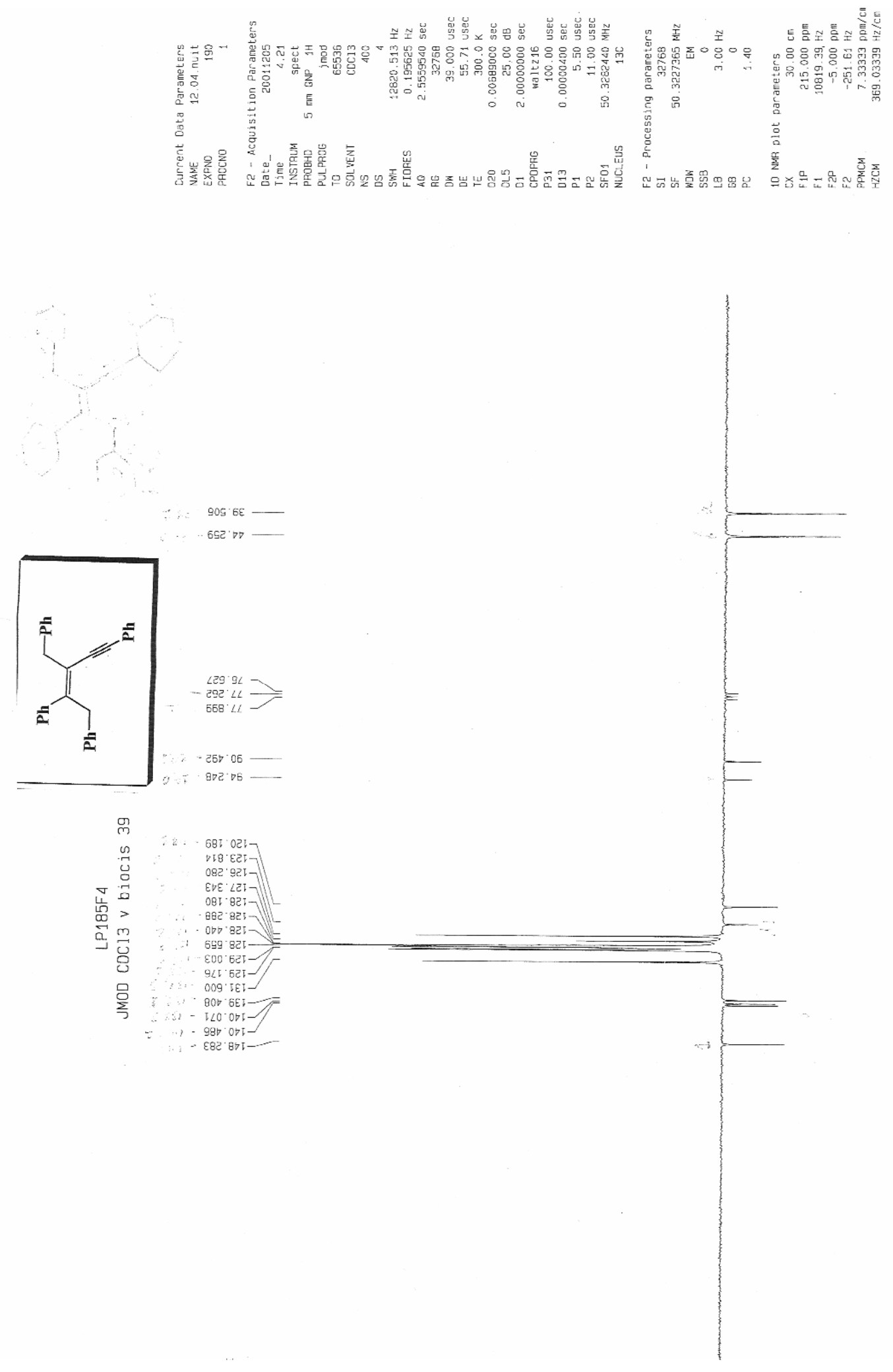


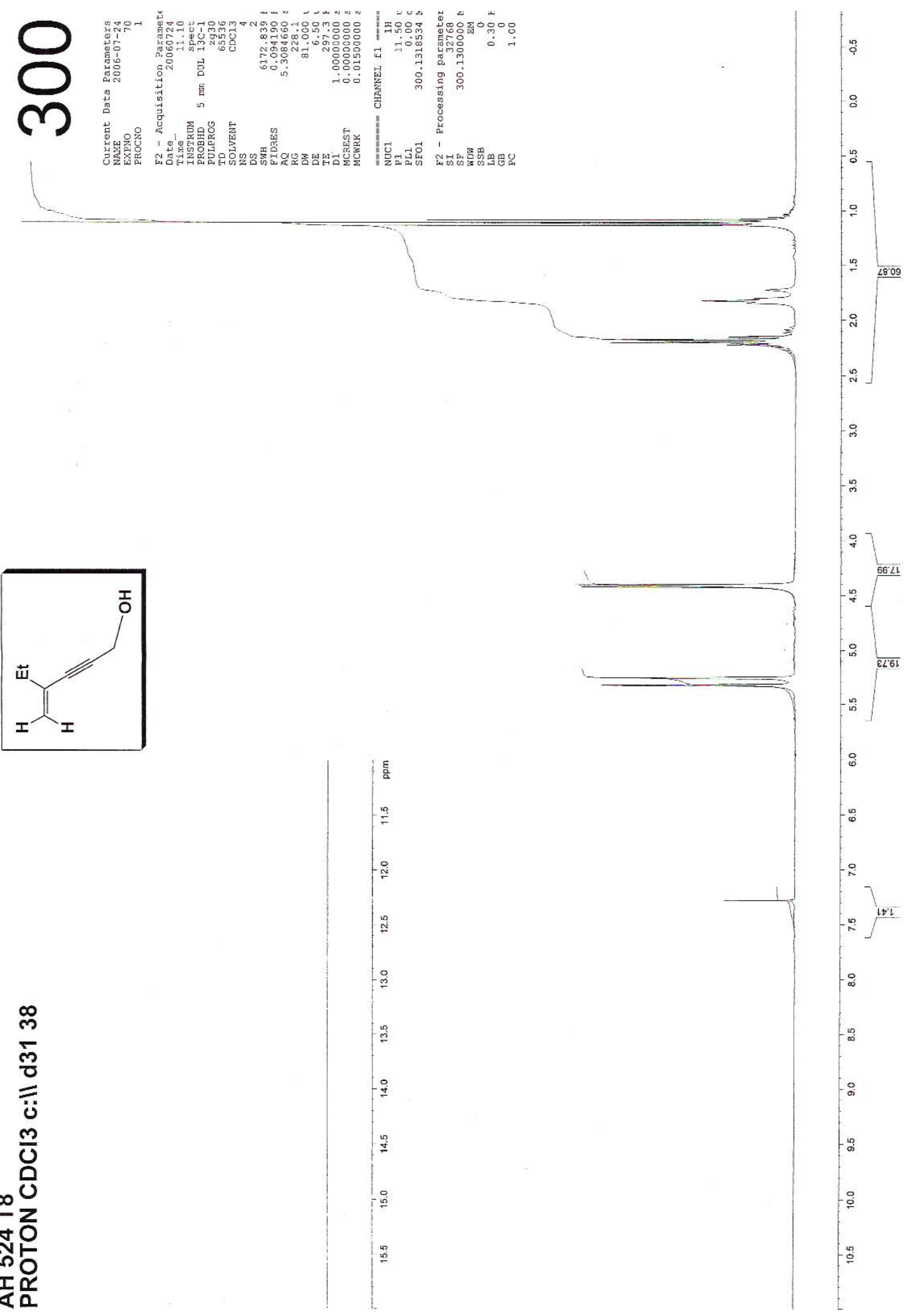




\section{8}

${ }^{2 x a}-\infty$

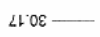

\&S'L -

$00^{\circ} 9 L-2 L=$
$97 L L$

8rige
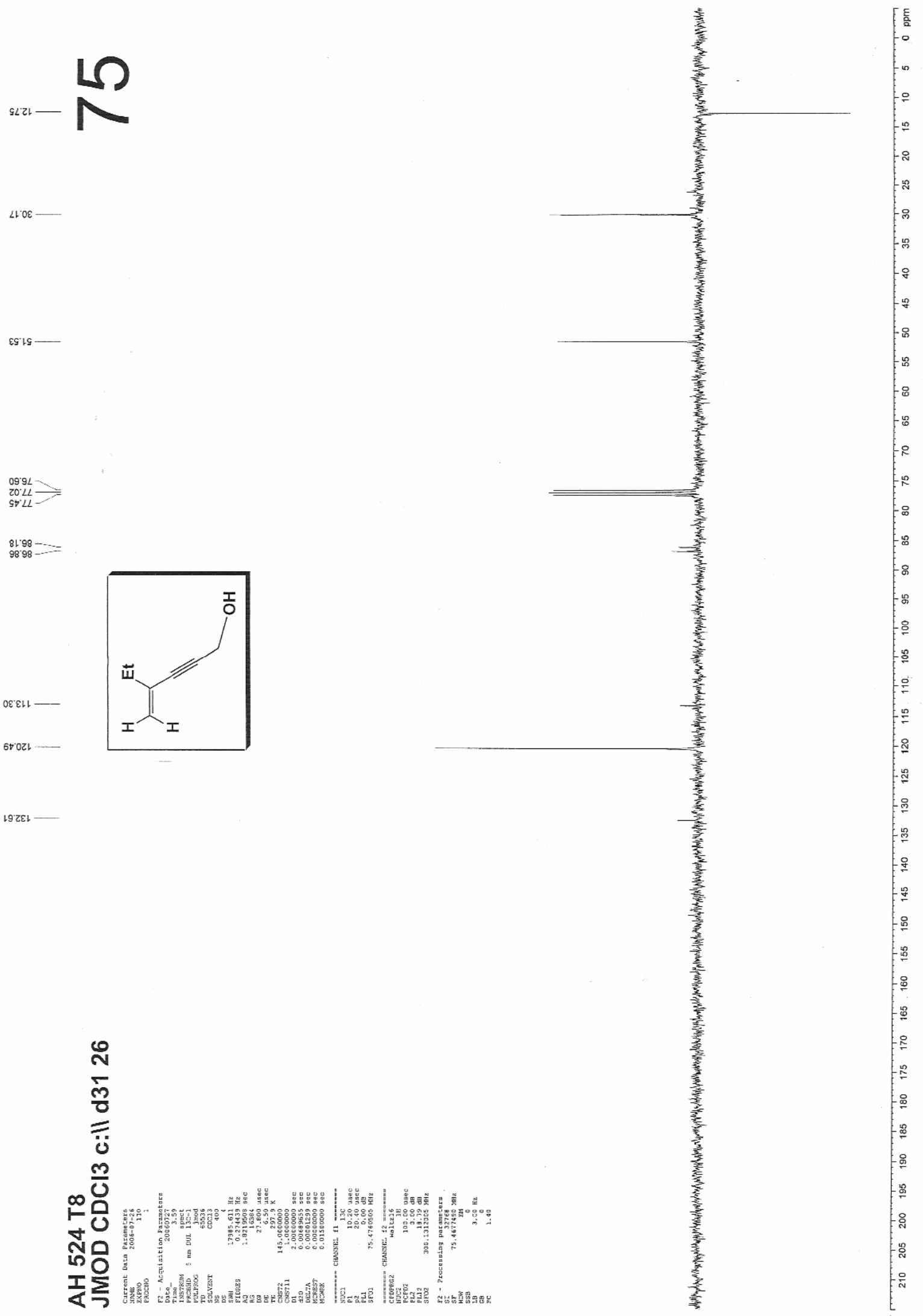

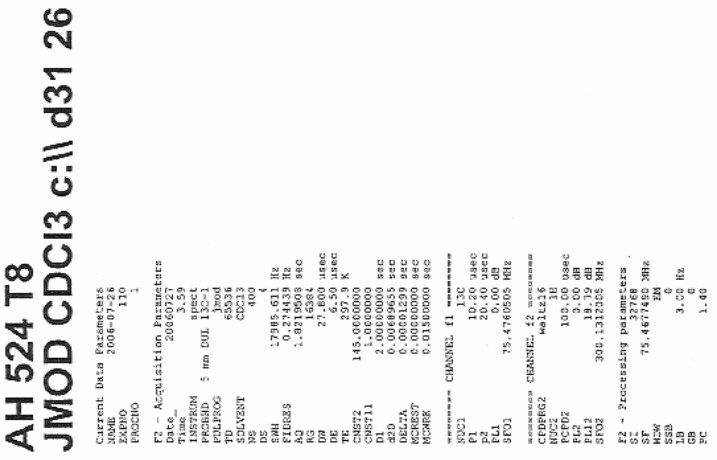

